\title{
Characterization of a soil bacterial community and biphenyl dioxygenase genes involved in the degradation of individual polychlorinated biphenyl congeners
}

\author{
Paola Correa \\ West Virginia University
}

Follow this and additional works at: https://researchrepository.wvu.edu/etd

\section{Recommended Citation}

Correa, Paola, "Characterization of a soil bacterial community and biphenyl dioxygenase genes involved in the degradation of individual polychlorinated biphenyl congeners" (2009). Graduate Theses, Dissertations, and Problem Reports. 2814.

https://researchrepository.wvu.edu/etd/2814

This Thesis is protected by copyright and/or related rights. It has been brought to you by the The Research Repository @ WVU with permission from the rights-holder(s). You are free to use this Thesis in any way that is permitted by the copyright and related rights legislation that applies to your use. For other uses you must obtain permission from the rights-holder(s) directly, unless additional rights are indicated by a Creative Commons license in the record and/ or on the work itself. This Thesis has been accepted for inclusion in WVU Graduate Theses, Dissertations, and Problem Reports collection by an authorized administrator of The Research Repository @ WVU. For more information, please contact researchrepository@mail.wvu.edu. 


\title{
Characterization of a soil bacterial community and biphenyl dioxygenase genes involved in the degradation of individual polychlorinated biphenyl congeners
}

\author{
Paola Correa
}

\author{
Thesis submitted to the \\ College of Engineering and Mineral Resources \\ at West Virginia University \\ in partial fulfillment of the requirements \\ for the degree of \\ Master of Science \\ in \\ Civil and Environmental Engineering
}

Approved by:

Benoit Van Aken, Ph.D., Committee Chairperson Lian-Shin Lin, Ph.D.

Jianbo Yao, Ph.D.

Department of Civil and Environmental Engineering

Morgantown, West Virginia

2009

Key words: Polychlorinated biphenyls, biodegradation, biphenyl dioxygenase, terminalrestriction fragment length polymorphism, real-time polymerase chain reaction 


\section{Abstract \\ Characterization of a soil bacterial community and biphenyl dioxygenase genes involved in the degradation of individual polychlorinated biphenyl congeners}

\section{Paola Correa}

Polychlorinated biphenyls (PCBs) are widespread, toxic, and persistent contaminants that threaten the environment and human health. PCBs represent a class of 209 congeners characterized by different degree of chlorination and substitution patterns. PCBs are known to be slowly degraded by the activity of soil microbes.

The general objective of this research was to investigate the effect of individual PCB congeners on the bacterial community and aerobic metabolism of PCBs in soil, for this reason three specific aims were pursuit.

The first specific aim was to test the hypothesis that exposure to individual PCB congeners results in different soil microbial community profiles, as well as different abundances of biphenyl dioxygenase (BPH) genes; experiments on soil microcosm were conducted using aerobic agitated soil slurries individually exposed to specific PCB congeners. It was observed that exposure to different PCB congeners modifies the structure of the microbial community resulting in higher representation of phyla involving PCB degraders and higher number of biphenyl dioxygenase genes, $b p h$.

The second specific aim focused on the characterization of the soil microbial community in contaminated soil samples from a heavily PCB-contaminated site, the Confined Disposal Facility (CFD) in South Chicago, Indiana. For this reason, terminal-restriction fragment length polymorphism (T-RFLP) analyses were carried out. The results provide preliminary evidence of a correlation between the microbial communities and the PCBs profiles. 
The last specific aim was to determine the potential toxicity of a selected group of PCB congeners and hydroxyl metabolites on pure cultures of Escherichia coli and Burkholderia xenovorans LB400. Preliminary results showed that exposure of pure bacteria culture to individual PCBs and their hydroxyl metabolites products resulted in different inhibition of bacterial growth. A significant impact on the bacterial growth was found when B. xenovorans LB400 was exposed to the PCB-3 metabolite, 4'-OH-PCB35. Likewise, it was found that B. xenovorans LB400 took a long period of time to acclimate to metabolites of PCB-3, which included 2'-OH-PCB-3, 3'-OH-PCB-3, and 4'OH-PCB-3. 


\section{Acknowledgements}

I would like to give special thanks to my supervisor, Dr. Benoit Van Aken, for his valuable guidance, advice and support. I also thank to the committee members, Dr. LianShin Lin and Dr. Jianbo Yao, for their helpful comments and suggestions. I thank the collaborators at University of Iowa for their technical assistance with the GC/MS analyses of the PCB samples. I want to thank also to Danielle Ellis from biology department at WVU for providing soil material and allows us to use the capillary electrophoresis equipment.

I would like to thank my family; they have been a great support to me for their continuous encouraging to me to pursuing this degree

Many and special thanks to my lab mates Mary and Meilin, for their valuable help and suggestions for some laboratory work

Finally, I acknowledge the National Institute of Health (NIH) for the financial support to this project. 


\section{Table of contents}

List of symbols / Nomenclature ...................................................................................

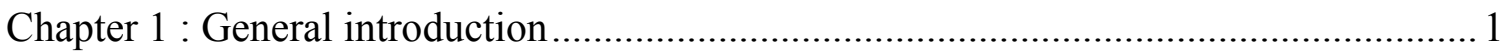

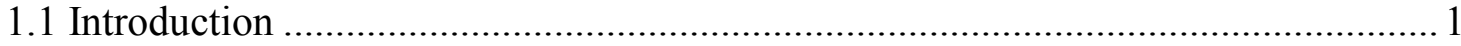

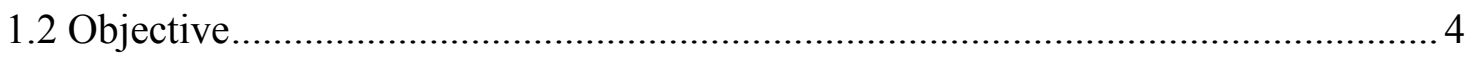

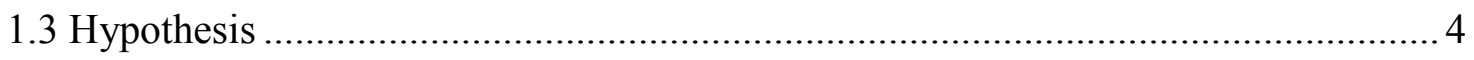

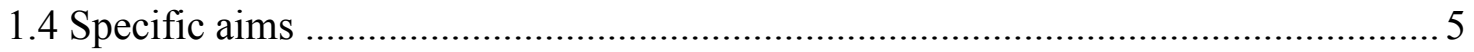

Chapter 2 : Polychlorinated biphenyls: literature review............................................... 7

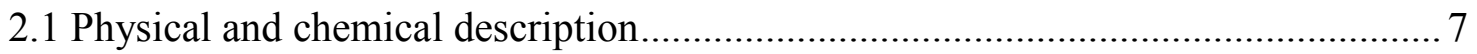

2.2 Sources and environmental cycling of PCBs .................................................. 9

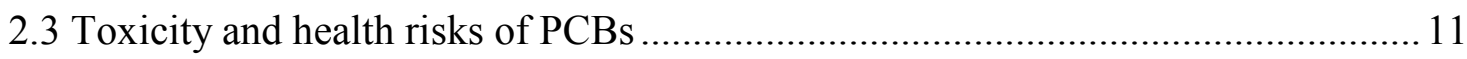

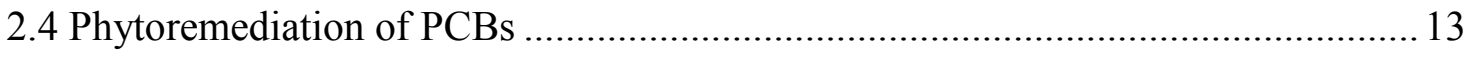

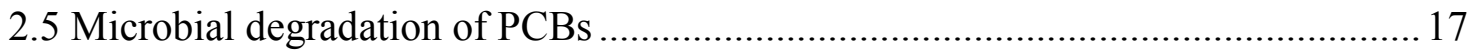

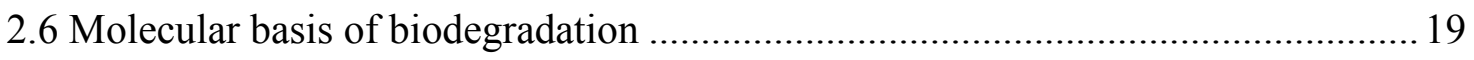

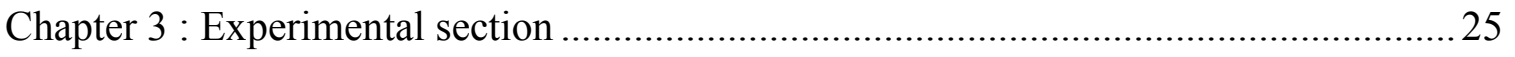

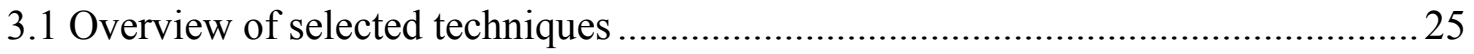

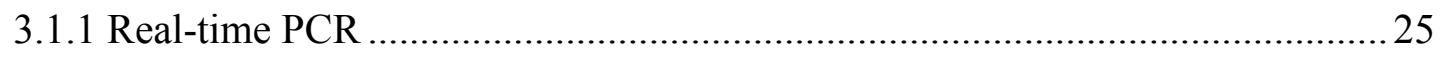

3.1.2 Terminal restriction fragment length polymorphism (T-RFLP)...................... 27

3.1.3 Gas chromatography/mass spectrometry (GC/MS) ....................................... 28

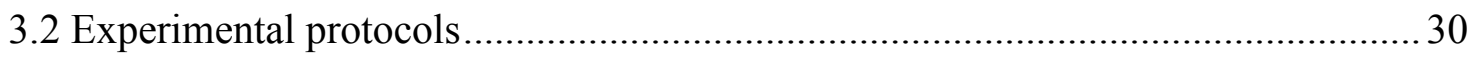

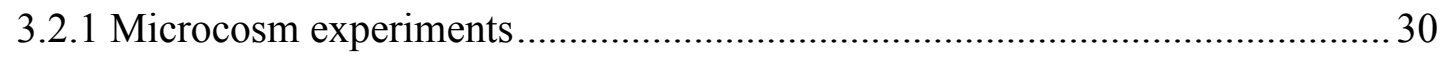

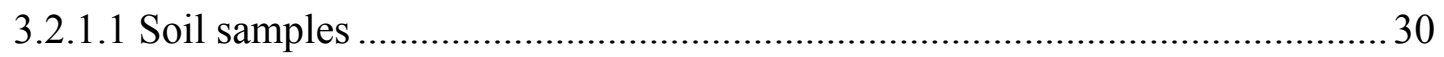

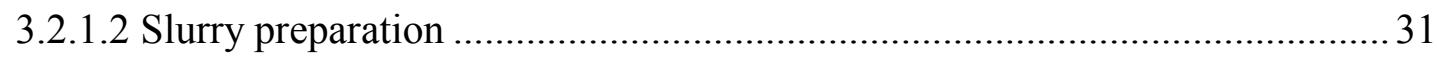

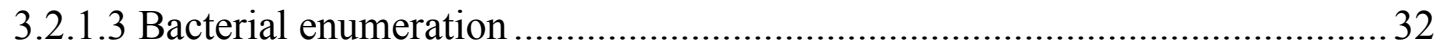

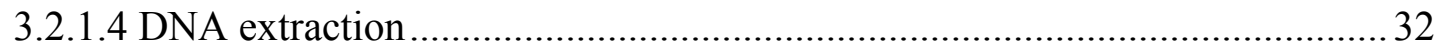

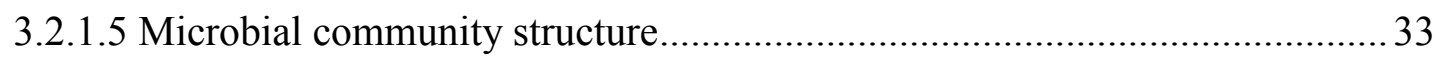




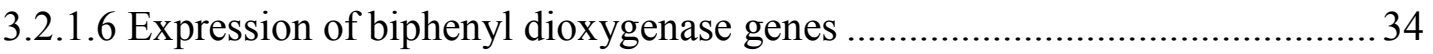

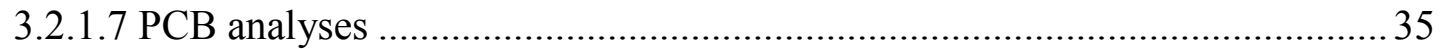

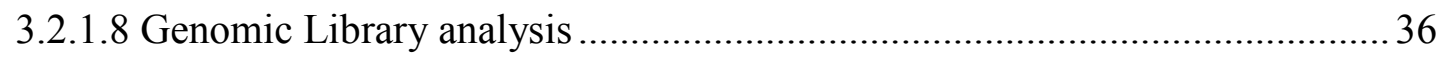

3.2.2 Terminal-restriction fragment length polymorphism (T-RFLP)....................... 36

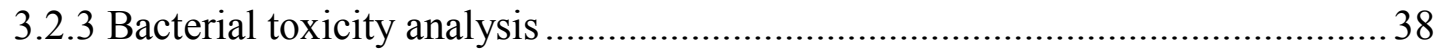

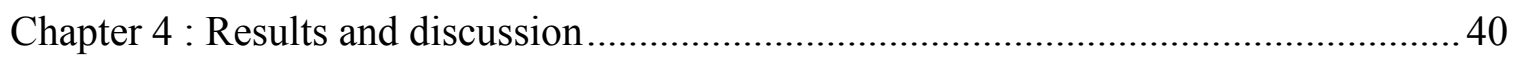

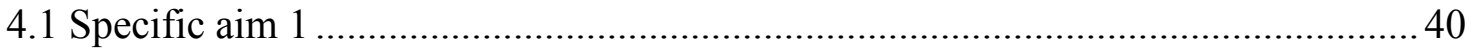

4.1.1 Microbial numbers and community structure ............................................. 40

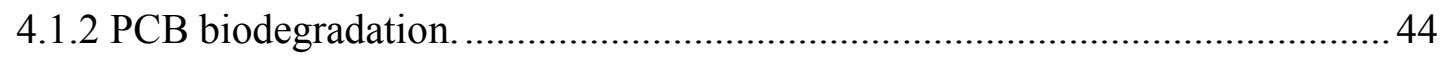

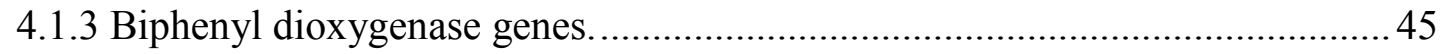

4.1.4 Evaluation of the effect of PCB-3 on a soil bacterial community structure using

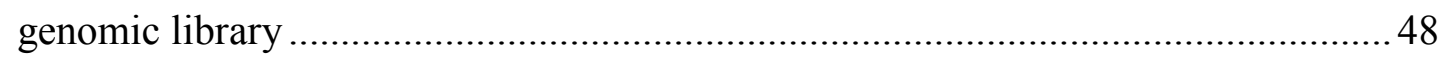

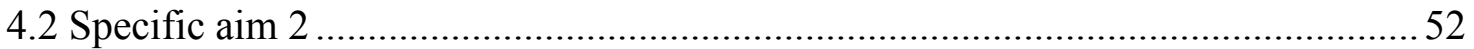

4.2.1 Terminal - restriction fragment length polymorphism ...............................52

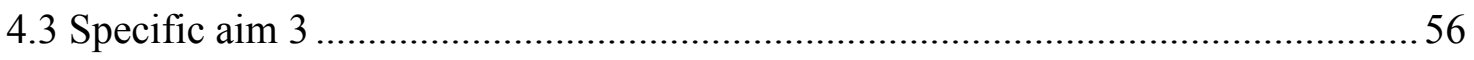

4.3.1 Effect of individual PCBs on bacterial growth ...............................................56

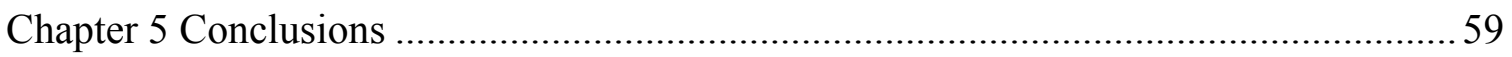

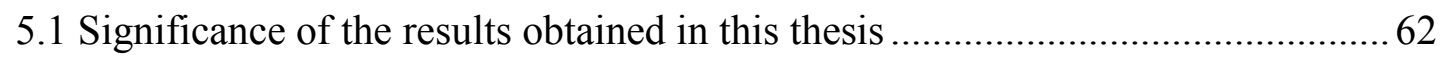

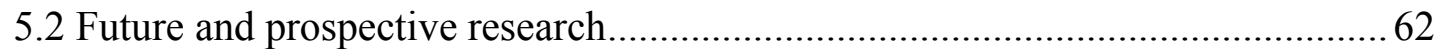

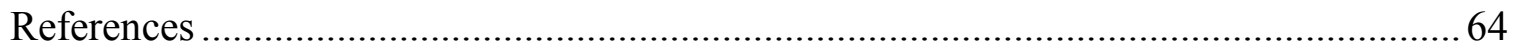




\section{List of figures and tables}

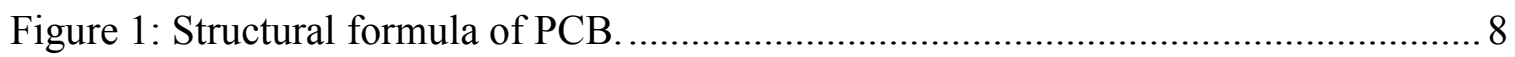

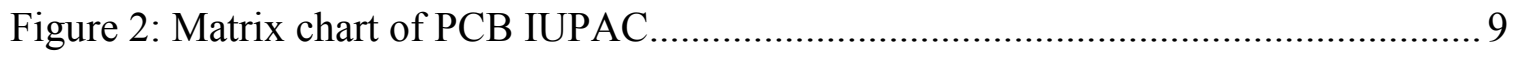

Figure 3: Global production of PCBs in various countries ........................................... 10

Figure 4: Structure of coplanar (dioxin-like) PCBs and non-planar PCBs ....................... 12

Figure 5: Structure of dioxins .................................................................................. 12

Figure 6: Processes involved in phytoremediation .......................................................... 14

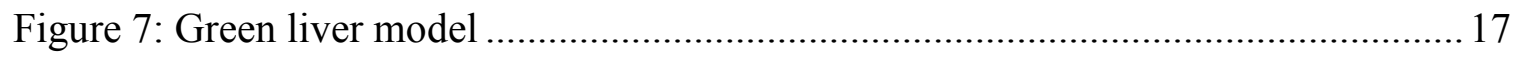

Figure 8: Bacterial anaerobic metabolism of PCB-20 …………………………....... 18

Figure 9: Bacterial aerobic metabolism of PCB-20 ………………………….......... 19

Figure 10: Pathway for degradation of biphenyl and organization of the $b p h$ gene cluster in P. pseudoalcaligenes KF707.................................................................... 22

Figure 11: Phylogenetic analysis of the large subunits of aromatic dioxygenase genes... 24

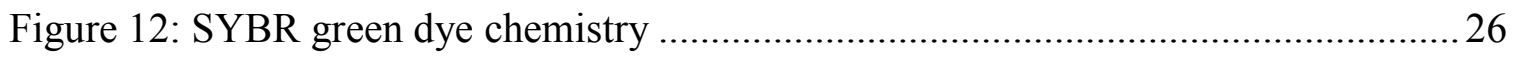

Figure 13: Scheme of a typical T-RFLP process ...........................................................28

Figure 14: Scheme of the GC/MS analysis method ....................................................... 30

Figure 15: Poplar plants used for soil microcosm preparation and soil slurry exposed to

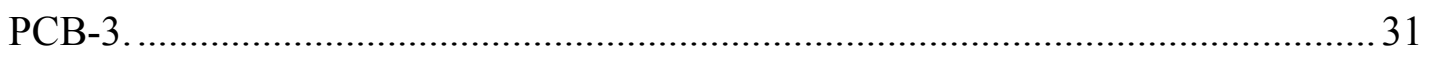

Figure 16: Profile of a soil microbial community in one analyzed sample using T-RFLP. 38

Figure 17: Structure of PCBs used in soil microcosm experiments..................................39

Figure 18: Structure of PCB metabolites used in toxicity experiments .............................39

Figure 19: Bacterial abundances in soil microcosm cultures ......................................... 43

Figure 20: Profiles of microorganisms in soil microcosms............................................... 44 
Figure 21: Biodegradation percentages of the different PCB congeners in aerobic soil

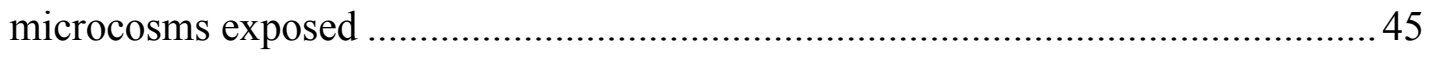

Figure 22: Quantification of bacterial biphenyl dioxygenase (BPH) genes...................... 47

Figure 23: Picture of plasmids digests run on a 1.5\% agarose gel.................................. 48

Figure 24: Percentages of microorganisms in a non-exposed soil microcosm ..................51

Figure 25: Percentages of microorganisms in soil microcosm exposed to PCB-3 .......... 51

Figure 26: Confined Disposal Facility (CDF - South Chicago). ........................................53

Figure 27(cont.): Terminal-restriction fragment profiles from 22 soil samples from the

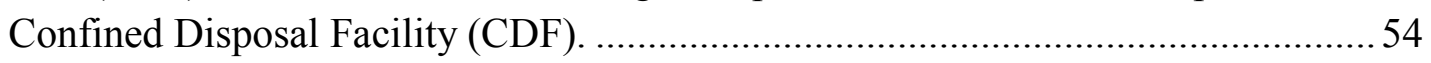

Figure 28: Correlation between microbial community structure and PCB profiles .........55

Figure 29: E.coli growth after $24 \mathrm{hr}$ exposed to different PCB congeners .......................57

Figure 30: E.coli growth exposed to different PCB OH-metabolites ...............................58

Figure 31: B. xenovorans LB400 growth exposed to different PCB OH-metabolites...... 58

Table 1: Primers used for group-specific bacterial identification and biphenyl

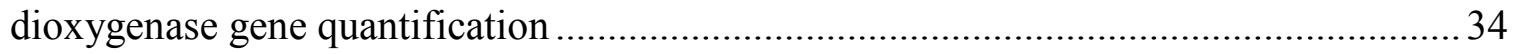

Table 2: Bacterial strains identified from a soil microcosm exposed to PCB-3 and a non-

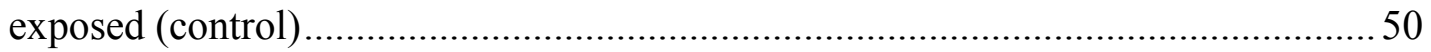




\section{List of symbols / Nomenclature}

\begin{tabular}{|c|c|}
\hline $\mathrm{AGE}$ & Agarose gel electrophoresis \\
\hline AhR & Aryl hydrocarbon receptor \\
\hline $\mathrm{AHH}$ & Aryl hydrocarbon hydroxylase \\
\hline BPH & Biphenyl Dioxygenase \\
\hline $\mathrm{CDF}$ & Confined disposal facility \\
\hline cDNA & Complementary deoxyribonucleic acid \\
\hline CFU & Colony forming unit \\
\hline DHHS & Department of Health and Human Services \\
\hline EI & Electron impact \\
\hline EPA & Environmental Protection Agency \\
\hline EROD & Ethoxyresorufin- $O$-deethylase \\
\hline GC/MS & Gas chromatography/mass spectrometry \\
\hline GMO & Genetically modified organism \\
\hline HOPDA & 2-hydroxy-6-phenyl-6-oxohexa-2,4-dieneoate hydrolase \\
\hline IARC & International Agency for Research on Cancer \\
\hline IUPAC & International Union of Pure and Applied Chemistry \\
\hline LB & Luria Bertani \\
\hline MRM & Multiple reaction monitoring \\
\hline NADH & Nicotinamide adenine dinucleotide \\
\hline NCBI & National Center for Biotechnology Information \\
\hline $\mathrm{OD}_{260 \mathrm{~nm}}$ & Optical density at $260 \mathrm{~nm}$ \\
\hline $\mathrm{OD}_{280 \mathrm{~nm}}$ & Optical density at $280 \mathrm{~nm}$ \\
\hline $\mathrm{OD}_{600 \mathrm{~nm}}$ & Optical density at $600 \mathrm{~nm}$ \\
\hline PBS & Phosphate buffer solution \\
\hline PCB & Polychlorinated biphenyl \\
\hline PCR & polymerase chain reaction \\
\hline RNA & Ribonucleic acid \\
\hline rDNA & Ribosomal-deoxyribonucleic acid \\
\hline RT-PCR & Real time-polymerase chain reaction \\
\hline SOC & Semi-volatile organic compound \\
\hline SOC (medium) & Super optimal broth with catabolite repression \\
\hline T-RFLP & Terminal-restriction fragment length polymorphism \\
\hline
\end{tabular}




\section{Chapter 1 : General introduction}

\subsection{Introduction}

Polychlorinated biphenyls (PCBs) are toxic environmental contaminants that were manufactured widely during a half-century and used for a variety of industrial applications, such as lubricants, dielectric fluids, and plasticizers. It is usually estimated that over 1.5 million tons of PCBs were produced worldwide (Pieper and Seeger, 2008). Because of their toxicity and persistence in the environment, production and usage of PCBs were banned in the U.S. since 1979 (Field and Sierra-Alvarez, 2008). However, because of their relative volatility and high chemical stability, PCBs have been largely dispersed and are today detected everywhere, in virtually every compartment of the ecosystem, including air, water, soil, sediments, and living organisms. PCBs are highly lipophilic and their bioaccumulation in the food chain makes even low environmental concentrations a threat for the wildlife and human health (Borja et al., 2005; Furukawa and Fujihara, 2008). Although acute toxicity for adult humans is rather low, chronic exposure to PCBs induces neurobehavioral and immunological disorders in children. According to the Department of Health and Human Services (DHHS), the U.S. Environmental Protection Agency (EPA), and the International Agency for Research on Cancer (IARC), PCBs are today suspected to be carcinogenic in animals and humans (Borja et al., 2005; Pieper and Seeger, 2008).

Due to their chemical stability PCBs are resistant to microbial biodegradation and persist over long periods of time in soil and sediments (Furukawa and Fujihara, 2008). PCB molecules consist of a biphenyl core with 1 to 10 chlorine atoms attached; resulting in 209 different congeners characterized by different degree of chlorination and substitution patterns. PCBs in the environment are generally found in complex mixtures originating from commercial formulations, such as Aroclor (Monsanto, USA) (Borja et al., 2005). 
Soils often contain a high proportion of higher-chlorinated congeners, although air is generally dominated by lesser-chlorinated fractions (Hornbuckle et al., 2004)

Although they are classified as "persistent" pollutants, biodegradation of PCBs has been well documented (Ohtsubo et al., 2004; Borja et al., 2005; Vasilyeva and Strijakova, 2007; Field and Sierra-Alvarez, 2008; Pieper and Seeger, 2008). Two major microbial metabolic routes are known for the degradation of PCBs: Anaerobic and aerobic, depending, among other factors, on the degree of chlorination of the PCB congener, the redox conditions, and the type of microorganism involved (Borja et al., 2005). Generally, PCB congeners with four or more chlorine atoms undergo microbial anaerobic reductive dechlorination, an energy yielding process where PCBs serve as electron acceptor for the oxidation of organic carbon. Chlorine atoms are preferentially removed from the meta and para positions of the biphenyl structure, leaving lesser-chlorinated ortho-substituted congeners (Olson et al., 2003). Microorganisms that reductively dechlorinate PCBs are widespread within PCB contaminated sediments and involve a variety of species (Tiedje and Boyd, 1987; Abraham et al., 2002; Cho et al., 2003). Lower-chlorinated PCBs congeners, possibly resulting from anaerobic dechlorination, undergo preferentially cometabolic aerobic oxidation mediated by dioxygenase enzymes, resulting in ring opening and potentially the complete mineralization of the molecule (Kohler et al., 1988; Furukawa et al., 2004; Vasilyeva and Strijakova, 2007).

The number of chlorine atoms per molecule and the position of chlorine atoms are important factors for the aerobic biodegradation via oxidative enzymes (Ohtsubo et al., 2004; Furukawa and Fujihara, 2008). Adjacent unchlorinated atoms allow for hydroxylation of the ring and formation of arene oxide intermediates, facilitating the aromatic ring cleavage (Borja et al., 2005). Generally, PCB congeners with three or fewer chlorine atoms per molecule are easily degraded, and the ones with five or more are quite recalcitrant (requiring reductive dechlorination prior to aerobic mineralization) 
(Field and Sierra-Alvarez, 2008). Aerobic biodegradation of PCBs typically involves two clusters of genes, the first one is responsible for the transformation into chlorobenzoates (upper pathway), and the second one is responsible for the further mineralization of chorobenzoates (lower pathway) (Furukawa and Fujihara, 2008). PCBs are typically first oxidized by different enzymes encoded by biphenyl dioxygenase genes (BPH) to produce cis-dihydrodiol intermediates that undergo ortho- or meta-ring cleavage to form chlorobenzoates (Borja et al., 2005). Although PCBs are theoretically biodegradable, even lower-chlorinated congeners in soil can be slow to degrade due to catabolite repression by other readily available substrates (Callahan and Slimak, 1979)

Although studies conducted with single PCB congeners suggest different susceptibility to degradation and metabolic routes depending on the chlorination degree and substitution pattern (Borja et al., 2005), there is currently very little information about the different effects of individual congeners on the soil microbial community and the induction of genes involved in PCB degradation. Indeed, most of studies about PCB-degrading microbial communities have been conducted on PCB mixtures, even though evidence accumulated in other organisms shows that exposure to different congeners induces different biological effects and responses (Nogales et al., 1999; Nogales et al., 2001; Leigh et al., 2006; Aguirre de Carcer et al., 2007).

Part of the results presented in this thesis has been submitted and accepted for publication (with minor revisions) in Environment International (Correa et al., 2009). In addition, part of the results were presented at the 52nd annual conference for the International Association for Great Lakes research (IAGLR), which took place on May 18-22, 2009 in Toledo, Ohio. 


\subsection{Objective}

The overall objective of this research is to investigate the effect of individual PCB congeners on the bacterial community and aerobic metabolism of PCBs in soil. Microcosm experiments were conducted using aerobic agitated soil slurries individually exposed to specific PCB congeners with different degrees of chlorination: PCB-3, 15, 28, and 77, and the commercial mixture, Aroclor 1242 (Figure 1). After four weeks of incubation, the extent of PCB transformation was determined by gas chromatography/mass spectrometry (GC/MS) and the microbial abundance in soil exposed to different PCBs was measured by cell counting and real-time polymerase chain reaction (PCR) amplification of ribosomal DNA (16S rDNA). The microbial community structure and abundance of BPH genes were characterized by real-time PCR using taxonomic group-specific primers and BPH-specific primers, respectively. In addition, terminal-restriction fragment length polymorphism (T-RFLP) was carried out to characterize the soil microbial community in contaminated soil samples from a heavily PCB-contaminated site, the Confined Disposal Facility (CFD) in South Chicago, Indiana.

\subsection{Hypothesis}

The working hypothesis of this research is that exposure to different PCB congeners, characterized by different degree of chlorination and substitution, will result in different bacterial community structures and gene expression patterns.

\subsection{Significance}

Thus, the significance of this work is that it can provide better understanding of the microbial degradation of single PCB congeners in soils or sediments. This will potentially contribute to the improvement of engineered and natural processes applied to 
in situ bioremediation of soils contaminated with PCBs. In addition it can be helpful to improve the implementation of techniques such as biostimulation of indigenous PCBdegrading bacteria, and bioaugmentation of soil with bacterial PCB degraders. Several efforts to increase the biotreatability of sites contaminated with PCBs have been carried out successfully. Leigh et al. (2006) indicated that attempts to biostimulate the indigenous PCB-degrading bacteria enhanced the aerobic degradation of PCBs in contaminated sites. Their studies indicate that rhizostimulation with naturally grown trees shown a significant increase of the number of indigenous PCB-degrading bacteria. It was found that the number of PCB degraders in the root zone of plants such as Austrian pine (Pinus nigra) and goat willow (Salix caprea) was significantly higher than those in the roots of other plants. On the other hand, Di Toro et al. (2006) found that bioaugmentation of contaminated soils with a consortium of non-adapted microorganisms obtained from composted material treated in soil bioreactors increased the number of PCB-degrading bacteria, as well as enhanced the rate of biodegradation of PCBs.

\subsection{Specific aims}

In order to achieve the overall objective of this thesis which consists of investigating the effect of individual PCB congeners on the bacterial community and aerobic metabolism of PCBs in soil, the following specific aims of were pursued:

Specific aim 1: To test the hypothesis that exposure to individual PCB congeners results in different soil microbial community profiles, as well as different abundances of biphenyl dioxygenase (BPH) genes. For this specific aim, laboratory-scale soil microcosms were exposed to individual PCB congeners, including PCB 3, 15, 28, and 77, for four weeks. DNA of microbes in the soil slurries was extracted and analyzed using molecular techniques to determine the abundance of $b p h$ genes and the microbial 
community structure associated with the PCB degradations. PCBs were extracted and analyzed using GC/MSto determine PCBs biodegradation

$\underline{\text { Specific aim 2: }}$ To analyze different soil samples from a PCB-contaminated site (CDF South Chicago) in order to establish a correlation between the microbial community structure and PCB profiles. In this specific aim, DNA extracted from real soil samples at a PCB-contaminated site was analyzed using T-RFLP. PCBs were extracted and analyzed by gas chromatography-mass spectrometry (GC/MS). The correlation between the structure of the bacterial community and the PCBs concentration was examined by clustering analysis.

$\underline{\text { Specific aim 3: }}$ To determine the potential toxicity of a selected group of PCB congeners and hydroxyl metabolites on pure cultures of Escherichia coli and Burkholderia xenovorans LB400. Since the two previous aims were based on complex soil microbial communities, it was difficult to establish the toxic effects of PCB congeners and metabolites on bacteria. In this specific aim, pure bacterial cultures were exposed to a high dose of individual PCBs and hydroxyl metabolites in order to determine their toxic effects on bacterial growth. 


\section{Chapter 2 : Polychlorinated biphenyls: literature review}

\subsection{Physical and chemical description}

Polychlorinated biphenyls (PCBs) are organic compounds characterized by a biphenyl, which is a molecule composed of two benzene rings, substituted by 1 to 10 chlorine atoms (Figure 1). A total of 209 compounds can be synthesized and are known as congeners. The high tendency to specific substitution reactions makes the commercial processes favorably to the production of mixtures (Campanella et al., 2002; Borja et al., 2005; Furukawa and Fujihara, 2008). The most known commercial mixture of PCBs produced in the United States were traded under the name of Aroclor and are identified according to the chlorine content, which is represented as percentage by weight. For example, Aroclor 1248, contains $48 \%$ chlorine by weight, the first two digits refer to the number of carbon atoms on the biphenyl molecule. Other PCB mixtures produced commercially were trade under the names of Aroclor, Kaneclor, Delor, Clophen, Fenclor, and Pyralene depending on the country and manufacturer (Giesy and Kannan, 1998; Chavez et al., 2006). On the other hand, the congeners are named based on the position of the chlorines atoms on the biphenyl molecule according to the International Union of Pure and Applied Chemistry (IUPAC) system (Mackova, 2006). Figure 2 represents the matrix chart which links the position of the chlorine atoms on the biphenyl ring to the PCB IUPAC number. 


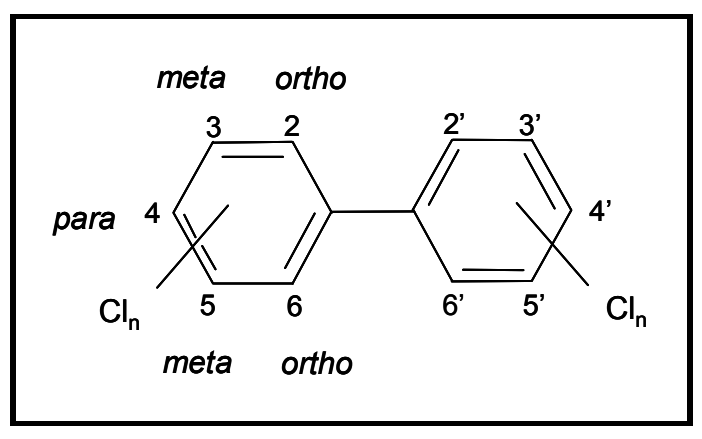

Figure 1: Structural formula of PCB. Source: (Borja et al., 2005)

The physicochemical properties of PCBs depend on different substitution patterns. As a general rule, the solubility of PCBs in water varies according to the degree of chlorination. For instance, congeners with high number of chlorine atoms are characterized by a low solubility in water or by a high tendency to dissolve in lipids, oil, fats, and other non-polar compounds, which increase their tendency to bioaccumulate along the food chain (Campanella et al., 2002; Borja et al., 2005; Chavez et al., 2006),. In addition PCBs are high thermally and chemically stable. They have the appearance of odorless or mildly aromatic solids or oily liquids (Giesy and Kannan, 1998; Campanella et al., 2002). 


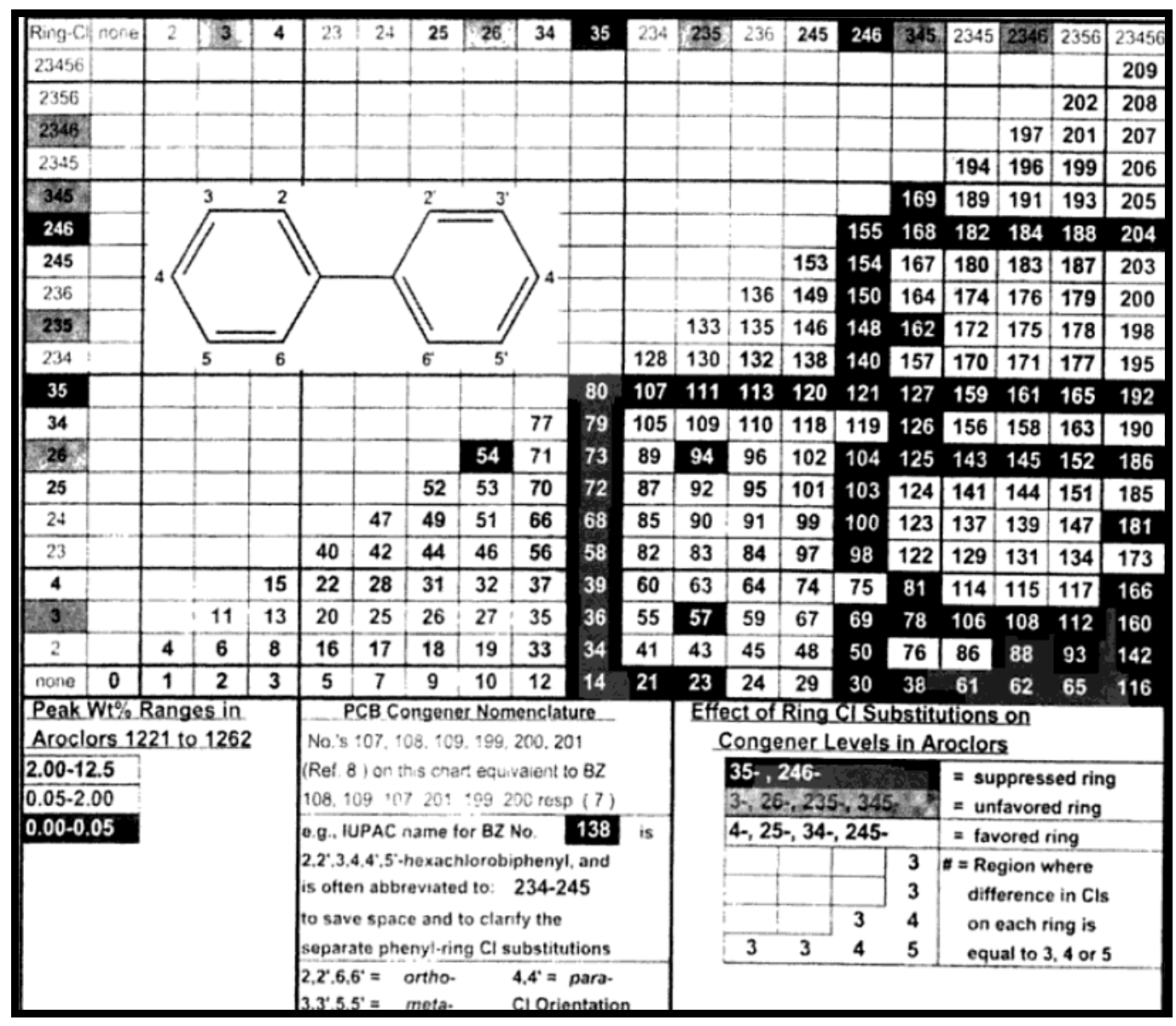

Figure 2: Matrix chart of PCB IUPAC. Row one represents $\mathrm{Cl}$ substitution positions in the left phenyl ring. Column one represents the chlorine substitution in the second phenyl ring. In addition, favorability of chlorine substitution on the Aroclor mixture is showed (Frame, 2001)

\subsection{Sources and environmental cycling of PCBs}

Environmental contamination of PCBs was first reported more than 40 years ago,

environmental concerns raised from the impact of PCBs in the environment resulting in the banning of PCBs production, processing and distribution in 1976 under the Toxic Substances Control Act in the U.S (Borja et al., 2005). Since that time, PCBs have been found in many places around the world including the Arctic and Antarctic regions, for this reason PCBs are considered one of the most widespread contaminants (Mackova, 2006). It is estimated that the total amount of PCBs produced worldwide is about 1.5 
million tons (Safe, 1993; Abraham et al., 2002; Campanella et al., 2002; Pieper and Seeger, 2008). The United States was the largest PCB producer (Figure 3) with approximately 600,000 tons produced from 1930 to 1980s (Borja et al., 2005; Rodrigues et al., 2006). During that period, PCBs were used in several industrial applications including dielectrics fluids in capacitors, transformer oils, hydraulic fluids for turbines, waxes, plasticizers, adhesives, and some other uses (Campanella et al., 2002; Furukawa et al., 2004; Borja et al., 2005). It is assumed that over hundred million pounds of PCBs have entered into the environment, mainly as complex mixtures (Abramowicz et al., 1993).

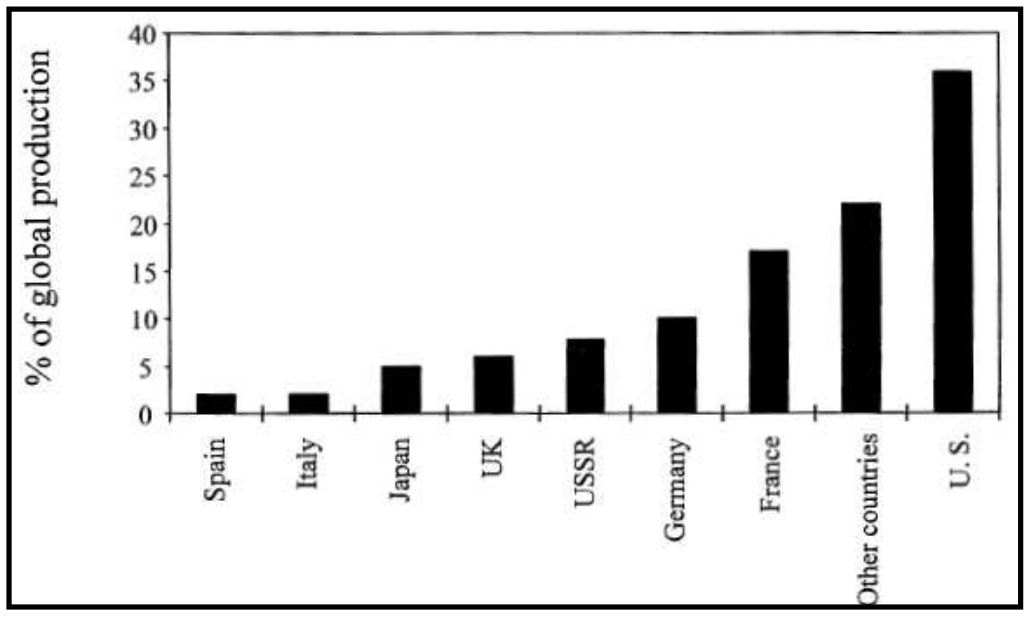

Figure 3: Global production of PCBs in various countries (Giesy and Kannan, 1998)

There is no evidence of natural sources of PCBs. It is assumed that they entered the environment during their use, manufacture, and disposal. Other sources of contamination may include spills of PCBs during their transport, as well as leaks of products such as old capacitors and transformers that contain PCBs (Holoubek, 2001; Borja et al., 2005). Since PCBs are semi-volatile, they have been transported through the environment mostly by the air and water, resulting in deposition on the sediments at the bottom of water bodies, and on leaves of plants. Other contamination routes come from the 
lipophilic properties of the PCBs, which makes them to accumulate in fat tissues of organisms such as fishes, birds, and humans (Safe, 1993; Holoubek, 2001; Campanella et al., 2002). In addition, PCBs attach strongly to soils, making them persistent for many years (Borja et al., 2005).

To mitigate the environmental contamination from PCBs, several remediation techniques have been applied or proposed, the most known alternative is the incineration, founding very little information about other possible $\mathrm{PCB}$ destruction technologies in the literature (Borja et al., 2005). However, some PCB remediation alternatives have been described in the literature including: on-site techniques, such as the use of surfactants or organic solvents to extract the contaminants, dechlorination by hydroxylation, and thermal desorption and incineration (Campanella et al., 2002).

\subsection{Toxicity and health risks of PCBs}

The health effects of PCBs on humans and laboratory animals have been broadly investigated, providing evidence that relates toxicity and exposure to congeners. The potential toxicity of PCBs is low-to-moderate and most of the health effects associated with PCBs result from an exposure during long periods, for instance at the work place (Borja et al., 2005).

The toxicity profiles of PCBs vary according to the different properties of individual congeners, as well as the route exposure. Despite PCB production ceased, exposure to them can still occur, mainly through contaminated air and food (Giesy and Kannan, 1998; Borja et al., 2005). Since PCBs are persistent, lipophilic, and stable compounds, they have been shown to affect the human health causing adverse effects on the nervous and immune system. Also they are known to be endocrine disrupters leading to reduction in the fertility, weight loss, and hypothyroidism, among other symptoms. Recently, new 
concerns have arisen about their potential carcinogenic characters (Giesy and Kannan, 1998; Abraham et al., 2002; Pieper and Seeger, 2008).

PCBs with coplanar configuration lack chlorine substitution at ortho positions, which facilitates the rotation of the two phenyl rings into the same plane. Coplanar PCBs are commonly referred as dioxin-like PCBs (Figure 4 and Figure 5). They have a strong affinity to bind the aryl hydrocarbon receptor, AhR, which is the cellular receptor with the capability to induce the aryl hydrocarbon hydroxylase $(\mathrm{AHH})$ and ethoxyresorufin- $O$ deethylase (EROD). The dioxin-like PCBs: PCB-81 (3,4,4',5-tetrachlorobiphenyl), PCB77 (3,3',4,4'-tetrachlorobiphenyl), PCB-126 (3,3',4,4',5-Pentachlorobiphenyl), and PCB-169 $\left(3,3^{\prime}, 4,4^{\prime}, 5,5^{\prime}\right.$-Hexachlorobiphenyl) are considered the most toxic congeners (Giesy and Kannan, 1998). There are still uncertainties about the reactions that govern the metabolism of the PCBs in mammals. However, looking at the variety of health effects associated with exposure to PCBs, metabolism of PCBs are likely to be associated to a variety of pathways (Campanella et al., 2002).
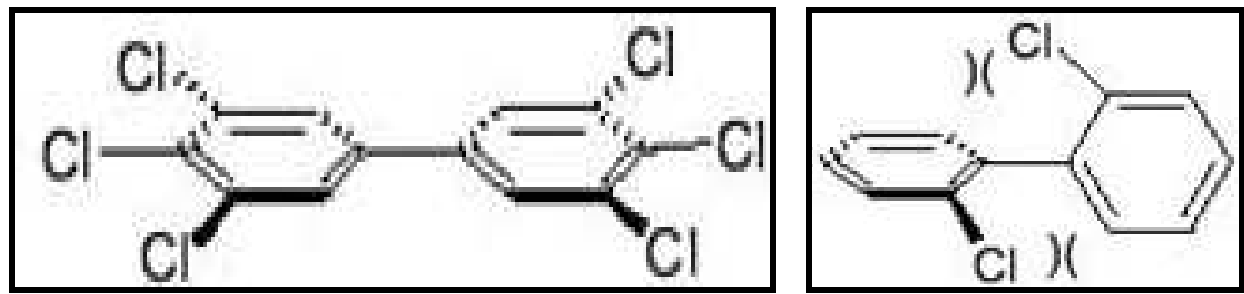

Figure 4: Structure of coplanar (dioxin-like) PCBs (left) and non-planar PCBs (right) (source: www.greenfacts.org).

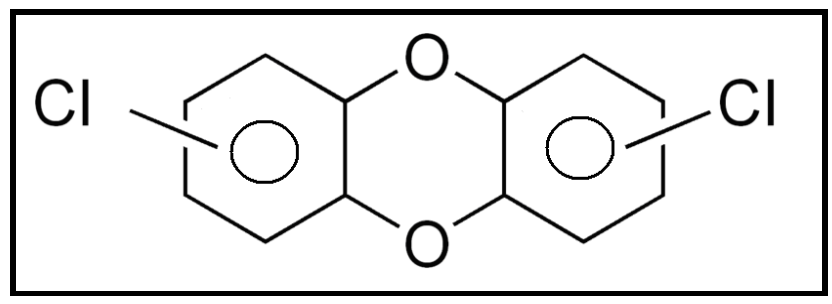

Figure 5: Structure of dioxins (adapted from: http://www.epa.gov/esd/chemistry/organal/reports/regmsf/regmsf.htm). 


\subsection{Phytoremediation of PCBs}

Phytoremediation is a process that consists in the mitigation of environmental contamination through the use of plants. It is a rising technology, which offers advantages such as low costs and less alteration of the environment compared to other remediation technologies (Chekol et al., 2004). The reliability of phytoremediation technology is supported by the fact that the Environmental Protection Agency (EPA) has recognized it as a promising technology, which is enlisted in approximately 150 remediation projects around United States. In addition, it is estimated that in 1999 a budget inferior to $\$ 50$ million was invested in phytoremediation programs, while in 2007, this value reached $\$ 300$ million dollars (Campos et al., 2008). According to Mackova (2006), plant cells have the potential to transform polychlorinated biphenyls at relatively high concentrations with no substantial toxicological effects.

The processes involved in phytoremediation of organic pollutants (Error! Reference source not found.) include: phytoextraction (uptake and retention of pollutants from soil into plant tissues), rhizhofiltration (absorption by the roots); phytotransformation (transformation of the pollutants by enzymes in plants); phytovolatilization (release into the atmosphere through the plant transpiration), phytostabilization (sequestration of the pollutant to the soil material resulting in the reduction of the bioavailability) (Macek et al., 2008). 


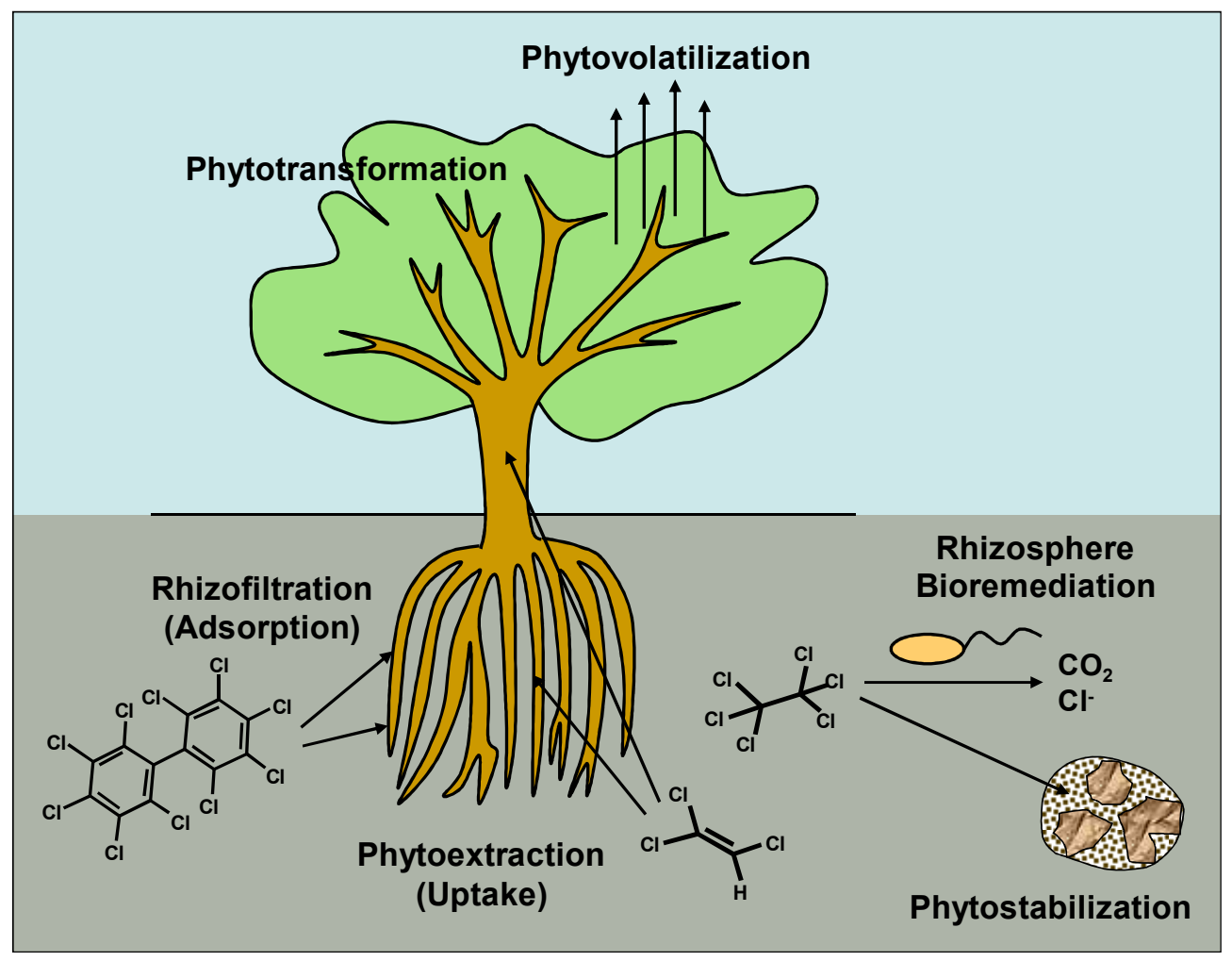

Figure 6: Processes involved in phytoremediation (Van Aken, 2008).

Plant metabolism of xenobiotic compounds consists in a three phase's process, known as the "green liver model" (Figure 7) because of its similarity to the detoxification process that occur in the mammalian liver; this concept was first introduced by Sandermann (1994). This model considers that once the organic pollutant is uptake by the plant, the functionalization of the molecules takes place. It is known as phase $I$, the initial activation, consists in an oxidation process where the polarity of the organic pollutant is increased by plant enzymes trough the addition of functional molecules such as hydroxyl; this is comparable to the transformation of xenobiotics compounds by the mammals' liver. In this phase plant enzymes such as cytochrome P-450 monooxygenases and peroxidases are involved in the initial reactions (Mackova et al., 1997a; Mackova et al., 2001; Chroma et al., 2003; Harms et al., 2003). On the other hand, The phase II involves conjugation of the activated compound produced in phase I with a plant molecule 
(glucose, aminoacids) resulting in the increase of its solubility and the reduction of the toxicity of the organic pollutant. Despite there is very little information about the enzymes involved in the conjugation phase in the PCB metabolism, it is suggested that various transferases, such as glutathione $S$-transferases are involved in the conjugation of PCBs in plants (Burken, 2003). In the last stage, phase III, conjugated is trapped within the plant, which guarantee a safe storage of the pollutant without to produce any alteration in the plant functions (Burken, 2003; Macek et al., 2008)

Several studies presented in the late 1970s and the early 1980s did provide evidence of phytoextraction of PCBs from soils (Zeeb et al., 2006). Since that time, an important number of studies on phytoremediation of PCBs have been conducted, providing evidence that plant species have the capability to degrade effectively different PCBs (Meagher, 2000). The efficiency of the phytoremediation of PCBs depends on the chlorination number, chlorine position, and the plant species (Campanella et al., 2002). Another important fact for the phytoremediation of PCBs is that it is most likely to be limited to tetra-chlorinated and lower chlorinated PCB congeners. Nevertheless, there is an apparent recalcitrance of some low chlorinated PCBs compared to the higher chlorinated, which originated from the substitution pattern (Van Aken et al., 2009b).

Most of studies on phytoremediation of PCBs demonstrate the capability of plants to transform PCBs into hydroxylated biphenyls. In vitro studies conducted by Mackova et al. (1997b) about the degradation of PCBs using hairy root cultures of solanum nigrum (black nightshade) demonstrated the $40 \%$ mineralization of the PCB mixtures (Delor 103) after 30 days of incubation. In addition, Kucerova et al. (2001) studied the capability of in vitro cultured cells to transform PCB mixtures (Delor 103). The plant species assayed include Solanum nigrum (black nightshade), Triticum aestivum (wheat), Hordeum vulgare (barley), Glycine max (soybean), Lycopersicum esculentum (tomato), Morus rubra (mulberry), and Betula pendula (birch). The results obtained showed that 
culture of wheat, barley, and soy presented the higher efficiency for the metabolism of PCBs. In order to determined the metabolites derived from the transformation of PCBs, Rezek et al. (2007) used hairy root of by Solanum nigrum (black nightshade) exposed individually to 25 different congeners, which demonstrated that PCBs with higher chlorination produce low number of metabolic products. For example, dichlorinated biphenyls usually formed two metabolites, while trichlorinated biphenyls produces only traces of metabolites. On the other hand, Chekol et al. (2004) investigated the effect of the rhizosphere from seven different plant species in the phytoremediation of a PCB mixture (Aroclor 1248). The species used in the study included alfalfa, flatpea, sericea lespedeza, deeertongue, reed canarygrass, switchgrass, and tall fescue. Observations made indicated a higher metabolism of PCBs in the presence of planted soil than in unplanted soil, which is possibly associated to an augmentation of the activity of microorganisms.

Despite the high potential of plants to transform PCBs, they lack of catabolic enzymes required for the complete mineralization of xenobiotics. In order to improve the phytoremediation of PCBs on the field, genetically modified organisms (GMO) such as plants and microorganisms have been developed (Van Aken, 2008; Macek et al., 2008). For instance, Francova et al. (2003) introduced the gene $b p h C$ into tobacco plants; the results obtained demonstrated a high transformation of the PCBs by transgenic plants. In the same way, Novakova et al. (2009) introduced bacterial genes ( $b p h C)$ from Pseudomonas testosteroni B-356 into tobacco plants confirming an increase in the efficiency of the biodegradation of the PCBs. 


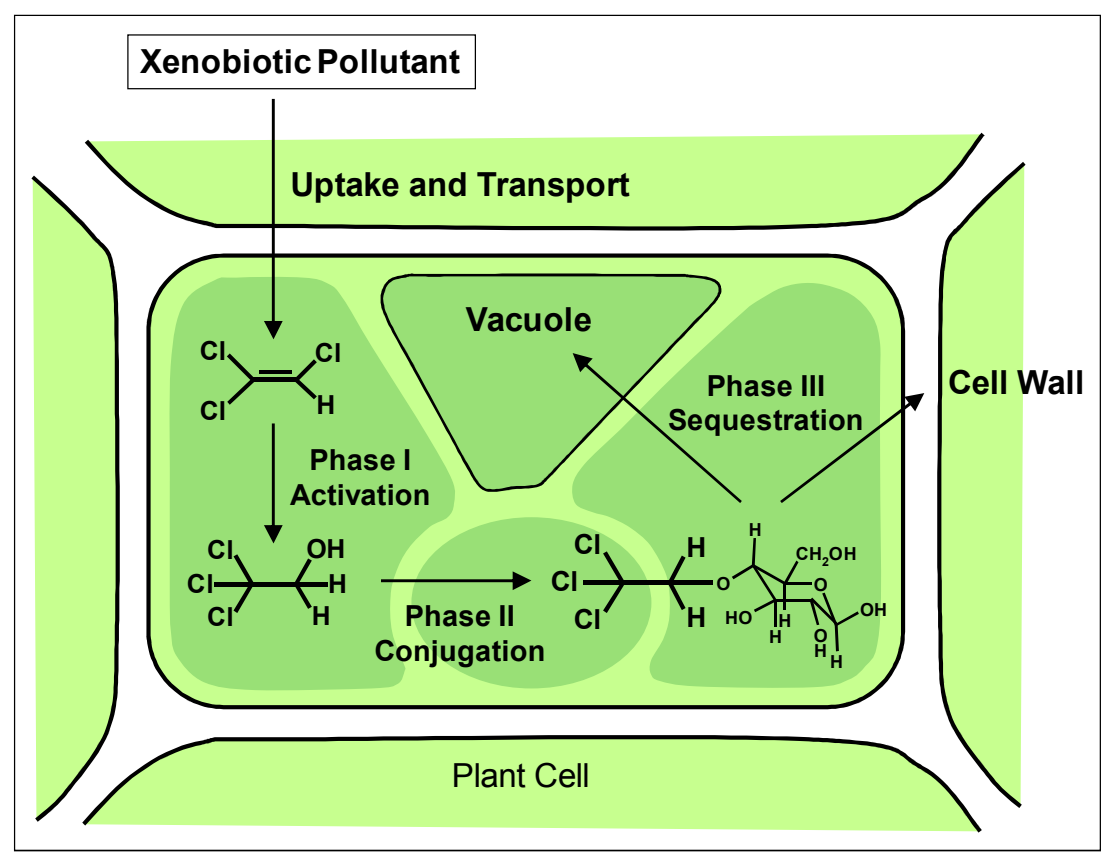

Figure 7: Green liver model (Van Aken, 2008).

\subsection{Microbial degradation of PCBs}

Even though PCBs are recalcitrant and persistent in the environment, it has been found that some microorganisms, such as bacteria, are very important in the remediation of environments contaminated with PCB (Ohtsubo et al., 2004; Borja et al., 2005; Vasilyeva and Strijakova, 2007; Field and Sierra-Alvarez, 2008; Pieper and Seeger, 2008). Although bioremediation constitutes a rising and valuable technology, it still needs to be studied in order to improve the understanding of the role of bacteria (Pieper and Seeger, 2008). Bioremediation is an attractive alternative compared to traditional remediation system, since it can lead to the degradation of the organic pollutants without to alter significantly the environment (Williams, 1994). Biphenyl-utilizing microorganisms have shown to have the capability to utilize PCBs as carbon and/or energy source (Abraham et al., 2002; Adebusoye et al., 2008). The two processes known for microbial degradation of PCBs are anaerobic (Figure 8) and aerobic (Figure 9). Biodegradation of PCBs 
depends mainly on the chlorine substitution and chlorine number of the congener as well as the structure of the microbial community (Borja et al., 2005). Higher chlorinated PCBs undergo reductive dechlorination by anaerobic process and lower chlorinated PCBs undergo aerobic degradation (Campanella et al., 2002).

The bacterial species known to be involved in the aerobic degradation of PCBs include Achromobacter, Acinetobacter, Alcaligenes, Burkholderia, Comamonas, Pseudomonas, Ralstonia, Sphingomonas, Corynebacterium, and Rhodococcus (Furukawa and Fujihara, 2008).

Despite the theoretical possibility of PCB degradation through microbes demonstrated at the laboratory level, bioremediation of real contaminated soils is impaired by the low bioavailability of PCB (Campanella et al., 2002; Borja et al., 2005; Di Toro et al., 2006). This fact is mainly associated to the tendency of PCBs to attach strongly to the soil, reducing the availability of congeners in the soil water-phase where most of the indigenous PCB-degrader microorganisms are located (Fedi et al., 2005).

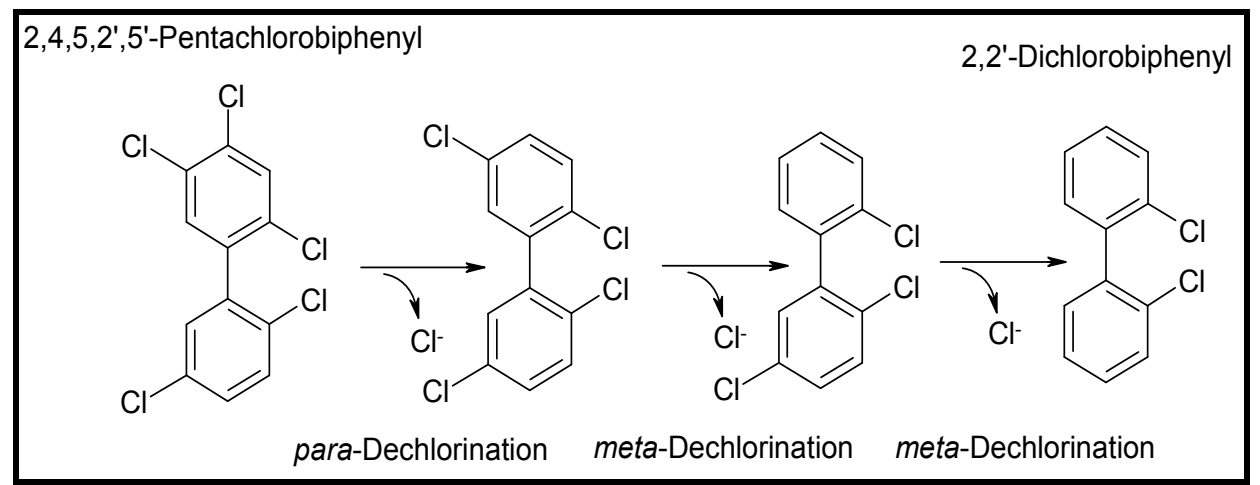

Figure 8: Bacterial anaerobic metabolism of PCB-20 (2,3,3'-trichlorobiphenyl) (Harms et al., 2003).

The number and location of chlorine atoms in the biphenyl molecule are the most important aspects on the microbial degradation of $\mathrm{PCB}$, besides other factors, such as the 
availability of carbon sources, oxygen, and nutrients. Higher chlorinated PCBs are more difficult to degrade. Also, the biodegradation of PCBs is slower when chlorines are located on both biphenyl rings, compared with those with chlorines only on one ring. In addition the double ortho-substituted PCBs are more difficult to degrade. The rate of PCB degradation, as well as the preference of ring that is attacked varies among the different bacterial strains (Furukawa and Fujihara, 2008).

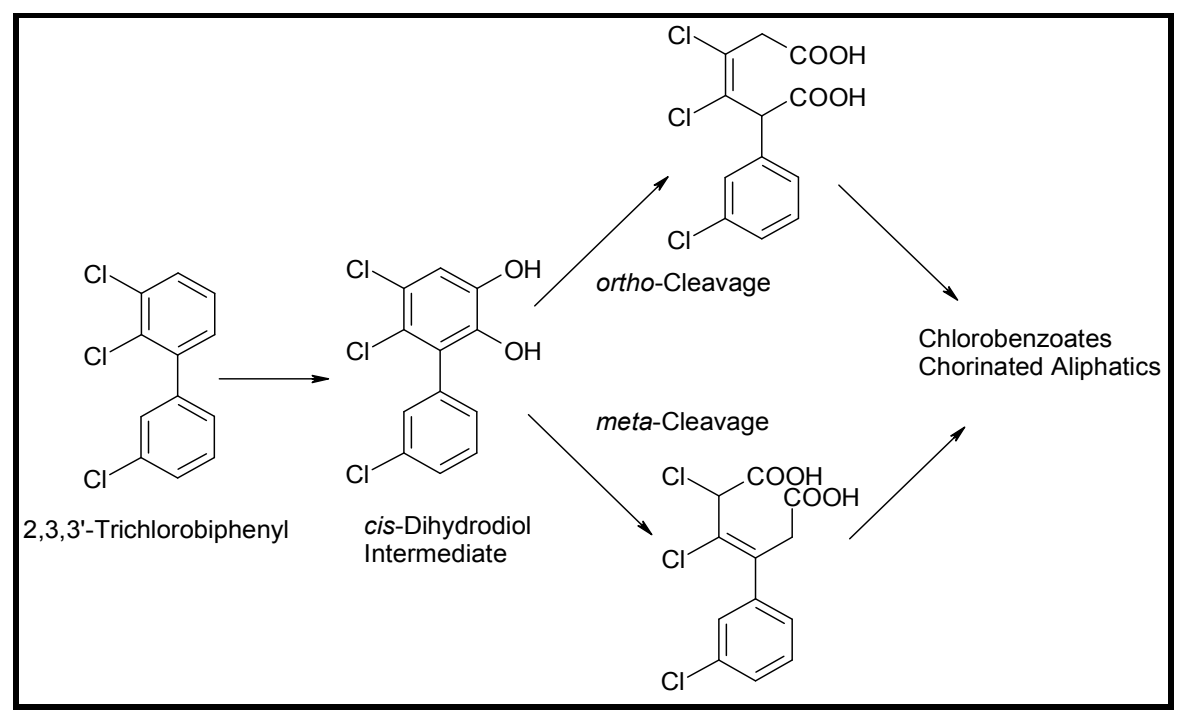

Figure 9: Bacterial aerobic metabolism of PCB-20 (2,3,3'-trichlorobiphenyl) (Harms et al., 2003).

\subsection{Molecular basis of biodegradation}

Advances in genetics have helped to a better understanding of the biodegradation of organic pollutants. Molecular techniques allow further characterization of the structure of complex microbial communities that cannot be easily analyzed with traditional microbiology techniques (Baldwin et al., 2003; Fedi et al., 2005). It is estimated that only 0.1-1\% of the soil bacterial species can be cultured in the laboratory (Hill et al., 2000; Baker et al., 2003). For this reason, molecular approaches have been using to analyze the nucleic acids of microbes contained in the environmental samples, in order to characterize the microbial community. The main reason to use this approach is that 
genetic information contained in the nucleic acids are important to describe the development and functioning of living organisms (Widada et al., 2002). This can be applied to the characterization of the microbial community of environmental samples contaminated with PCB congeners.

Despite the lack of information in the literature about bacterial genes involved in the reductive dehalogenation of PCBs, it is known that anaerobic bacteria can use chloroaromatic compounds as an electron acceptor. The most common dechlorination pattern indicates that anaerobic dehalogenating bacteria have a high tendency to remove chlorine from the meta and para substitution with a low occurrence for the removal of chlorine from the ortho substitution. Some anaerobic dechlorinating bacteria related to Dehalococoide, such as $o-17$ and DF-1, have been identified, which have the capability to dehalogenate chlorinated compounds such as tetrachloroethene (Pieper and Seeger, 2008).

On the other hand, the aerobic degradation of PCBs have been well studied. Biphenyl dioxygenases constitute a family of enzymes involved in the aerobic degradation of PCBs.These enzymes are encoded in biphenyl dioxygenase genes and are known to catalyze the degradation of biphenyl and PCBs. Enzymes involved in the biphenyl upper pathway (Figure 10) include BphA, BphB, BphC, BphD, BphE, BphF, and BphG (Furukawa et al., 2004; Ohtsubo et al., 2004; Pieper and Seeger, 2008). The initial reaction in the aerobic degradation of $\mathrm{PCB}$ is catalyzed by biphenyl dioxygenase, $\mathrm{BphA}$, a Rieske non-heme iron oxygenase enzyme composed by three different subunits, a large subunit which is encoded by $b p h A$, a small subunit encoded by $b p h A 2$, and a ferrodoxin reductase subunit encoded by bphA3 (Furukawa et al., 2004; Furukawa and Fujihara, 2008; Pieper and Seeger, 2008). The last subunit is responsible to transfer electrons from nicotinamide adenine dinucleotide (NADH) dehydrogenase enzyme to the terminal oxygenase (Gibson and Parales, 2000). The second enzyme involve in the biphenyl upper 
pathway is a cis-2,3-dihydro-2,3-dihydroxybiphenyl dehydrogenases, $\mathrm{BphB}$, belonging to the short-chain alcohol dehydrogenases family. The third step of the pathway is catalyzed by a 2,3-dihydroxybiphenyl 1,2-dioxygenase (BphC), a homo-octamer enzyme, in which the subunits are divided into two domains. It has been observed that ortho-chlorinated metabolites have the capability to inhibit the BphC enzyme. The fourth enzyme is known as 2-hydroxy-6-phenyl-6-oxohexa-2,4-dieneoate (HOPDA) hydrolases, which belong to the $\alpha / \beta$ hydrolase enzyme super family (Furukawa et al., 2004; Furukawa and Fujihara, 2008; Pieper and Seeger, 2008). There is limited information about the participation of this enzyme in the transformation of chlorinated compounds, however some evidence suggests the possible limitation of this enzyme in the metabolism of PCB congeners (Seah et al., 2000; Seah et al., 2001). Additional enzymes, such as glutathione- $S$ transferases (BphK), have been shown to be involved in the biphenyl pathway, although their functions in the metabolism of PCBs have not been described in the literature (Bartels et al., 1999). 


\section{Pseudomonas pseudoalcaligenes KF707 bph gene cluster}
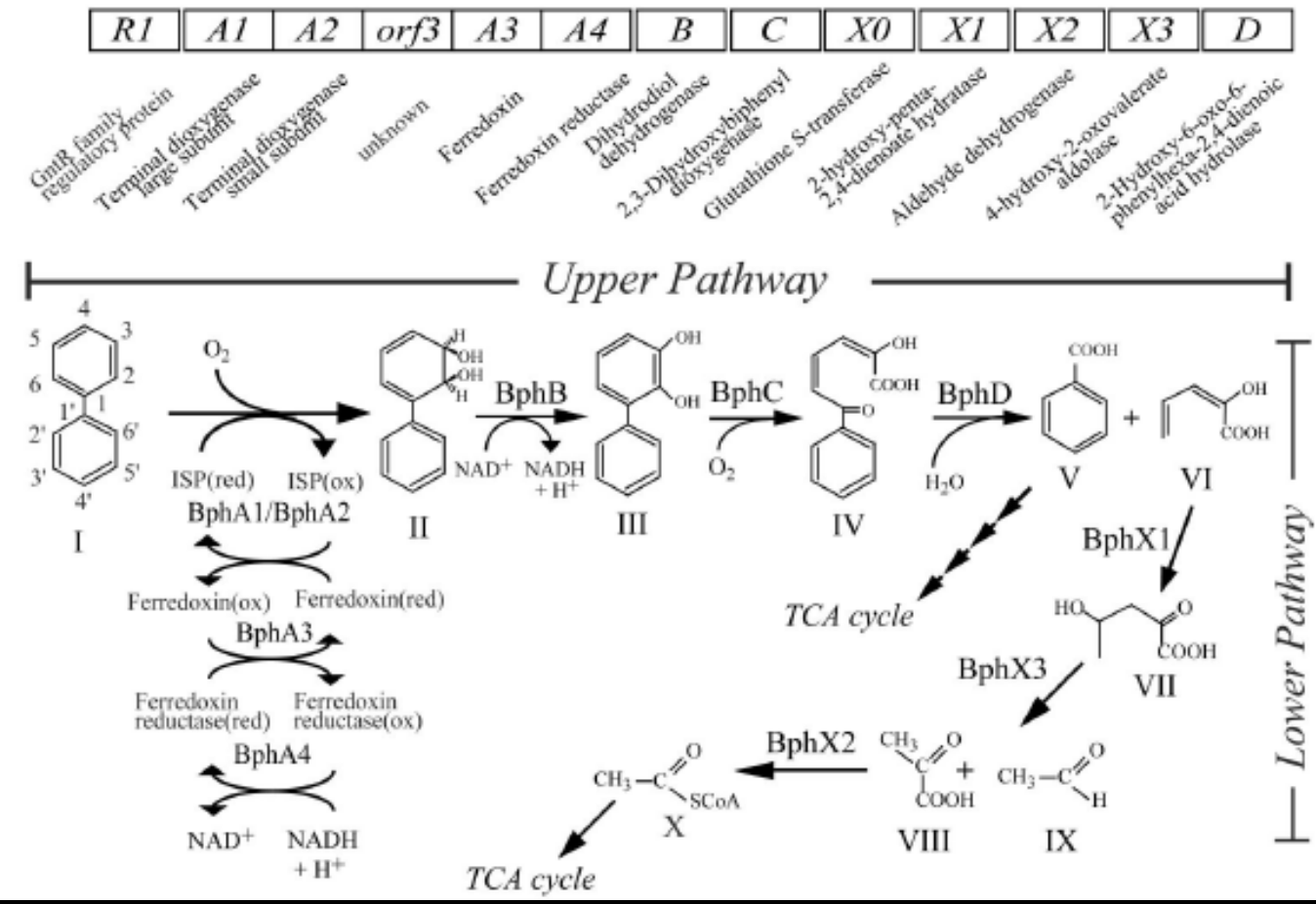

Figure 10: Pathway for degradation of biphenyl and organization of the $b p h$ gene cluster in $P$. pseudoalcaligenes KF707. The compounds designations are: I ( $b p h A)$, biphenyl 2,3 dioxygenase; II ( $b p h B)$, dihydrodiol compound; III ( $b p h C)$, 2,3-dihydroxybiphenyl; IV ( $b p h D)$, biphenyl meta-cleavage product; V, benzoic acid; VI, 2-hydroxypenta-2,4-dienoic acid; VII, 4-hydroxy-2-oxovaleric acid; VIII, pyruvic acid; IX, acetaldehyde; X, acetyl-coenzyme A (Furukawa and Fujihara, 2008)

The PCB metabolism is carried out by the biphenyl catabolic enzymes described above, and consists in a four enzymatic steps. In the initial reaction of the metabolism, the 2,3dioxygenation is catalyzed by a biphenyl dioxygenase catalyzes leading to the formation of 2,3-dihydrodiol, this is dehydrogenated to 2,3-dihydroxybiphenyl by a dihydrodiol dehydrogenase forming a compound known as 2,3-dihydroxybiphenyl dioxygenase, which cleaves an dihydroxylated ring to produce 2-hydroxy-6-oxo-6-phenylhexa-2,4dienoic acid. This acid is hydrolyzed to benzoic acid and 2-hydroxypenta-2,4-dienoate by a hydrolase. To the date, no known biphenyl degrading bacteria has the capability to 
further degrade chlorobenzoic acids (Furukawa et al., 2004; Sondossi et al., 2004;

Furukawa and Fujihara, 2008; Pieper and Seeger, 2008)

Even though PCBs are xenobiotic compounds (artificial substances), bacteria have shown PCB-degradation capabilities. In addition, efforts to engineer the genes encoding enzymes with the capability to degrade PCBs have been carried out (Furukawa and Fujihara, 2008). Figure 11 shows the phylogenetic tree, in which are represented the subunits of the biphenyl dioxygenase and other aromatic dioxygenase genes. 


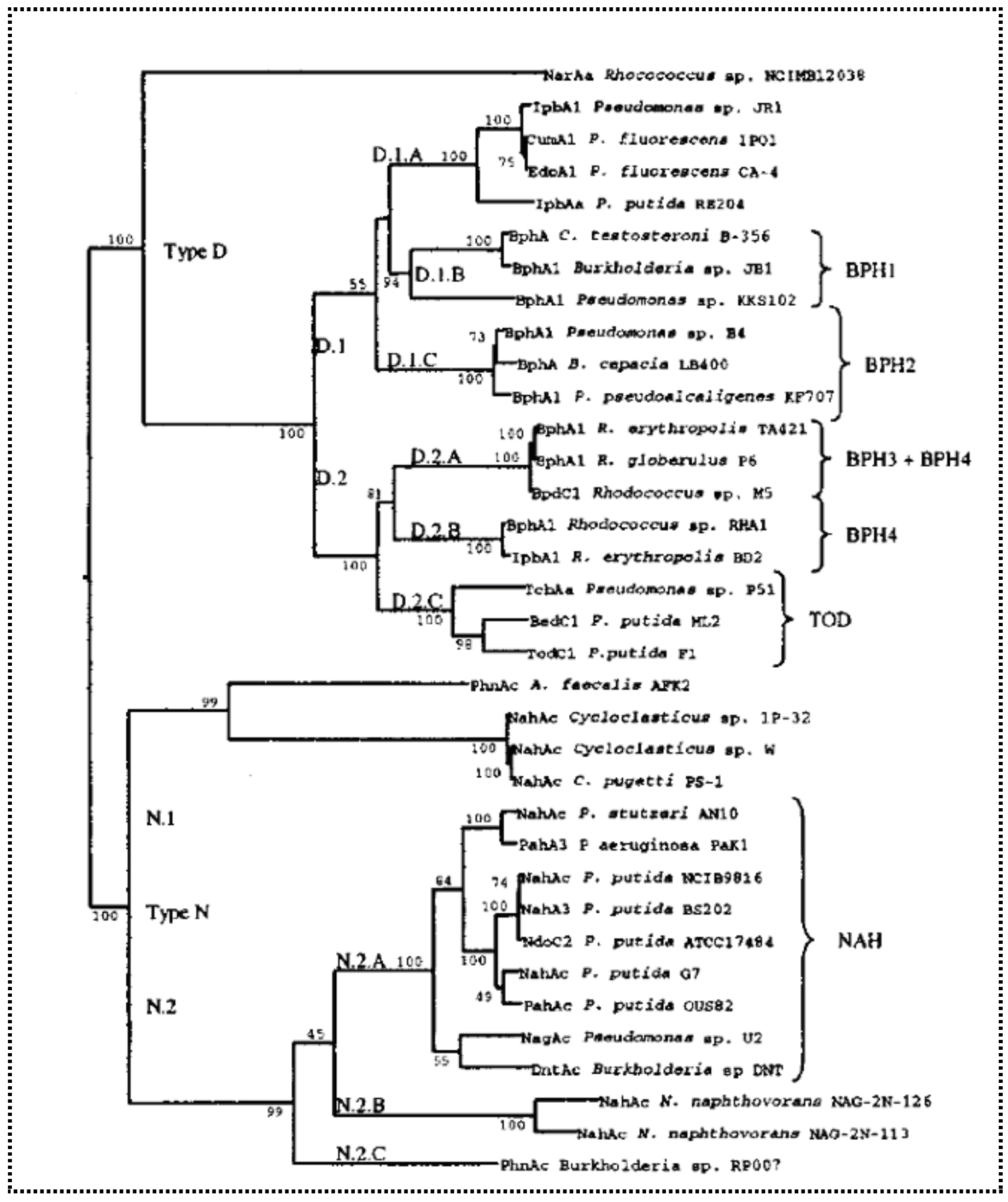

Figure 11: Phylogenetic analysis of the large subunits of aromatic dioxygenase genes. The branch designations are D.1.A: type (D), family (1), and subfamily (A). To identify the primer set, alignments were performed using subfamilies of genes (Baldwin et al., 2003). 


\section{Chapter 3 : Experimental section}

\subsection{Overview of selected techniques}

\subsubsection{Real-time PCR}

The polymerase chain reaction (PCR) is a molecular biology technique that allows the amplification of one specific gene. Two specific primers are used (forward and reverse), which anneal to each side of the target region of the DNA. Polymerization of new DNA occurs from the initial DNA template. However, regular PCR is an end-point technique that does not allow accurate quantification of the DNA. On the other hand, real-time PCR is a method which allows DNA quantification using the PCR process through the "real time" monitoring of the DNA amplification (Dale, 2007). Real-time PCR is a quantification method, which is more sensitive, leading to higher accuracy in the results (Baldwin et al., 2003).

The fundamental of the real-time PCR consists of a PCR reaction in the presence of a dye; at each cycle, the fluorescent dye SYBR Green binds double strand DNA, and a fluorescent signal is generated (Figure 12). Thus, the increase of the fluorescence is directly related to amount of the PCR product, which is quantified at the end of each PCR cycle (http://www.realtimepcr.dk/principle.html). To determine the amplification plot, an arbitrary threshold is set above the baseline data. The point where fluorescence crosses the threshold is known as cycle threshold $\left(\mathrm{C}_{\mathrm{t}}\right)$ (Heid et al., 1996).

There are two methods to analyze data from real-time PCR: relative quantification and absolute quantification. The relative quantification allows determination of the change in expression of genes, while the absolute quantification method is applied to determine the copy number of a gene. The relative quantification method was used in this thesis to compare the abundance of the BPH genes and bacterial groups (Livak, 2001). This 
method employs a statistical approach, which is based on the comparison of the differences $(\Delta)$ between the threshold cycles $(\mathrm{Ct})$. The components of the relative quantification method include the nucleic acid that is being studied (target), a sample used as a point of reference for comparative results, which is usually a non-treated sample (calibrator), a gene with a stable expression level, commonly housekeeping genes, such as $\beta$-actin, rRNA, etc., used as a reference to normalize the quantification of the DNA (endogenous control). It is very important to use replicates for each sample to be analyzed and the endogenous control, in order to have a statistical significance in the analysis of the data. Triplicates of each sample were analyzed using SYBR green chemistry. Individual $\mathrm{Ct}$ values were obtained and the standard deviation was calculated from the total number of samples (Livak, 2001; Applied-Biosystems, 2005; Pfaffl, 2009)

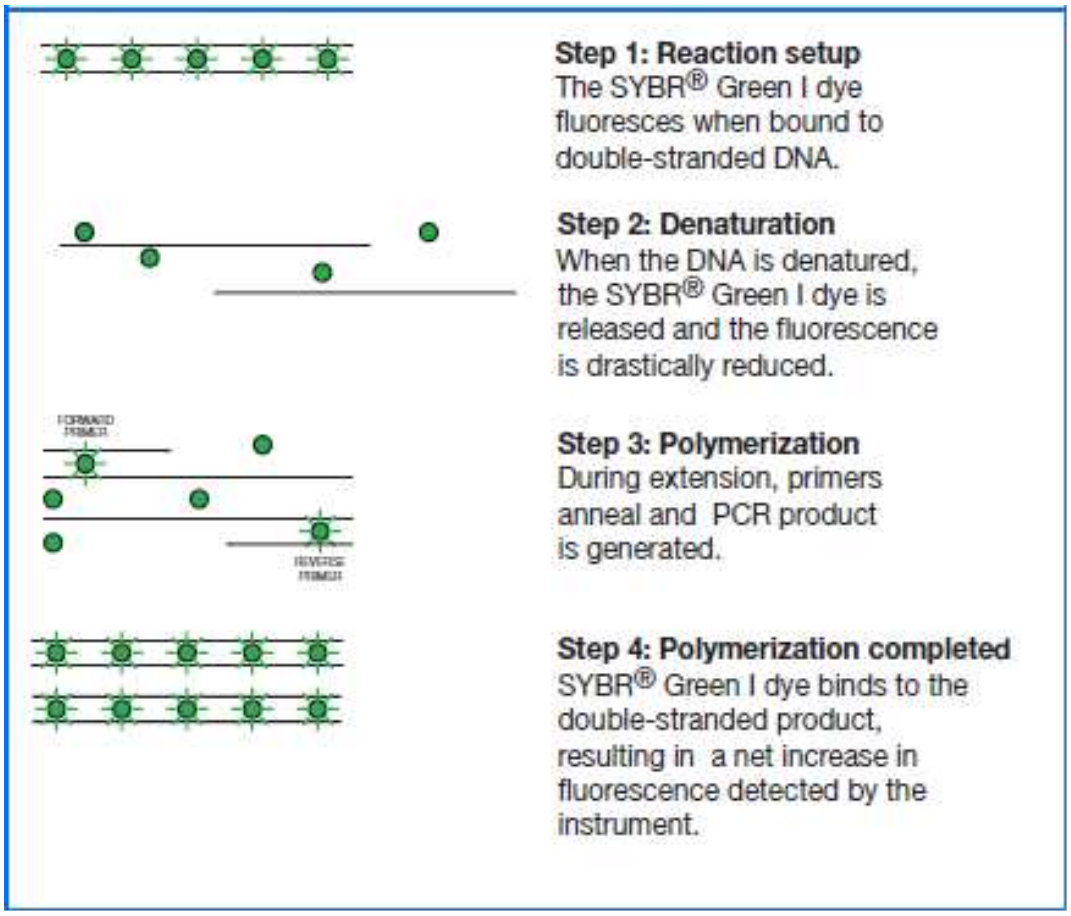

Figure 12: SYBR green dye chemistry used in the detection of real-time PCR products (AppliedBiosystems, 2005) 


\subsubsection{Terminal restriction fragment length polymorphism (T-RFLP)}

Terminal restriction fragment length polymorphism (T-RFLP) is a molecular biology technique used to obtain a fingerprinting of microbial communities based on the $16 \mathrm{~S}$ rDNA. The technique involves different steps including DNA extraction, PCR amplification, digestion of purified DNA, and analysis of the T-RFLP patterns. Typically, DNA is isolated from an environmental sample; PCR is conducted to amplify the target region of the $16 \mathrm{~S}$ rDNA using a fluorescently labeled primer. The PCR products are then purified and digested with selected restriction enzymes, which target specific DNA at a specific recognition site. Restriction fragments obtained from digestion are separated by electrophoresis on an ABI (Applied Biosystems) DNA sequencer. Finally, the distribution and intensity of taxonomic groups are displayed in a T-RFPL profile (Figure 13). Statistical analysis of the distribution is required (Liu et al., 1997; Marsh, 1999). There are several software to carry out the statistical analysis in a more effective an accurate way, these programs are based mainly in a clustering method and may include: an algorithm to identified 'true peaks' from a predetermine baseline, comparison of electropherograms and bin fragments and clustering according the size, and selection of the representative samples from each cluster (Abdo et al., 2006)

T-RFLP is based on the link between size of the restriction fragments and sequence databases. It has been used effectively as a mechanism to analyze the microbial community structure in soil, water, plant tissues, and other (Thies, 2007).

T-RLFP is an effective method to compare complex communities in environmental samples. It is a sensitive, rapid, and easily reproducible technique (Marsh, 1999; Thies, 2007). (Blackwood et al., 2005; Fierer et al., 2005) suggested that it is necessary to select an appropriate statistical method for the analysis of the fragments in order to improve the accuracy on the characterization. 


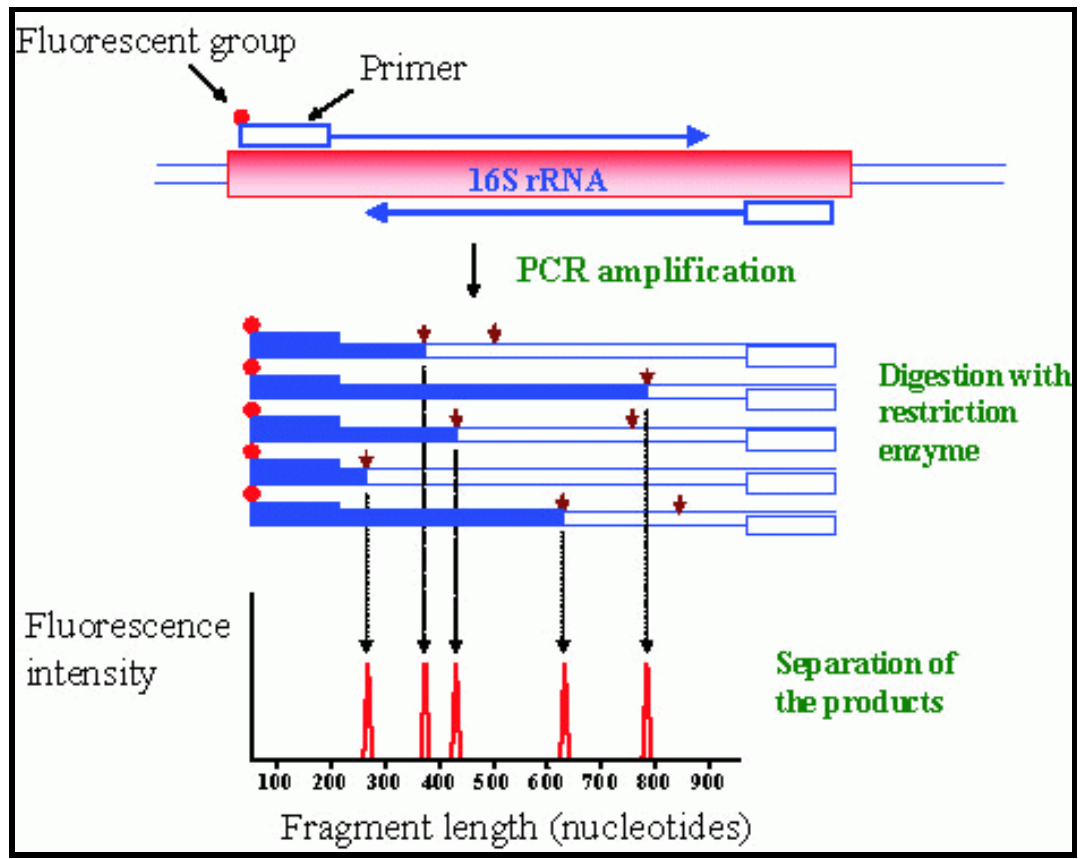

Figure 13: Scheme of a typical T-RFLP process (Source: http://nodens.ceab.csic.es/t-rfpred/method)

\subsubsection{Gas chromatography/mass spectrometry (GC/MS)}

Gas chromatography/mass spectrometry (GC/MS) is an analytical method, which combines two techniques, gas chromatography (GC) and mass spectrometry (MS). In a GC/MS analysis, the components of the gas mixture (analytes) are injected into a GC column which consists of an injection entry on a metal column packed with substrate material and a detector placed at the exit of the column. A gas propels the sample through the column in which the compounds are separated. Separated compounds then enter into the MS system which consists of three basic steps including ionization, mass analysis, and detection. The most common process for the ionization is the electron impact ionization (EI) operating at an effective applied energy of $70 \mathrm{eV}$, in this process the electron energy is applied to the gas coming from the $\mathrm{GC}$ unit leading to the formation of charged particles. These charged ions are analyzed through a quadrapole mass spectrometer, which is a device with four parallel metal rods that separates ions based on 
their $\mathrm{m} / \mathrm{z}$ ratio by using the stability of trajectories in oscillating electric fields. The ion analysis is based on the mass to charge ratio $(\mathrm{m} / \mathrm{z})$. In the detection process the abundance of mass/charge $(\mathrm{m} / \mathrm{z})$ is recorded by the detector and a mass spectrum is obtained. It displays the relative abundance on the y-axis and the mass to charge ratio on the X-axis (http://www.chem.arizona.edu/massspec) (Hübschmann, 2001). This technique is useful to obtain structural information about the analytes such as molecular weight and the chemical structure. The analysis of organic compounds by GC/MS is commonly given by the comparison of the obtained spectrum against a reference spectrum (Hites, 1997). Figure 14 shows a general scheme of the GC/MS process.

The analysis of samples containing PCBs was performed by using a method based on the modified EPA method 1668A. The quantification of the PCB homologues in this work was perform by GC/MS/MS, which involves a second phase of mass fragmentation operating under the electron impact ionization (EI) at $70 \mathrm{eV}$. The analysis was performed by multiple reactions monitoring $(\mathrm{MRM})(\mathrm{Hu}, 2008)$. The $\mathrm{MRM}$ is a technique that allows the simultaneous analysis of multiple fragment ions. The analysis invovles an initial electrospray ionization followed by two stages mass selection. In the first mass selection stage, the first quadrupole is set at a particular fraction $\mathrm{m} / \mathrm{z}$. The optimal collision energy is set in order to produce the ideal fragment of the parent compound, while in the second quadrupole, the precursor ion is fragmented. In the second stage of the mass analysis, the third quadrupole is set on a specific $\mathrm{m} / \mathrm{z}$ of that fragment. This leads to a selective reaction monitoring where only the ions with the same arrangement than the selected analyte will be identified (Anderson and Hunter, 2006). The use of internal standards in the MRM approach allows the absolute quantification of the analyte (Gerber et al., 2003). 


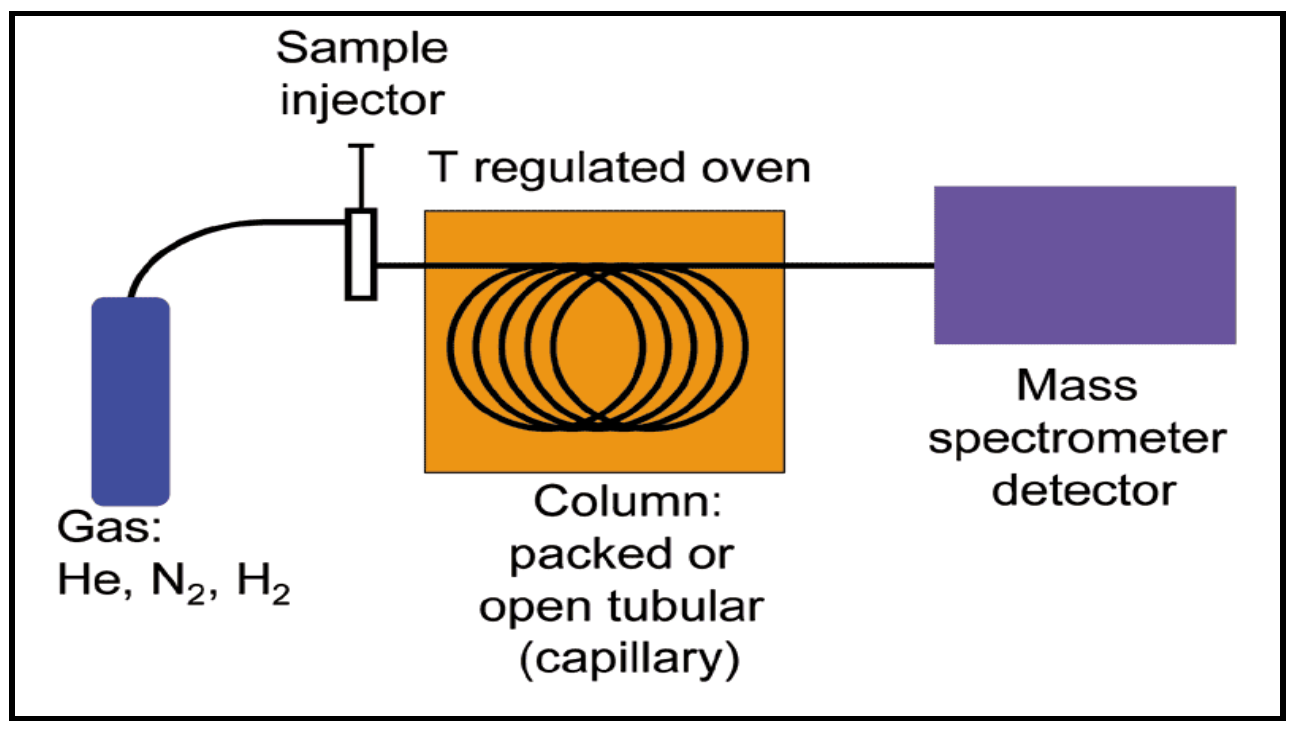

Figure 14: Scheme of the GC/MS analysis method (http://en.wikipedia.org/wiki/Gas_chromatographymass_spectrometry).

\subsection{Experimental protocols}

\subsubsection{Microcosm experiments}

\subsubsection{Soil samples}

A synthetic soil medium was prepared by mixing the general-purpose peat-based medium, PRO-MIX BX (Premier Horticulture, Quakertown, PA) with all-purpose sand (Quikrete, Atlanta, GA) in the proportion of 40:60 by weight. PRO-MIX BX growing medium consisted in Canadian sphagnum peat moss ( 75 - $85 \%$ by volume), horticulturalgrade perlite, vermiculite, and dolomitic and calcitic limestone. The medium was characterized as follows: $\mathrm{pH}: 5.5-6.5$, electrical conductivity: $1.3-2.0 \mathrm{mmhos} \mathrm{cm}^{-1}$, air porosity: $17-22 \%$ by volume, and bulk density: $0.13-0.16 \mathrm{~g} \mathrm{~cm}^{-3}$. 


\subsubsection{Slurry preparation}

Soil slurries were prepared by mixing synthetic soil aliquots with sterile distillated water in a ratio $1: 2 \mathrm{w} / \mathrm{v}$. Forty $(40) \mathrm{mL}$ of slurry were then introduced into pre-sterilized 250 $\mathrm{mL}$ penicillin bottles. Slurry samples were spiked with individual PCB congeners and Aroclor 1242 (formulated as $5 \mathrm{mg} \mathrm{mL}^{-1}$ acetone stock solution) to a final concentration of $60 \mathrm{ug} \mathrm{mL} \mathrm{mL}^{-1}$. Flasks were sealed with Teflon-lined rubbers stoppers. Non-exposed control flasks containing similar soil slurries spiked with an equivalent volume of acetone. Control sterile PCB-exposed flasks were spiked with $60 \mathrm{ug} \mathrm{mL} \mathrm{m}^{-1}$ of PCB and autoclaved for 1 hour at $121^{\circ} \mathrm{C}, 1 \mathrm{~atm}$. Flasks were then incubated under shaking at $125 \mathrm{rpm}$ at room temperature in the dark for 4 weeks (Figure 15). In order to maintain an aerobic condition, flasks were flushed every three days with air for 3 min under a chemical hood. After four weeks of incubation, aliquots of slurries were collected for bacterial counts, $\mathrm{PCB}$ analyses, microbial community structure characterization, and quantification of $\mathrm{BPH}$ genes. For viable bacteria counting, samples were stored at $4{ }^{\circ} \mathrm{C}$ for less than 6 hours until processing. For PCB analysis and DNA extraction, samples were stored for longer periods of time at $-80^{\circ} \mathrm{C}$.

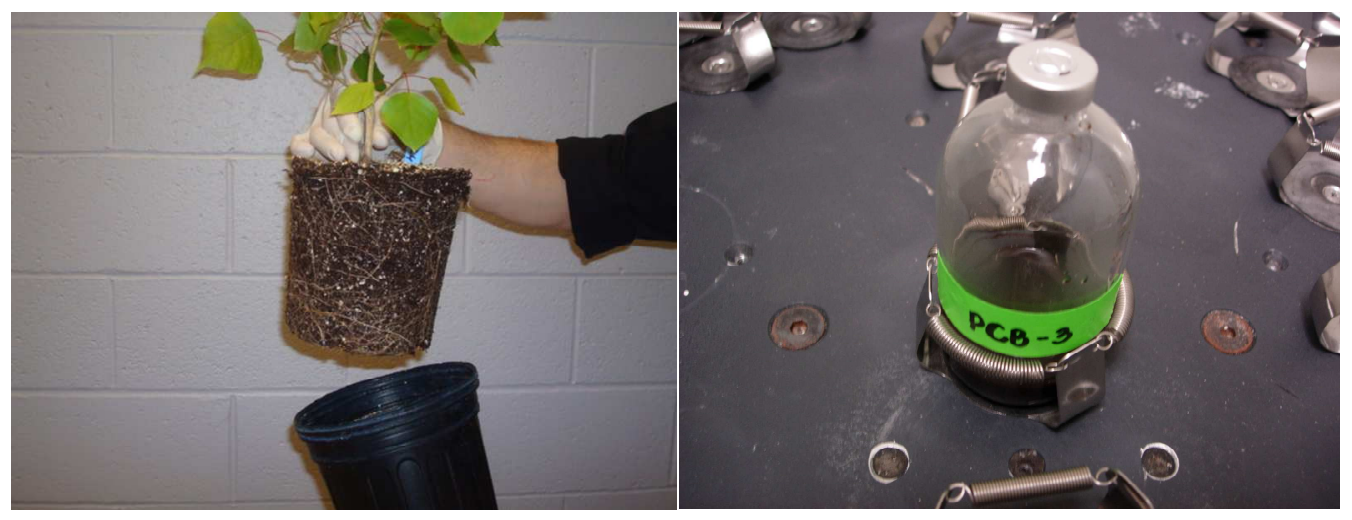

Figure 15: Poplar plants used for soil microcosm preparation (left). Soil slurry exposed to PCB-3 and incubated at room temperature during four weeks (right). 


\subsubsection{Bacterial enumeration}

To determine the bacterial concentration in slurries exposed to different PCB congeners, 1-mL aliquots were collected, weighted, and diluted 10 times in sterile phosphate buffer solution (PBS) in 15-mL centrifugation tubes. Tubes were agitated horizontally at 200 rpm for 1 hour (Ogram, 1998). Suspensions were then centrifuged under refrigeration at $1,000 \mathrm{rpm}$ for $2 \mathrm{~min}$ to remove soil particles. Serial dilutions were made with sterile PBS and plated on two different media: Luria-Bertani (LB) agar and soil LB-supplemented agar prepared as follows: $50 \mathrm{~g}$ of soil were blended with $250 \mathrm{~mL}$ PBS and centrifuged at 4,000 rpm for $10 \mathrm{~min}$ to remove solid particles; the supernatant was mixed with $8 \mathrm{~g} \mathrm{LB}$ agar and $9 \mathrm{~g}$ granulated agar, watered to $1,000 \mathrm{~mL}$, and autoclaved for $15 \mathrm{~min}$ at $121^{\circ} \mathrm{C}, 1$ atm. Plates were incubated for 2 days in the dark at $28^{\circ} \mathrm{C}$ before colony forming unit (CFU) counting. Only plates containing between 100 and 300 CFUs were considered and at least 3 plates were counted per sample (Gerhardt, 1993). Typically, less than 1\% of soil bacteria are cultivable (Hill et al., 2000); (Baker et al., 2003). The cell biomass was also estimated based on the quantification of bacterial ribosomal DNA (16S rDNA).

\subsubsection{DNA extraction}

Total DNA was extracted from 500 to $750 \mathrm{mg}$ of pre-weighted soil slurry using UltraClean ${ }^{\mathrm{TM}}$ Soil DNA Isolation Kit (MO BIO Laboratories, Carlsbad, CA) following the manufacturer's recommendations. Purified DNA was eluted from the silica membrane using two times $50 \mathrm{uL}$ of elution buffer. DNA extracts were quantified by the O.D.260 using a NanoDrop ND-1000 spectrophotometer (NanoDrop, Wilmington, DE). The quality of the DNA was assessed by the ratio O.D.260/O.D.280 (all DNA samples showed a ratio higher than 1.9). When necessary, DNA was concentrated by ethanol precipitation using standard protocols (Ausubel et al., 1999). Purified DNA was stored at $-80^{\circ} \mathrm{C}$. 


\subsubsection{Microbial community structure}

The effect of different PCB congeners on the soil microbial community structure was assessed using real-time (quantitative) PCR following a method described by Blackwood et al. (2005) and Fierer et al., (2005). Total DNA extracted from soil slurries was used as a template for the PCR-amplification of ribosomal DNA using taxonomic group-specific primers (Table 1). PCR reactions were carried out on an ABI Prism ${ }^{\circledR} 7300$ Sequence Detection System using SYBR ${ }^{\circledR}$ Green PCR Master Mix with the passive reference ROX $^{\mathrm{TM}}$ (Applied Biosystems, Foster City, CA). Cycling conditions were as prescribed by the manufacturer: Briefly, initial activation/denaturation at $95^{\circ} \mathrm{C}$ for $10 \mathrm{~min} ; 40$ cycles: denaturation at $95^{\circ} \mathrm{C}$ for $15 \mathrm{sec}$ and annealing-extension at $60^{\circ} \mathrm{C}$ for $1 \mathrm{~min}$. The dissociation protocol was run from 60 to $95{ }^{\circ} \mathrm{C}$. Results were calculated according to the manufacturer's recommendations using the relative quantification method: Specifically, the amplification levels of group-specific genes were normalized by the amplification level of "all bacteria" ribosomal DNA, used as an internal standard (Fierer et al., 2005), and expressed by reference with DNA of non-exposed soil controls. Results were computed with ABI Prism 7300 software v1.3.1. standard. Results were expressed by reference with control microcosms non-exposed to PCBs (CT). The error bars represent standard errors between analytical triplicates. 
Table 1: Primers used for group-specific bacterial identification and biphenyl dioxygenase gene quantification

\begin{tabular}{|c|c|c|c|}
\hline Target group & Sequence (5'-3') & Primer & Reference \\
\hline All bacteria $(\mathrm{F})$ & ACT CCT ACG GGA GGC AGC AG & Eub338 & Fierer et al. (2005) \\
\hline All bacteria $(\mathrm{R})$ & ATT ACC GCG GCT GCT GG & Eub518 & \\
\hline$\alpha$-Proteobacteria $(\mathrm{R})$ & TCT ACG RAT TTC ACC YCT AC & Alf685 & \\
\hline$\beta$-Proteobacteria $(\mathrm{R})$ & TCA CTG CTA CAC GYG & Bet680 & \\
\hline Actinobacteria $(\mathrm{F})$ & CGC GGC CTA TCA GCT TGT TG & Actino235 & \\
\hline Firmicutes $(\mathrm{F})$ & GCA GTA GGG AAT CTT CCG & Lgc353 & \\
\hline Bacteroidetes $(\mathrm{F})$ & GTA CTG AGA CAC GGA CCA & $\mathrm{Cfb} 319$ & \\
\hline Acidobacteria $(\mathrm{F})$ & GAT CCT GGC TCA GAA TC & Acid31 & \\
\hline BPH D.1.B (F) & GGA CGT GAT GCT CGA (C/T)CG C & BPH1-F & Baldwin et al. (2003) \\
\hline BPH D.1.B (R) & TGT T(C/G)G G(C/T)A CGT T(A/C)A GGC CCA T & BPH1-R & \\
\hline BPH D.1.C (F) & GAC GCC CGC CCC TAT ATG GA & BPH2-F & \\
\hline BPH D.1.C (R) & AGC CGA CGT TGC CAG GAA AAT & BPH2-R & \\
\hline BPH D.2.A (F) & CCG GGA GAA CGG CAG GAT C & BPH3-F & \\
\hline BPH D.2.B (F) & AAG GCC GGC GAC TTC ATG AC & BPH4-F & \\
\hline BPH D.2.A and B (R) & TGC TCC GCT GCG AAC TTC C & BPH3/4-R & \\
\hline 16S rDNA (F) & GAA TTG ACG GGG GCC CGC ACA AG & E916F & Baker et al. (2003) \\
\hline 16S rDNA (R) & AGG GTT GCG CTC GTT G & E1115R & \\
\hline
\end{tabular}

\subsubsection{Expression of biphenyl dioxygenase genes}

The abundance of the BPH genes in the slurries exposed to different PCB congeners was determined by real-time PCR using gene-specific primers (Figure 11), as described by (Baldwin et al., 2003). Bacterial ribosomal DNA (16S rDNA) primers, used as an internal standard, were designed according to Baker et al. (2003) (Table 1). PCR reactions were carried out as previously described on an ABI Prism ${ }^{\circledR} 7300$ Sequence Detection System using SYBR ${ }^{\circledR}$ Green PCR Master Mix (Applied Biosystems), except for the cycling conditions that were as in Baldwin et al. (2003): Initial activation/denaturation at $95^{\circ} \mathrm{C}$ for $10 \mathrm{~min} ; 40$ cycles: denaturation at $95^{\circ} \mathrm{C}$ for $15 \mathrm{sec}$, annealing at $57-63{ }^{\circ} \mathrm{C}$ for $30 \mathrm{sec}$, and extension at $87^{\circ} \mathrm{C}$ for $1 \mathrm{~min}$. The dissociation protocol was run from 60 to $95{ }^{\circ} \mathrm{C}$. Results were calculated using the relative 
quantification method: The amplification levels of BPH genes were normalized by the amplification level of $16 \mathrm{~S}$ rDNA, used as an internal standard. Results were expressed by reference to the amplification levels recorded in non-exposed soil controls.

\subsubsection{PCB analyses}

For PCB analysis, 1-mL aliquots of microcosm slurries were aseptically removed using a cut-off pipette tip, while maintaining the flask under agitation, and directly transferred into pre-weighted 8-mL glass vials sealed with Teflon-lined screw caps (aliquots were collected as four 250-uL fractions combined in one tube). Aliquots were weighted and then extracted using a procedure described in Bedard et al. (2005): PCBs were extracted with $5 \mathrm{~mL}$ of anhydrous diethyl ether (Acros Organics, Morris Plains, NJ) by vigorous horizontal shaking at $250 \mathrm{rpm}$ on a platform shaker for $16 \mathrm{~h}$. Extraction efficiency was controlled by the extraction of standards prepared by spiking sterile slurries with 0,10 , 25 , and $100 \mathrm{ug} \mathrm{mL} \mathrm{m}^{-1}$ of PCB. Standards curves constructed after extraction and analysis showed linear trends with $\mathrm{R}^{2}>0.99$. Second extraction of $100 \mathrm{ug} \mathrm{mL}^{-1}$ standards resulted in $1-5 \%$ of PCB recovery. PCB analyses were as described elsewhere (Hu, 2008): PCB extracts were diluted by 10 folds using hexane and spiked with 2,2',3,4,4',5,6,6'octachlorobiphenyl (PCB-204) as an internal standard before analysis. Samples were analyzed for a suite of 209 congeners using gas chromatography/mass spectrometry/mass spectrometry (GC/MS/MS) based on a modified EPA method 1668A. The quantification of PCB homologues was performed using an Agilent $6890 \mathrm{~N}$ gas chromatograph equipped with an Agilent 7683 series autosampler (Agilent, Santa Clara, CA) and coupled to a Waters Micromass Quattro Micro GC mass spectrometer (Milford, MA, USA).

Operational conditions were: Electron impact (EI) positive mode at $70 \mathrm{eV}$, multiple reaction monitoring (MRM), and trap current $200 \mu \mathrm{A}$. Two uL of sample were injected in splitless mode in a Supelco SPB ${ }^{\text {TM}}-$ Octyl fused silica capillary column $(30 \mathrm{~m} \times 250 \mu \mathrm{m}$ i.d. $\times 0.25 \mu \mathrm{m}$ film thickness; Supelco, St Louis, MO) with helium as carrier gas at a constant flow rate of $0.8 \mathrm{~mL} \mathrm{~min}{ }^{-1}$. The collision gas was carrier-grade argon. The oven 
temperature profile was $75^{\circ} \mathrm{C}$, held constant for $5 \mathrm{~min}$, then increased to $150{ }^{\circ} \mathrm{C}$ at $15{ }^{\circ} \mathrm{C}$ per min, held for $1 \mathrm{~min}$, then increased to $280^{\circ} \mathrm{C}$ at $2.5^{\circ} \mathrm{C}$ per min, and held for 3 minutes.

\subsubsection{Genomic Library analysis}

A clone library was built from DNA extracted from soil microcosm exposed to PCB-3 and from a non-exposed control. TOPO TA cloning® kit (Invitrogen, Carlsbad, CA) was used. 16S rDNA was purified and ligated into a vector plasmid. Ligation mix (insert DNA and vector) was mixed with high efficient $E$. coli competent cells for transformation. This mixture was chilled on ice during $5 \mathrm{~min}$ and then exposed to heat shocking at $42{ }^{\circ} \mathrm{C}$ during $30 \mathrm{~s}$. Cells were resuspended in super optimal broth with catabolite repression (SOC) and incubate during $1 \mathrm{hr}$ at $37{ }^{\circ} \mathrm{C}$ and shaking at $200 \mathrm{rpm}$. $100 \mu 1$ of each cell suspension were plated onto LB agar plates containing antibiotic. Plasmids from sorted colonies were extracted using QIAprep ${ }^{\circledR}$ Miniprep Kit (Qiagen). Amplification of plasmids was conducted by PCR using M13 primers. PCR product were digested with restriction enzymes HaeIII and RsaI (New England Biolabs, Beverly, MS) and checked on 1.5\% agarose gel electrophoresis (AGE). Finally, purified plasmids were sequenced (Davis Sequencing, Davis, CA). Bacterial identification was performed by searching public databases as the National Center for Biotechnology Information (NCBI) and the ribosomal database project.

\subsubsection{Terminal-restriction fragment length polymorphism (T-RFLP)}

Soil samples from the Confined Disposal Facility (CDF - South Chicago, Indiana) were collected by a team from the University of Iowa in 2006. Samples were kept in $50 \mathrm{~mL}$ tubes and stored at $-80{ }^{\circ} \mathrm{C}$ until they were analyzed by T-RFLP (Figure 26). This analysis is expected to provide a correlation between microbial community structure and PCB profiles. Total DNA was extracted from 500 to $750 \mathrm{mg}$ of pre-weighted Chicago soil sample using Ultraclean ${ }^{\mathrm{TM}}$ Soil DNA Isolation Kit (MO BIO Laboratories, Carlsbad, 
CA) following the manufacturer's recommendations. PCR amplification was performed using universal primers 27F labeled with a fluorescent molecule (FAM) (5'-/56-FAM/ AGAGTTTGATCCTGGCTCAG-3) and 1492R. The cycling conditions were: Initial activation/denaturation at $95{ }^{\circ} \mathrm{C}$ for $15 \mathrm{~min} ; 30$ cycles: Denaturation at $95^{\circ} \mathrm{C}$ for $1 \mathrm{~min}$, annealing for $1 \mathrm{~min}$ at $55^{\circ} \mathrm{C}$, and extension at $72{ }^{\circ} \mathrm{C}$ for $1.5 \mathrm{~min}$; and final extension at $72{ }^{\circ} \mathrm{C}$ for $10 \mathrm{~min}$. PCR products were purified using QIAquick PCR Purification Kit (QIAGEN, Chatsworth, CA). Purified DNA was digested at $37{ }^{\circ} \mathrm{C}$ for 3 hours using four different restriction enzymes: AluI (recognition site: $5^{\prime} \ldots \mathrm{AG}^{\wedge} \mathrm{CT}$....3'), HaeIII (recognition site: $5^{\prime} \ldots \mathrm{GG}^{\wedge} \mathrm{CC} \ldots 3^{\prime}$ ), HhaI (recognition site: $5^{\prime} \ldots \mathrm{GC}^{\wedge} \mathrm{GC} \ldots 3^{\prime}$, and $R s a \mathrm{I}$ (recognition site: $\left.5^{\prime} \ldots \mathrm{GT}^{\wedge} \mathrm{AC} \ldots 3^{\prime}\right)$ (New England Biolabs). The reaction mixtures with a total volume of $20 \mu \mathrm{L}$, contained $2 \mu \mathrm{L}$ of $10 \mathrm{x}$ restriction enzyme buffer, $0.5 \mu \mathrm{L}$ of the restriction enzyme, $7.5 \mu \mathrm{L}$ of water, and $10 \mu \mathrm{L}$ of the purified DNA. Quality of digested DNA was analyzed on AGE. $0.5-1 \mu \mathrm{L}$ of digested 16s rDNA was mixed with $0.5 \mu \mathrm{L}$ of ROX-1000 DNA Size Standard (Applied Biosystems, Foster City, CA) and 8.5-9 $\mu \mathrm{L}$ of deionized formamide. Aliquots of the mixture $(0.5-1 \mu \mathrm{L})$ were load in $96-$ well microplates, denaturated at $95^{\circ} \mathrm{C}$ during $3 \mathrm{~min}$ and then centrifuge at $1,500 \mathrm{rpm}$ for a short period. Finally the fragments analyzed on a capillary electrophoresis with an ABI 377 DNA automated sequencer (Applied Biosystems) (Liu et al., 1997; Dunbar et al., 2001; Fedi et al., 2005). The sizes of the different fragments were analyzed using the Genescan v2.0.2 and GeneMapper v4.0 software (Applied Biosystems). Terminal fragments smaller than 10 were discarded to avoid error from internal marker. T-RFLP profiles were obtained for clustering analysis. The area of each peak was normalized by dividing by the total peak area for each sample. The profiles obtained represent the species composition in the microbial communities for that sample (Figure 16). 


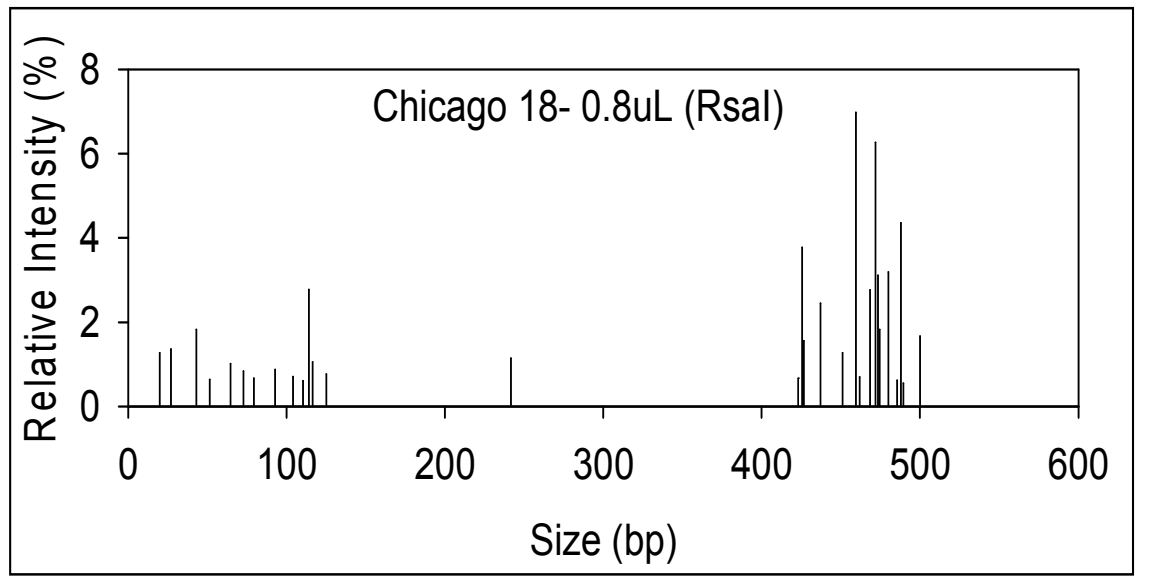

Figure 16: Profile of a soil microbial community in one analyzed sample using T-RFLP.

\subsubsection{Bacterial toxicity analysis}

To test the effect of individual PCBs on bacterial growth, pure cell cultures were exposed to PCBs. A set of individual PCBs [PCB-3, PCB-15, 28, 77 (Figure 17)] and hydroxyl metabolites stock solutions [3-OH-PCB-3, 2-OH-PCB-3, 4-OH-PCB-3, 4-OH-PCB-35, and 4-OH-PCB-79 (Figure 18)] were prepared by dissolving $10 \mathrm{mg}$ of each PCB into 2 $\mathrm{mL}$ acetone $\left(\mathrm{OC}\left(\mathrm{CH}_{3}\right)_{2}\right)$ to get $5 \mathrm{mg} \mathrm{mL}^{-1}$ concentration.

Cultures of Escherichia coli and Burkholderia xenovorans LB400 were grown in Luria Bertani (LB) broth at $37^{\circ} \mathrm{C}$ and $30^{\circ} \mathrm{C}$ respectively. PCB-containing medium was prepared in a 10-mL round glass sample cell (Hach Company, Loveland, CO): $20 \mu \mathrm{L}$ of PCB stock solution was added to $10 \mathrm{~mL}$ of sterile $\mathrm{LB}$ broth $(5 \mathrm{x})$ to obtain a final concentration of $10 \mathrm{mg} \mathrm{L}^{-1}$. This mixture was leaving under shaking for 24 hours to allow the PCB to dissolve before addition of bacterial cells. $20 \mu \mathrm{L}$ of bacterial cells were added to the PCB-containing medium and flasks were incubated at $37^{\circ} \mathrm{C}$ and $30^{\circ} \mathrm{C}, 200 \mathrm{rpm}$, depending on the bacterial strain. Optical density (O.D.) was recorded at specific time points using a spectrophotometer at $600 \mathrm{~nm}$. O.D.600 vs. time was drawn into a graph to determine the growth rate (Figure 29, Figure 30, and Figure 31) 


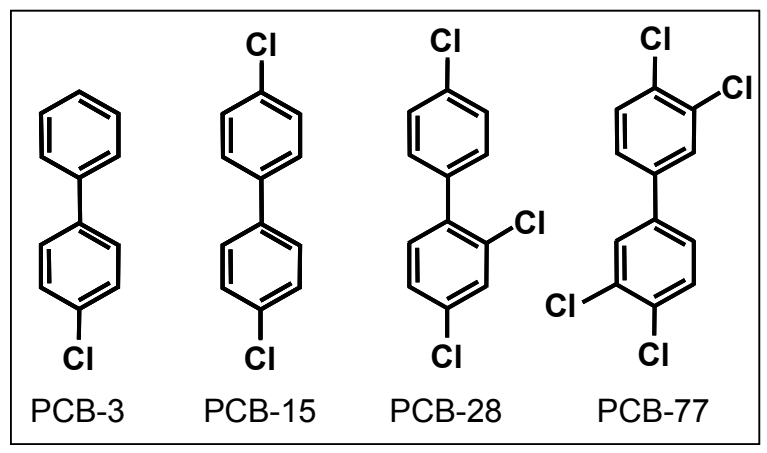

Figure 17: Structure of PCBs used in soil microcosm experiments. The PCB names used refer to the IUPAC numbers: PCB-3: 4-monochlorinated biphenyl, PCB-15: 4,4'-dichlorinated biphenyl, PCB-28: 2,4,4'-trichlorinated biphenyl, and PCB-77: 3,4,3',4'-tetrachlorinated biphenyl.

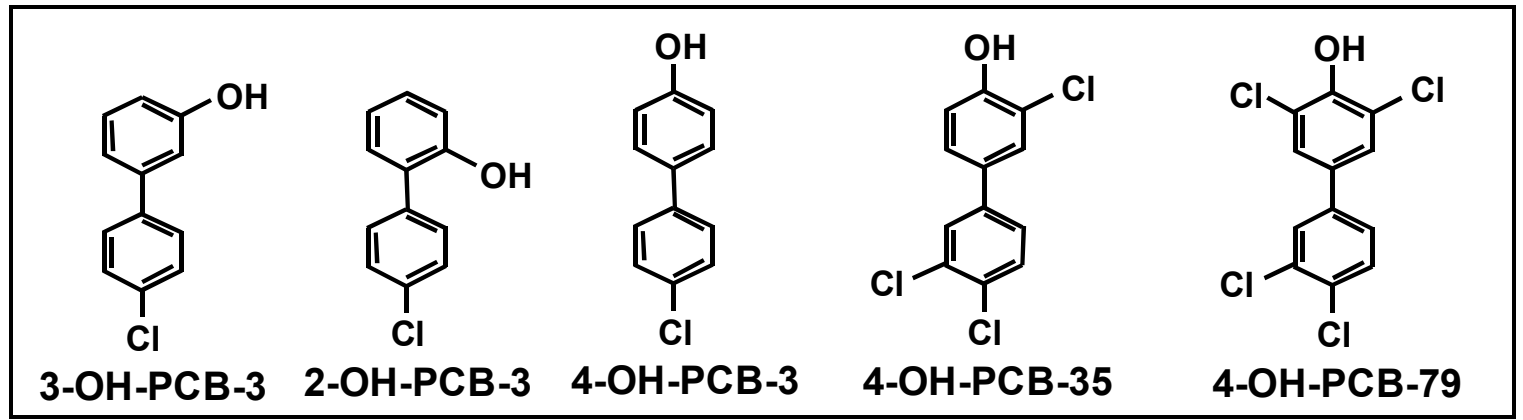

Figure 18: Structure of $\mathrm{PCB}$ metabolites used in toxicity experiments in pure cell culture. The PCB names are: 3-OH-PCB-3, 2-OH-PCB-3 and 4-OH-PCB-3 which are monohydroxy metabolites of PCB-3; 4-OHPCB-35 and 4-OH-PCB-79 


\section{Chapter 4 : Results and discussion}

\subsection{Specific aim 1}

Evaluation of the different effects generate by exposure to individual PCB congeners on the soil microbial community profiles and the abundances of biphenyl dioxygenase (BPH) genes, was conducted with a laboratory made soil microcosm

\subsubsection{Microbial numbers and community structure}

Incubation of soil microbial communities for 4 weeks in agitated microcosm experiments was conducted to investigate the effect of different PCB congeners on both the bacterial abundance and community structure (distribution of bacterial groups). Total bacterial numbers were estimated by CFU counting and quantification of bacterial ribosomal DNA (16S rDNA). Figure 2 shows the relative bacterial numbers in microcosms exposed to different PCB congeners. We observed that exposure to higher-chlorinated congeners: PCB-28, PCB-77, and Aroclor 1242, resulted in lower bacterial numbers (as measured by colony counting). This may be explained by a higher toxicity of higher-chlorinated PCBs for some bacterial groups. Indeed, PCB-77 is expected to be the most toxic, both because of a higher number of chlorine atoms and chlorination at 3,4-position (Borja et al., 2005). On the other hand, as a mixture of PCBs, Aroclor 1242 may contain more toxic congeners. Toxicity of PCBs for bacterial cells has been well documented: (Camara et al., 2004) reported a significant decrease of the viability of $E$. coli cells exposed to $2 \mathrm{mM}$ of PCB-1, 5, and 23 (377, 446, and $\left.515 \mu \mathrm{g} \mathrm{mL}^{-1}\right)$. However, unlike observations, the authors noticed a slight decrease of toxicity with increased chlorine substitution. The relationship between bacterial toxicity and degree of chlorination is highly variable according to the source: For instance, using the bioluminescent bacteria Photobacterium phosphoreum, (Chu et al., 1997), observed a high variability of the toxicity of PCB congeners from dichlorinated to hexachlorinated biphenyls without clear correlation with the degree of chlorination or co-planarity of the molecule. The situation is likely to be 
further complicated because PCBs can be transformed by bacteria into potentially more toxic metabolites, such as dihydrodiols, dihydroxybiphenyls, chlorobenzoates, and chlorocatechols (Camara et al., 2004; Parnell et al., 2006; Vasilyeva and Strijakova, 2007). In addition, in the presence of high concentration (as used in the experiments), the hydrophobicity of PCBs can cause membrane degradation leading to cell lysis (Ohtsubo et al., 2004; Vasilyeva and Strijakova, 2007)

Real-time or quantitative PCR has recently emerged as a popular tool to quantified DNA and it has been used for estimating the abundance of microbial groups or specific metabolic genes, or for gene expression analysis when coupled with a reversetranscription step. In this research, we used real-time PCB both to estimate the relative abundance of important bacterial taxonomic groups and $\mathrm{BPH}$ genes in soil microcosms exposed to different PCB congeners and the commercial mixture Aroclor 1242.

Except for PCB-28, a generally good correlation was obtained between estimation of bacterial biomass based on CFU counting and amplification of $16 \mathrm{~S}$ rDNA. Notoriously, only a small fraction of bacteria in the environment is cultivable $(<1 \%)$, which could lead to significant differences between results obtained using cultivation-based and cultivation-independent methods (Baker et al., 2003). However, for large and diverse bacterial communities, such as found in soil, one can expect to observe similar trends using both methods.

The microbial community structure in soil microcosms exposed to different PCB congeners and Aroclor 1242 was characterized by the real-time PCR amplification of dominant bacterial groups following an approach described by (Blackwood et al., 2005; Fierer et al., 2005). Figure 19 shows the relative abundance of each bacterial group as calculated by the ratio between the copy number of different group-specific markers and the "all bacteria" marker. The relative abundance (or fractional copy number) constitutes 
a more reliable measurement of bacterial group representation, since the efficiency of PCR amplification is expected to vary across DNA samples (Fierer et al., 2005). Although an important variability was observed between analytical replicates, an emergent pattern can be identified in the different microcosms: Exposure to individual congeners and Aroclor 1242 resulted in higher numbers of $\beta$-Proteobacteria (2.2 to 7.9 times higher) and Acidobacteria (1.6 to 4.0 times higher). In addition, a higher proportion of $\alpha$-Proteobacteria was detected in microcosms exposed to PCB-77 and Aroclor 1242 (3.1 and 7.9 times higher). Interestingly, $\beta$-Proteobacteria constitutes one of the major bacterial groups were BPH genes where described, i.e., Comamonas and Burkholderia sp., suggesting that exposure to PCBs selected for members of PCB-degraders. None of the primer sets used was specific to $\gamma$-Proteobacteria, so no information was obtained about the relative abundance of this other group of potential PCB-degraders (Pseudomonas sp.). On the other hand, exposure to PCB-77 and Aroclor-1242 selected higher fractions of Actinobacteria (2.2 and 1.3 times higher), involving Rhodococcus sp., another well characterized group of PCB-degraders. The results are generally consistent with other reports about the microbial community structure in PCB-exposed soils obtained based on 16S rDNA: Studying the phylogenetic distribution of bacterial groups and BPH genes in planted and non-planted soils, (Aguirre de Carcer et al., 2007), observed an enrichment of $\beta$-Proteobacteria, dominated by the Burkholderiales order, in PCB-contaminated soil (Delor 103, Czech Republic) by comparison with noncontaminated soil. Using RNA extracts from soil heavily contaminated with PCBs (Wittenberg, Germany), (Nogales et al., 1999; Nogales et al., 2001) identified a large majority of $\alpha-, \beta-$, and $\gamma$-Proteobacteria $(34 \%, 33 \%$, and $7 \%$ ), as well as Acidobacteria $(14 \%)$ and Actinobacteria (6.5\%), which is rather consistent with the observations using group specific primers. Especially, the authors reported a higher abundance of $\beta$ Proteobacteria than usually observed in soil (Nogales et al., 2001). However, it is noteworthy that the estimated relative abundances obtained using real-time PCR may not reflect the true percentages of bacterial groups analyzed because of differences in DNA 
extraction efficiencies, ribosomal DNA copy numbers, and the exclusion of several potentially important bacterial phyla (Fierer et al., 2005)

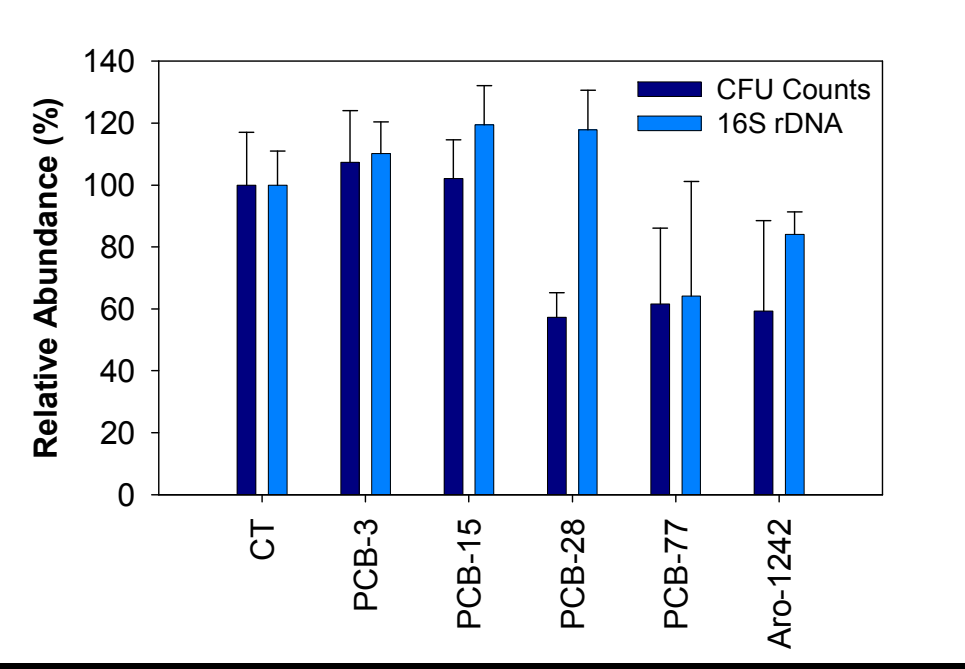

Figure 19: Bacterial abundances in soil microcosm cultures, after 4 weeks of incubation in the presence of different PCB congeners and the mixture Aroclor 1242, as determined by CFU counting and real-time PCR quantification of $16 \mathrm{~S}$ rDNA. Relative abundances were calculated by reference with non-exposed control microcosms (CT). The error bars represent standard errors between analytical triplicates. 


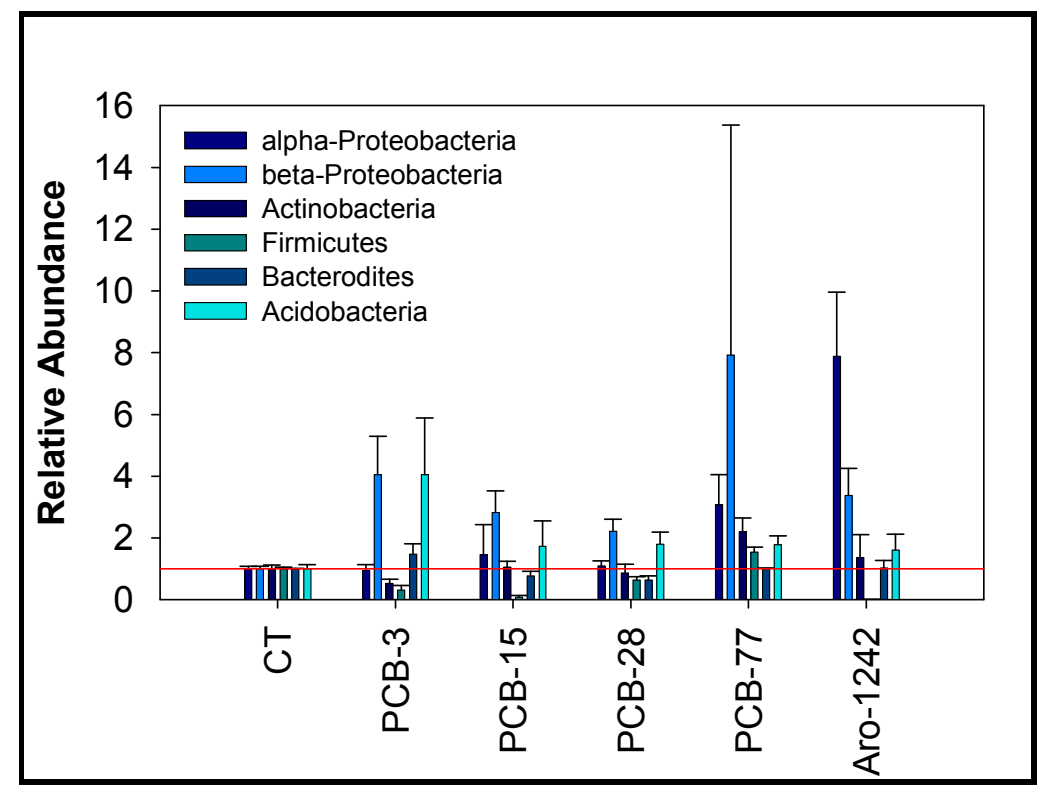

Figure 20: Profiles of microorganisms in soil microcosms incubated for 4 weeks in the presence to different PCB congeners. The microbial abundance of different taxonomic groups was obtained by quantitative PCR-amplification of group-specific markers (Fierer et al., 2005). Relative abundance was calculated by normalizing the amplification level of each group by "all bacteria" ribosomal DNA, used as an internal

\subsubsection{PCB biodegradation.}

The biodegradation percentages of the different PCB congeners after 4 weeks of incubation in aerobic soil microcosms were as follow: PCB-3: 75\%, PCB-15: 7\%, PCB28: 53\%. PCB-77: 22\%, and Aroclor 1242: 22\%. Except for PCB-15 that was not significantly transformed, we observed that PCBs were efficiently biodegraded in active microcosms by comparison with autoclaved controls (Figure 21). Aerobic degradation rates decreased with the degree of chlorination, which is consistent with previous reports (Vasilyeva and Strijakova, 2007; Furukawa and Fujihara, 2008). Indeed, the presences of more chlorine substituents reduce the electron density of the aromatic cycle(s), making more difficult the oxidative attack by dioxygenases. The rates of degradation observed are also consistent with aerobic degradation of PCBs described in the literature (Kohler $e t$ al., 1988; Borja et al., 2005; Vasilyeva and Strijakova, 2007). 


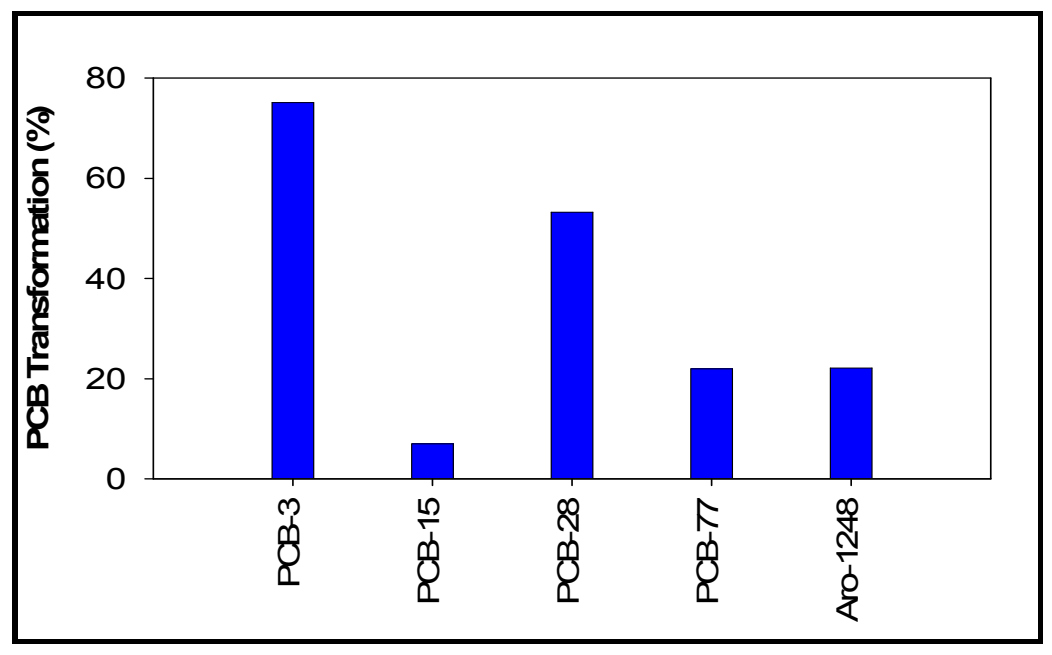

Figure 21: Biodegradation percentages of the different PCB congeners in aerobic soil microcosms exposed

\subsubsection{Biphenyl dioxygenase genes.}

Primers specific to BPHs were designed to amplify the gene coding for the large subunit (bphA1), which determines the substrate specificity (Furukawa et al., 2004; Fedi et al., 2005; Furukawa and Fujihara, 2008). Based on the sequence similarity of the large subunit, BPHs belong to two different families of aromatic oxygenases: D.1, which includes the Gram-negative BPHs, D.1.B and D.1.C, and D.2, which includes the Grampositive BPHs, D.2.A and D.2.B. D.1.B includes BPHs from Comamonas testosteroni B356, Burkholderia sp. JB1, and Pseudomonas sp. KKS102; D.1.C includes BPHs from Pseudomonas sp. B4, Burkholderia sp. LB400, and P. pseudoalcaligenes KF707; D.2.A includes BPHs from Rhodococcus erythropolis TA421, R. globerulus P6, and Rhodococcus sp. M5; and D.2.B includes BPHs from Rhodococcus sp. RHA1 and $R$. erythropolis BD2 (Baldwin et al., 2003; Furukawa et al., 2004).

Figure 22 shows the relative abundance of bacterial BPH genes in microcosms exposed to the different PCB congeners and the mixture Aroclor 1242. Four genes were tested representing the four subfamilies of biphenyl dioxygenases, D.1.B (PBH-1), D.1.C (BPH- 
2), D.2.A (PBH-3 and BPH-4), and D.2.B (BPH-4) (Figure 11) (Baldwin et al., 2003). Results are presented for three out of the four BPH genes since no significant amplification signal was obtained with $\mathrm{PBH}-2$. A significant increase of two out of the three genes quantified, BPH-1 and BPH-4, was consistently observed in microcosms exposed to PCB congeners and the Aroclor mixture (up to 6.3 for BPH-1 and 3.4 for BPH-4). A higher amplification of PBH-3 was also detected upon exposure to PCB-15 and PCB-77. BPH-1 primers were designed to amplify specifically BPH genes of the subfamily D.1.B, which involves Comamonas testosteroni B-356 and Burkholderia sp. JB1, two well described PCB-degraders belonging to $\beta$-Proteobacteria, which were detected at higher levels in all microcosms exposed to PCBs. A similar observation can be made regarding BPH-3 and BPH-4, involving BPHs belonging to D.2.A and D.2.B subfamilies, which involve different Rhodococcus sp. Many Rhodococcus species are PCB-degraders and they belong to Actinobacteria, also detected at slightly higher levels in soil exposed to PCB-77 and Aroclor 1242. However, even though this correlation is attractive, these results do not provide evidence that the higher numbers of BPH genes observed actually belong to any of the $\beta$-Proteobacteria or Actinobacteria species detected at higher levels in the samples exposed to PCBs. No clear quantitative relationship can be observed between the relative abundance of bacterial groups and BPH genes in the microcosms exposed to different PCBs. Also it is likely that the groupspecific primers used in the experiments overlap other bacterial groups or miss members of the group intended to be quantified and it is equally likely that the BPH primer sets used did not detect all BPH genes (or other genes) involved in the aerobic transformation of PCBs.

Nevertheless, the observations suggest that, overall, exposure to individual PCB congeners and Aroclor 1242 resulted in higher levels of bacteria belonging to potential PCB-degraders and higher abundance of BPH genes. The regulation of BPH genes has been studied in some strains and shows different transcriptional control mechanisms by 
biphenyl, salicylate, and/or cleavage products of PCBs (Furukawa and Fujihara, 2008). However, in this research, the expression of BPH genes was not specifically investigated; only BPH gene numbers were detected, reflecting the abundance of potential PCBdegraders. Higher numbers of BPH genes in microcosms exposed to PCBs is therefore better explained by a competitive advantage of PCB-degraders than by induction in the presence of specific compounds.

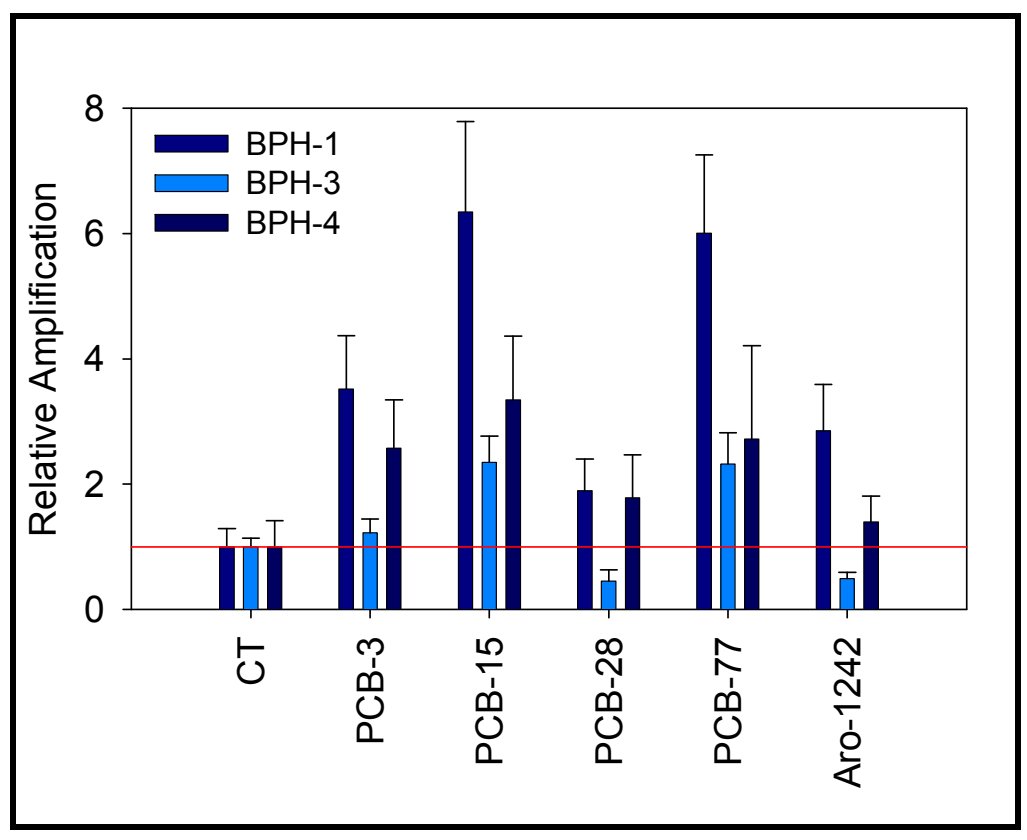

Figure 22: Quantification of bacterial biphenyl dioxygenase (BPH) genes: BPH-1, BPH-3, and BPH-4 in microcosm in the presence of different PCB congeners. The error bars represent standard errors between analytical triplicates. 


\subsubsection{Evaluation of the effect of PCB-3 on a soil bacterial community structure using genomic library}

In order to test the hypothesis that exposure to individual PCBs will affect the soil microbial community structure, two clone libraries from soil microcosm samples were built, the first one from a control non-exposed soil slurry and the second one from a soil microcosm exposed to PCB-3. Based on the fragment size of the digested DNA observed from the gel electrophoresis (Figure 23) samples were grouped and at least one representative sample from each group was sequenced. A total of 20 out of 35 colonies were analyzed for the non-exposed microcosm and only 10 out of 20 colonies were analyzed for the microcosm exposed to PCB-3.
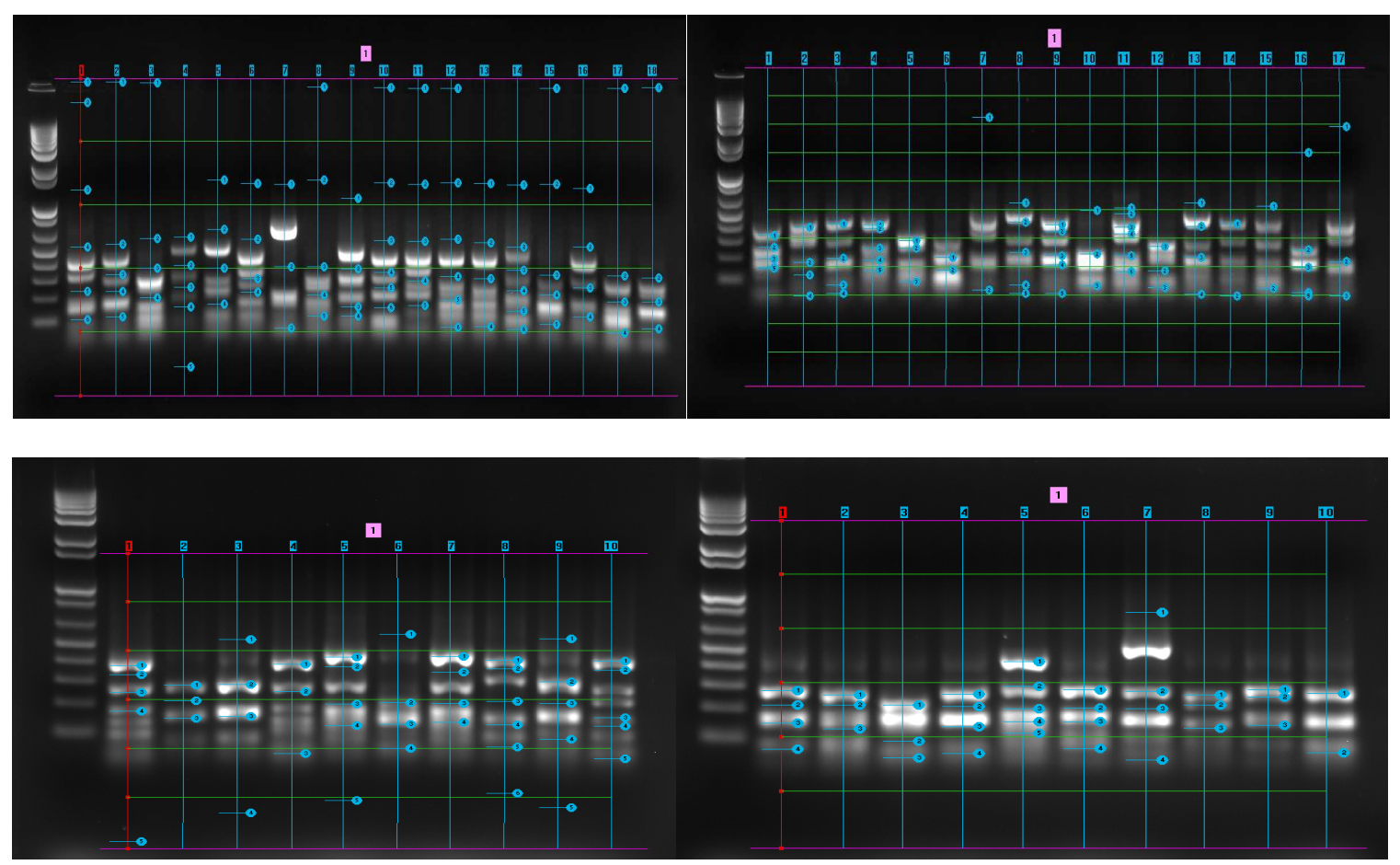

Figure 23: Picture of plasmids digests run on a 1.5\% agarose gel. The DNA size marker is a commercial $1 \mathrm{kbp}$ ladder. The image in the top represents plasmids from the 35 sorted colonies from the non expose soil microcosm; and the image in the bottom corresponds to plasmids belonging to the 20 sorted colonies 
After sequencing, it was identified a large majority of $\alpha-, \beta-$, and $\gamma$-Proteobacteria $(30 \%$, $15 \%, 10 \%)$, as well as Bacteroidetes (10\%) and Verrumicrobia (10\%) in the non exposed soil from a total of 20 clones analyzed (Figure 24). On the other hand, for the soil microcosm exposed to PCB-3 from a total of 10 bacterial strains analyzed, it was found that highest abundance corresponds to the $\alpha$-proteobacteria (40\%) and Bacteroidetes $(20 \%)$, as well as verrumicrobia, plantomycetes, and $\beta$ - and $\delta$-proteobacteria $(10 \%$ each one) (Figure 25). Most of the sequences belong to the $\alpha$-proteobacteria phylum which is consistent with observations found by Nogales et al. (1999) and (2001). In contrast with these observations, Fedi et al. (2005) found a very limited abundance of bacteria belonging to the $\alpha$-proteobacteria phyla, which can be explained for possible difference in the $\mathrm{pH}$ of the soil. However; the estimated abundances obtained from the genomic library may not reflect the real percentages of the bacterial groups in the soil microcosm because of the relative small quantity of colonies that were analyzed, resulting in the exclusion of a variety of potentially important bacteria. 
Table 2: Bacterial strains identified from a soil microcosm exposed to PCB-3 and a nonexposed (control)

\begin{tabular}{|c|c|}
\hline \multicolumn{2}{|c|}{ Bacterial species } \\
\hline Non-exposed soil microcosm & Soil microcosm exposed to PCB-3 \\
\hline Flavisolibacter ginsengiterrae & Flavisolibacter ginsengiterrae \\
\hline Alpha proteobacterium A0904 & Alpha proteobacterium A0904 \\
\hline Sphingobacteriales G23010 & Sphingoterrabacterium koreensis \\
\hline Phyllobacterium sp. T1293 & Phyllobacterium sp. T1293 \\
\hline Bacterium ellin 516 & Bacterium ellin 516 \\
\hline Bacterium ellin 6067 & Bacterium ellin 6067 \\
\hline Pirellula staleyi & Pirellula staleyi \\
\hline Delta proteobacterium MLMS-1 & Delta proteobacterium MLMS-1 \\
\hline Phyllobacterium sp. T1293 & Bacterium ellin 362 \\
\hline Bacterium Ellin 362 & \\
\hline Sediminibacterium salmoneum & \\
\hline Beta proteobacterium INBF007 & \\
\hline Prosthecobacter vanneervenii & \\
\hline Ruminococcus sp. Eg2 & \\
\hline Beggiatoa sp. $1401-13$ & \\
\hline Sphingomonas sp. BAC84 & \\
\hline Halomonas sp. B-1083 & \\
\hline Caulobacter sp. & \\
\hline Beta proteobacterium A1020 & \\
\hline
\end{tabular}




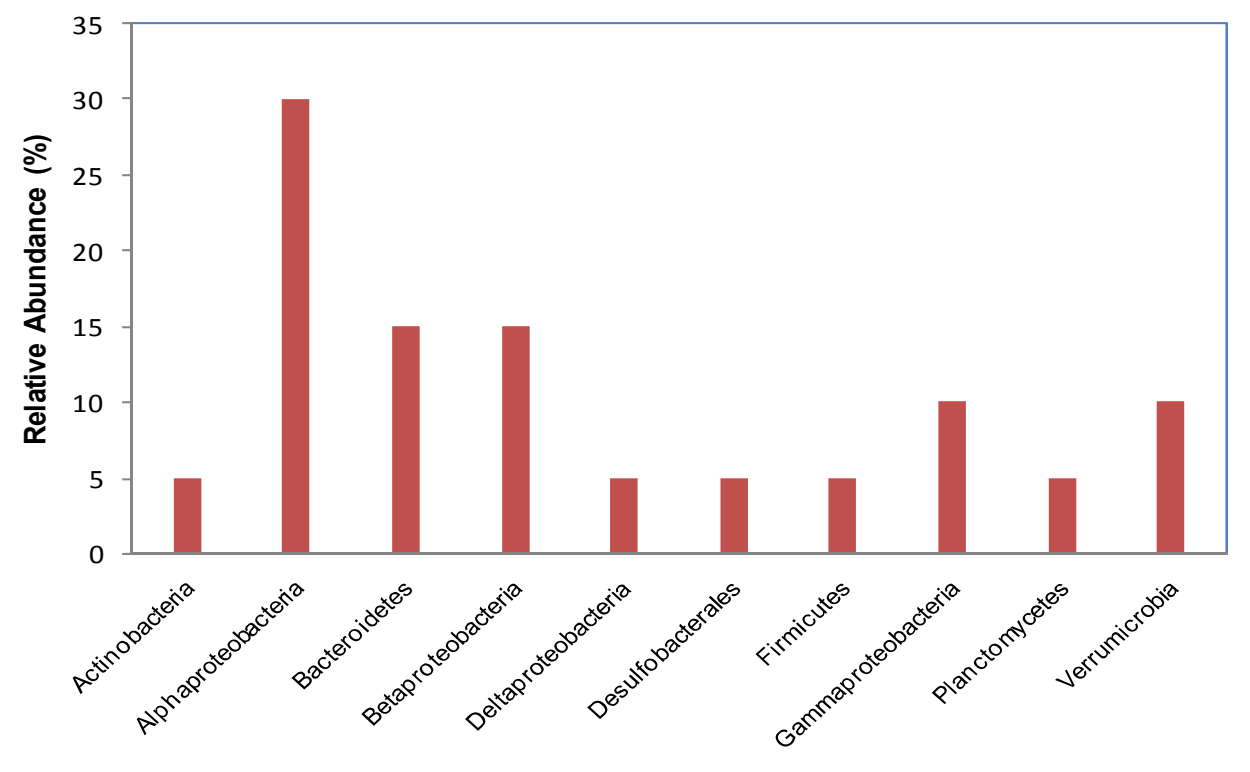

Figure 24: Percentages of microorganisms in a non-exposed soil microcosm incubated for 4 weeks. The different taxonomic groups were identified from the bacterial strains analyzed by genomic library.

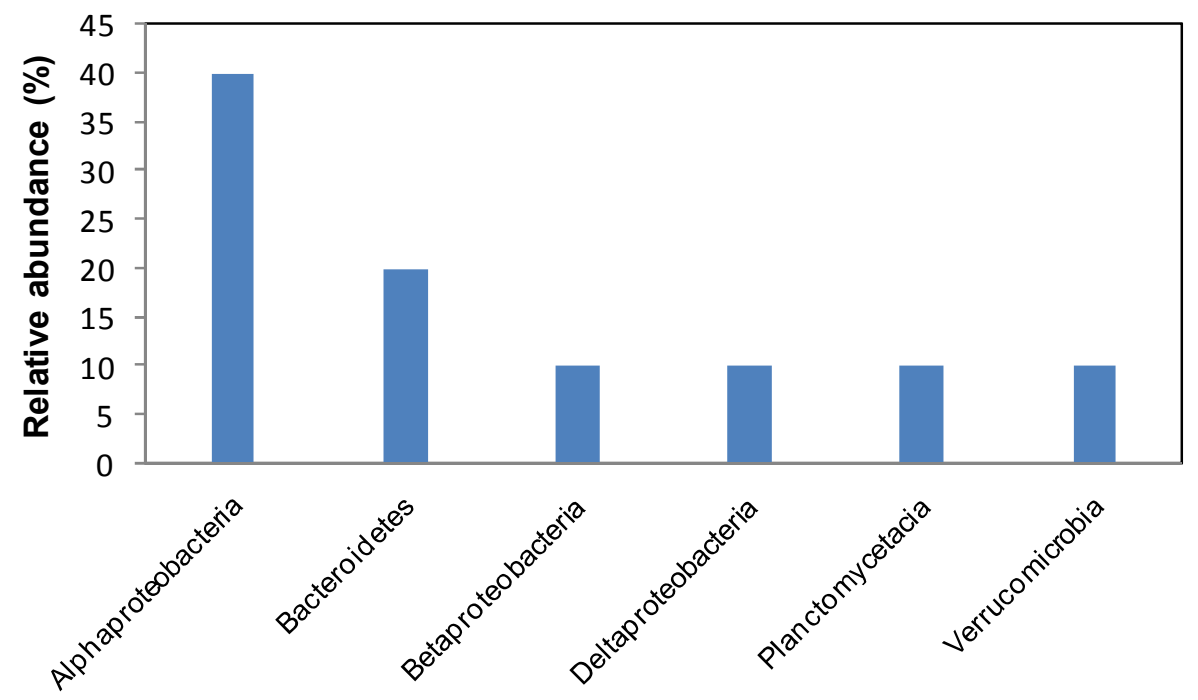

Figure 25: Percentages of microorganisms in soil microcosm exposed to PCB-3 and incubated for 4 weeks. The different taxonomic groups were identified from the bacterial strains analyzed by genomic library. 


\subsection{Specific aim 2}

To establish a correlation between the microbial community structure and PCB profiles. Real soil samples from a PCB-contaminated site (CDF) in South Chicago, Indiana were analyzed using T-RFLP and GC/MS.

\subsubsection{Terminal - restriction fragment length polymorphism}

The objective of this specific experiment was to try to find a correlation between the bacterial community structure and the profile of PCBs concentration in PCBcontaminated soil samples the Confined Disposal Facility (CFD) in South Chicago, Indiana (Figure 26). The 16S DNA extracted from soil samples was amplified using the universal primers and digested with four different restriction enzymes as mentioned in the previous section. Similar to observations by (Fedi et al., 2005), best discriminating profiles were obtained when digestion was carried out with $R s a \mathrm{I}$; then only the profiles obtained from this enzyme are presented in this document (Figure 27). These profiles were obtained after normalization by the sum of the areas for each group of peaks. Observation of a strong correlation between the PCBs profiles and the microbial community profiles (Figure 28) could be investigated in further studies. The PCB profiles represent the relative abundance and distribution of each congener in the individual samples

To determine the similarity of the values generated in the T-RFLP experiment, a cluster analysis was performed using SAS PROC and processed by using the Ward's minimumvariance clustering, which is a hierarchical method designed to optimize the minimum variance within clusters (http://marketing.byu.edu/htmlpages/books/pcmds/WARD.html) In order to display the relationships among the clusters, a dendrogram was built (Figure 28). It represents the multidimensional distances between clusters or objects; the distance of the clusters or samples is represented in the length of the horizontal line. 


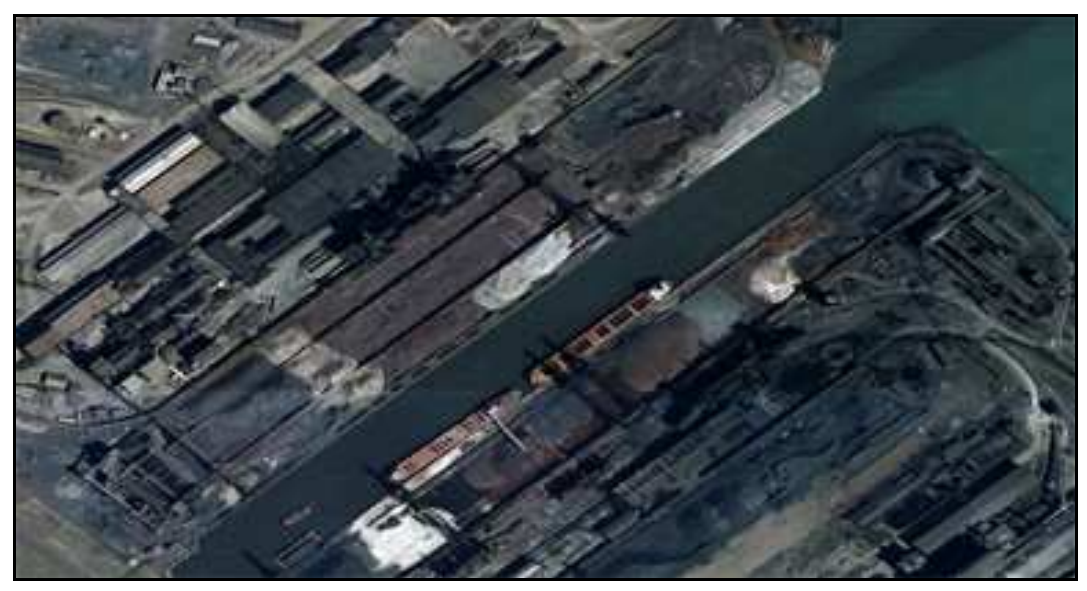

Figure 26: Confined Disposal Facility (CDF - South Chicago).
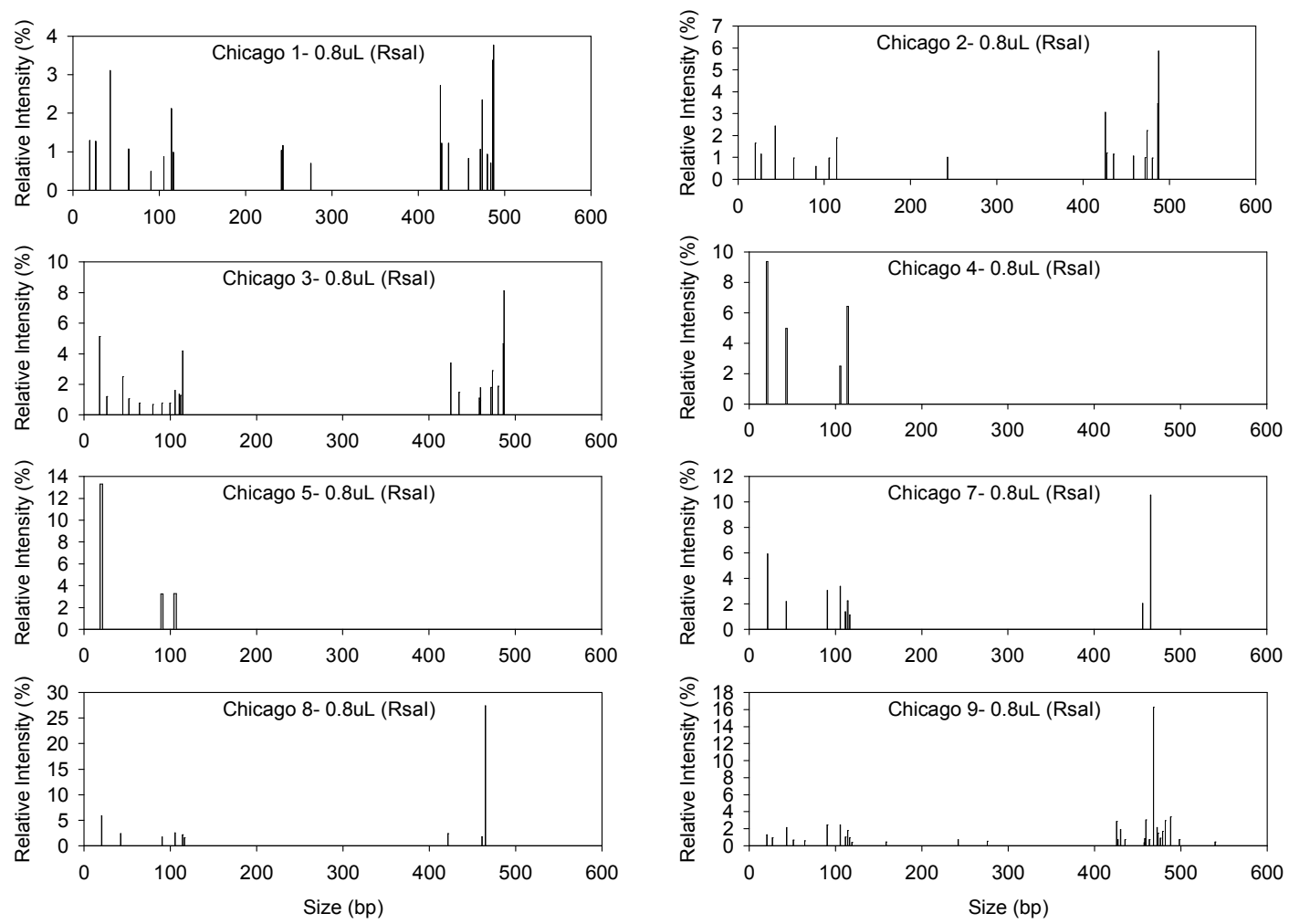

Figure 27: Terminal-restriction fragment profiles from 22 soil samples from the Confined Disposal Facility (CDF). 

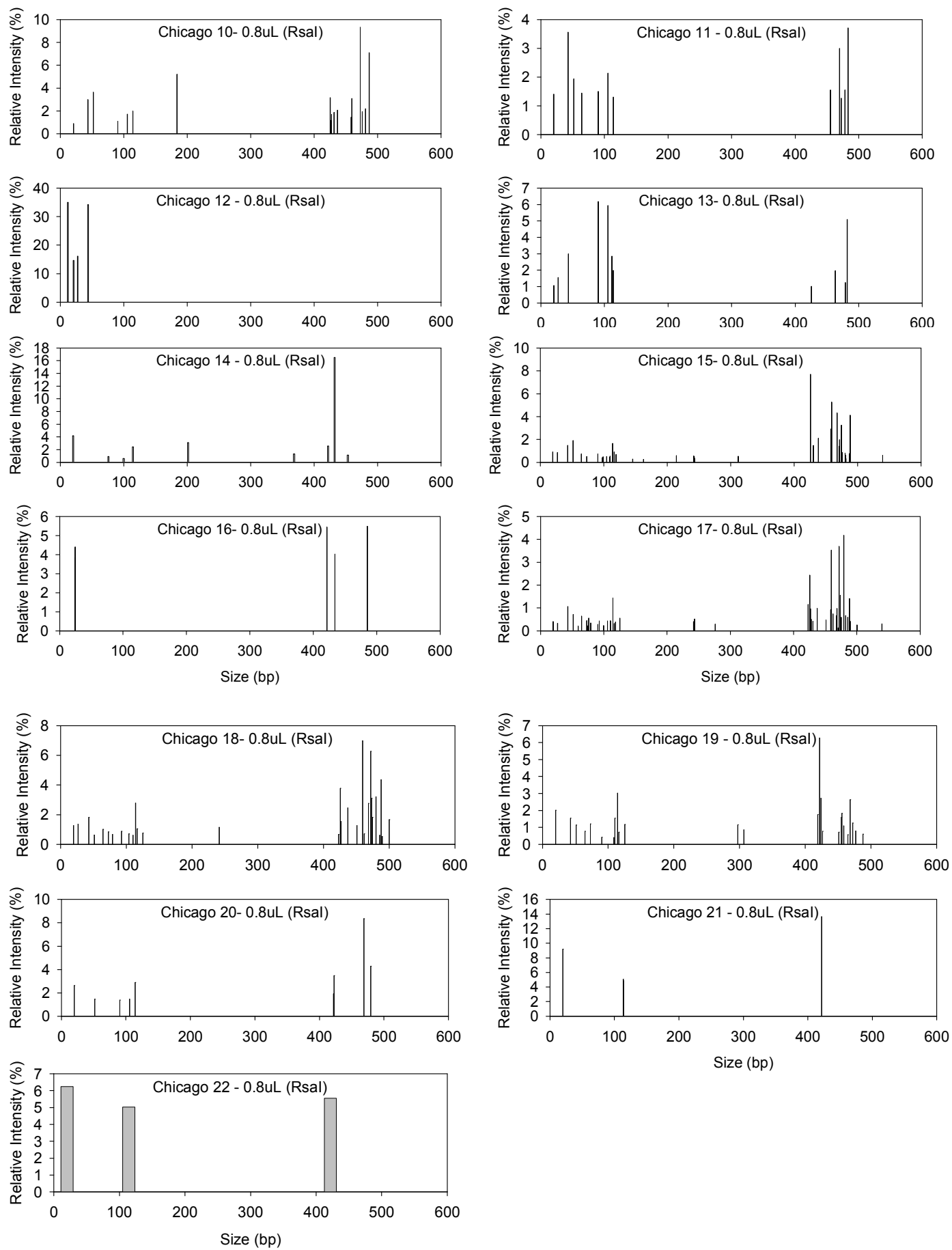

Figure 27(cont.): Terminal-restriction fragment profiles from 22 soil samples from the Confined Disposal Facility (CDF). 


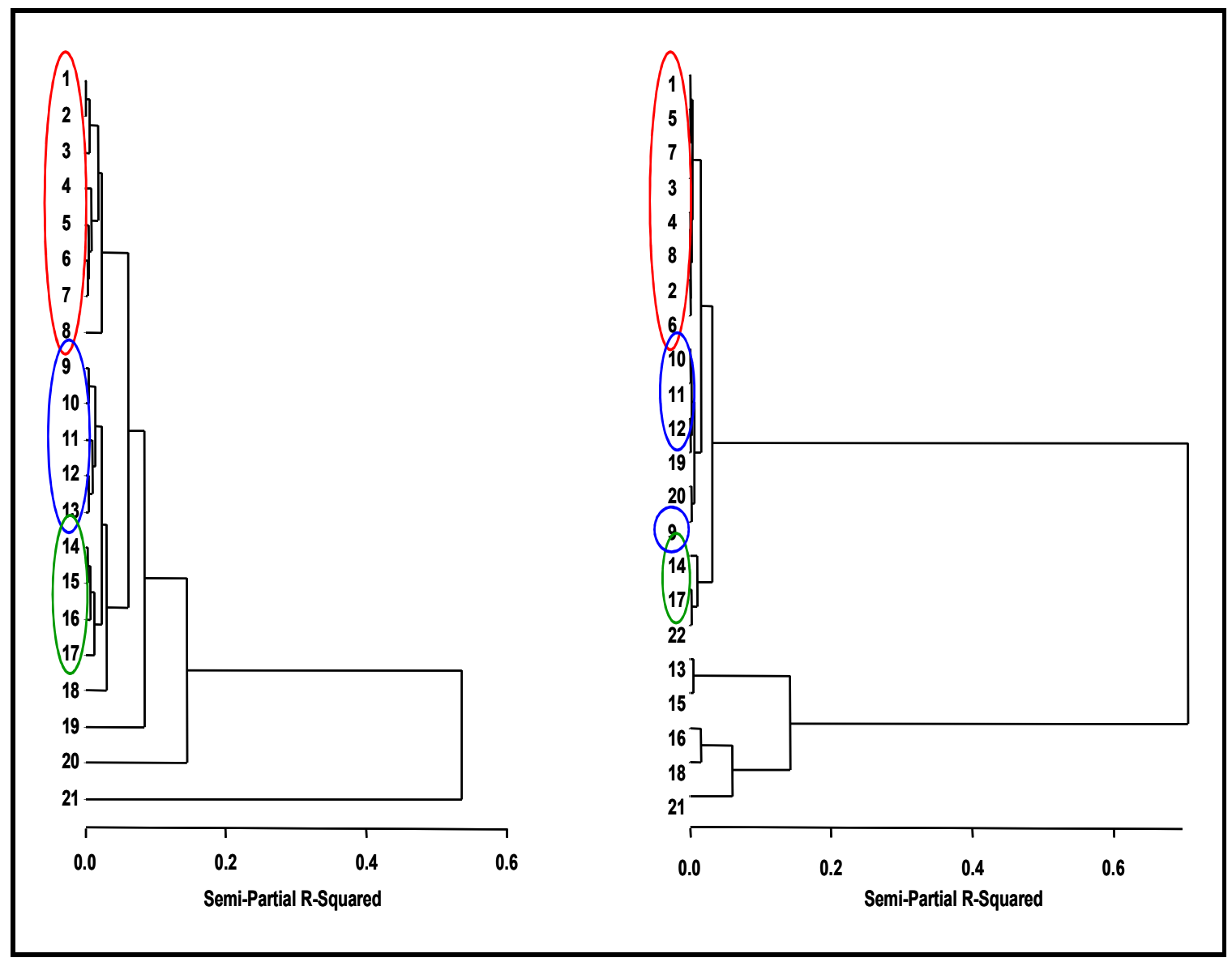

Figure 28: Correlation between microbial community structure (left) and PCB profiles (right). 


\subsection{Specific aim 3}

It is difficult to determine the potential toxicity of PCB congeners and hydroxyl metabolite PCBs on the bacterial community from the two different soil microcosms. Thus, it was necessary to evaluate the toxicity effect using pure cell culture.

\subsubsection{Effect of individual PCBs on bacterial growth}

To test the effect of individual PCBs on bacterial growth, pure cell cultures of E. coli and Burkholderia xenovorans LB400 were exposed to a high dose of PCBs during $24 \mathrm{~h}$. The bacterial growth was recorded periodically by measured of the optical density at $600 \mathrm{~nm}$. Figure 29 shows the growth curves of the $E$. coli exposed to different PCBs and Figure 30 shows the growth curves of the $E$. coli exposed to different hydroxyl metabolites of PCBs. In Figure 31 is shown the growth rate for B. xenovorans LB400 exposed to different metabolites.

Exposure to single PCB congeners resulted in not significant differences in E. coli growth rate. After $6 \mathrm{~h}$ of incubation it is observed acclimation of bacteria to PCBs. This results indicate that chlorination number may have not a significantly impact on the cell growth. It can be attributed to the fact that some bacteria can use biphenyl as carbon source (Adebusoye et al., 2008)

Nevertheless, when E. coli is exposed to the hydroxyl metabolite 4-OH-PCB35, it results in a remarkable inhibition on the cell bioavailability during the first $10 \mathrm{~h}$. Likewise, growth of $B$. xenovorans LB400 was extremely affected when exposed to that metabolite. Moreover, exposure of B. xenovorans LB400 to hydroxyl metabolites of PCB-3 (2-OHPCB3, 3-OH-PCB3, and 4-OH-PCB3) has an apparent inhibition of the bacterial growth during the first 6 hours with a noticeable increased on the bacterial availability after that time. There is a very little information in the literature related to impact of the hydroxyl 
metabolites PCBs on the bacterial growth. Camara et al. (2004) suggest that the toxicity of the metabolites can be associated to the recalcitrance of the PCB to biodegradation.

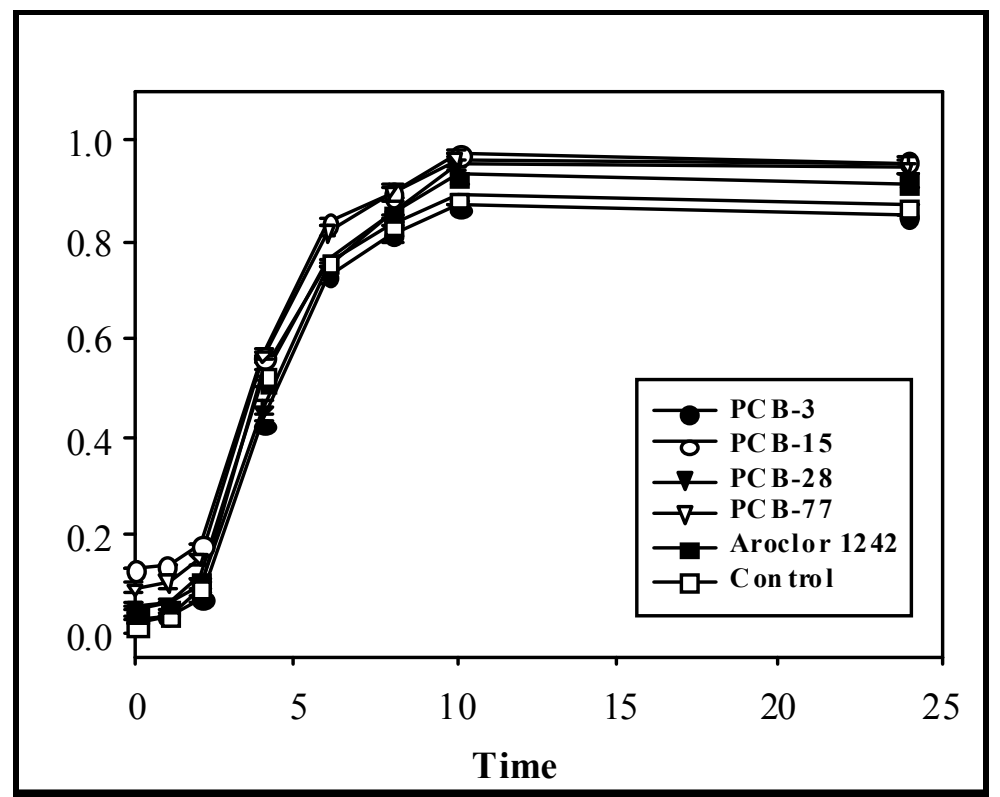

Figure 29: E.coli growth after $24 \mathrm{hr}$ exposed to different PCB congeners 


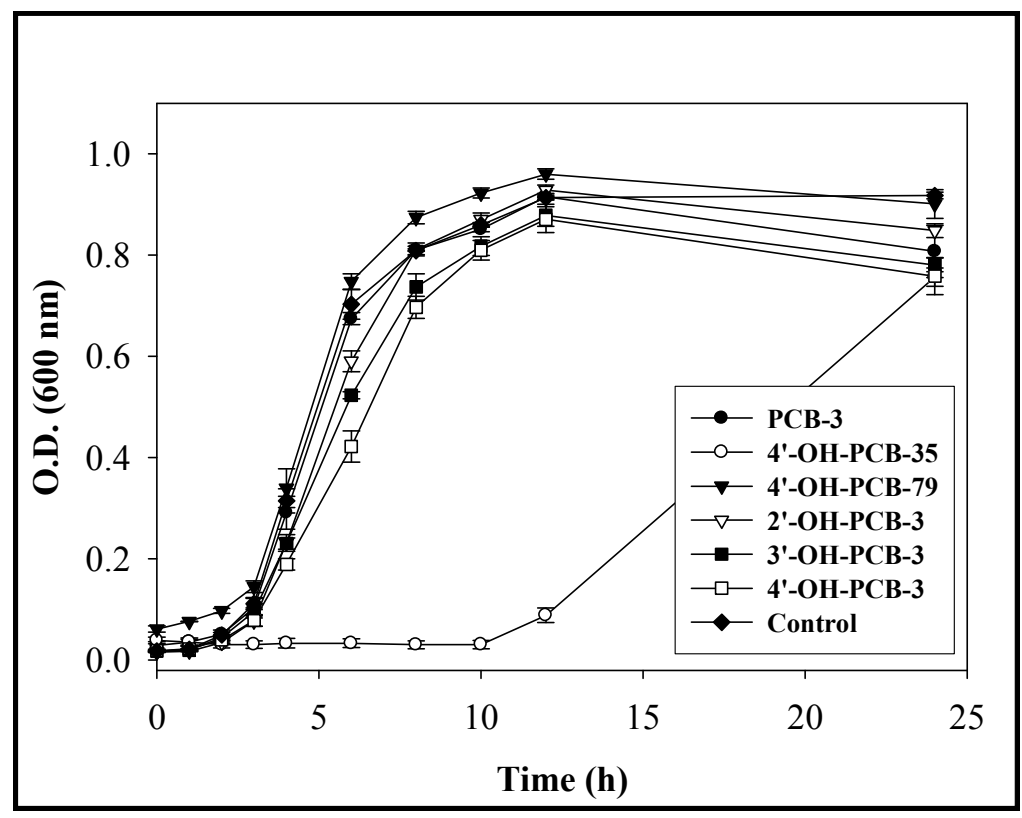

Figure 30: E.coli growth exposed to different $\mathrm{PCB}$ OH-metabolites

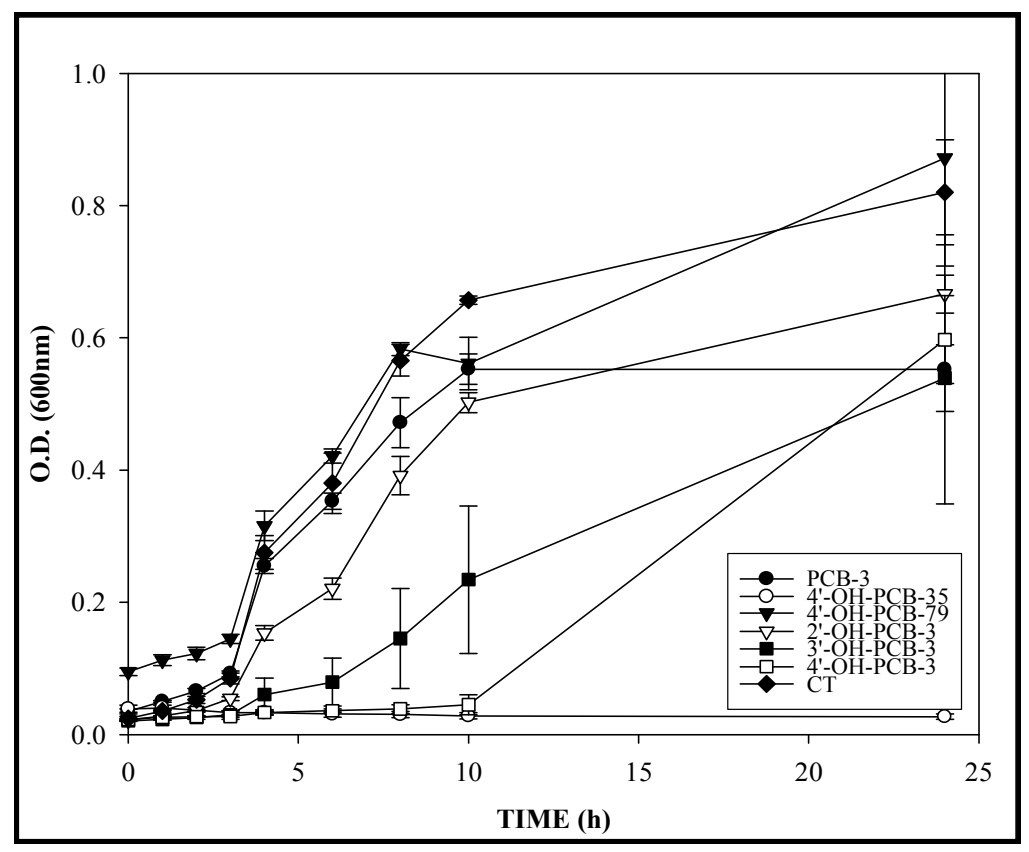

Figure 31: B. xenovorans LB400 growth exposed to different PCB OH-metabolites 


\section{Chapter 5 Conclusions}

PCBs production and usage were stopped approximately 30 years ago; however, they are still found in the environment, mainly due to their semi-volatile, lipophilic and stability properties. Since they are recalcitrant to degradation, there have been developed many technologies oriented to mitigating PCBs contamination. This includes traditional remediation techniques, such as incineration and physical-chemical dechlorination (Campanella et al., 2002). The cost of application of these techniques is extremely high, which make them not feasible (Supriyo, 2004). Biodegradation is an attractive remediation alternative, because of its lower costs than other methods and environmental affinity. It is estimated that cost of treatment of organic pollutants in soils by traditional techniques such as excavation and incineration ranges from $\$ 200$ to $\$ 1,500$ per ton, while the treatment of the same contaminated soil by phytoremediation varies from $\$ 25$ to $\$ 100$ per ton (http://www.biology-online.org/articles/phytoremediation_-_green_solution.html)

Although PCB bioremediation have been extensively studied at laboratory scale, there is little information about engineered bioremediation systems applied to contaminated sites. In addition, majority of the studies conduct on PCBs bioremediation have been focusing on PCBs mixtures. Thus, thenovelty of this research is that it focused on the biodegradation of individual PCB congeners, which is still lacking in the literature

The objective of this research was to assess the impact of individual PCB congeners on soil microbial community structure and the abundance of genes involved in the aerobic metabolism of PCBs. The hypothesis underlying this research is that the bacterial soil community structure that is responsible for PCB biodegradation, and the expression of genes involved in PCB breakdown vary depending on the individual PCB congeners they are exposed to. The significance of this work is that it is expected to improve the understanding of the mechanisms in the biodegradation of individual PCB congeners in 
soils. This will lead to application of techniques such as bioaugmentation and biostimulation, to enhance the degradation of PCBs. In the case of bioaugmentation natural or genetically modified organisms are introduced to a contaminated environment to enhance the degradation of PCBs. On the other hand, in biostimulation remediation conditions (e.g., nutrients, carbon source, oxygen, etc.) are improved to stimulate the indigenous microorganisms to degrade PCBs.

The experimental approaches used in this research were based mostly on molecular biology techniques, which included PCR, agar gel electrophoresis (AGE), real-time PCR and T-RFLP.

\section{$\underline{\text { Specific aim } 1}$}

Soil slurries were prepared and exposed to individual PCB congeners for four weeks under aerobic agitation. At the end of the exposure period, PCBs concentration was determined by $\mathrm{GC} / \mathrm{MS}$, bacterial concentration was estimated by cell counting, and microbial abundance of the different taxonomic groups and the BPH genes abundance were determine by real-time PCR using specific primers. Based on the results obtained from the exposure of soil slurries to individual PCB congeners, different bacterial community structures and abundance of BPH genes were observed. One of the most remarkable observations from the results is that the exposure of soil slurry to different PCB congeners modifies the structure of the microbial community. One interesting fact is that exposure to PCB-77 (dioxin-like), which has the highest chlorination number among the PCBs used in the studies and also is considered one of the most toxic PCB congeners, resulted in higher numbers of $\mathrm{PCB}$ degraders and $\mathrm{BPH}$ genes, as compared to other PCBs. It was observed that BPH-1 was the most abundant gene (6 times more abundant than in the non-exposed controls) and bacteria associated with this gene, $\beta$ - and $\gamma$ Proteobacteria, were also identified (8 times). Similarly, gene BPH-4 (2-3 times) and associated bacteria, Actinobacteria ( 2 times), showed a noticeable abundance in presence 
of PCB-77. Other congeners, for instance PCB-15, also resulted in significant bacterial and gene abundance. Likewise, bph genes associated with bacterial groups Comomonas, Burkholderia, pseudomonas ( $\beta$ - and $\gamma$-Proteobacteria) and Rhodococcus (Actinobacteria) were found in higher abundance. Interestingly, the $b p h$ genes and bacterial groups with more representation are associated to well know PCB-degraders.

\section{Specific aim 2}

The second specific objective of this thesis consisted of the analysis of different soil samples from a real PCB-contaminated site (CDF - South Chicago) in order to characterize the microbial community structure and PCB profiles. The microbial community structure from this soil was investigated by using T-RFLP and statistical analysis tools and the PCBs profiles were determined by using GC/MS. Four different restriction enzymes were used in the T-RFLP analysis, but only the profiles obtained from $R s a \mathrm{I}$ were presented in this thesis, since they provided better discriminating profiles than others. Our results provide the first evidence of a correlation between the microbial communities and the PCBs profile.

\section{$\underline{\text { Specific aim } 3}$}

The last specific objective of this thesis was to determine the potential toxicity of a group of individual PCB congeners and metabolites on E. coli and B. xenovorans LB400 pure culture. Pure bacterial cultures were exposed to high dose of different PCB congeners and metabolites. It was observed that exposure of pure bacteria culture to individual PCBs and their hydroxyl metabolites products resulted in different inhibition on the bacterial growth. The growth rate of $E$. coli, when exposed to individual congeners, was not significantly affected, as it was when exposed to the metabolite 4'-OH-PCB-35. A remarkable impact on the bacterial growth was found when B. xenovorans LB400 was exposed to metabolites 4'-OH-PCB-35. The culture B. xenovorans LB400 took a long 
period of time to acclimate to metabolites of PCB-3, which included: 2'-OH-PCB-3, 3'OH-PCB-3, and 4'-OH-PCB-3.

\subsection{Significance of the results obtained in this thesis}

One of the most important contributions of this work to the field of PCB biodegradation is the understanding of the effects of individual PCBs on the microbial community structure and the $\mathrm{BPH}$ abundance. This knowledge is valuable in the improvement of engineered and natural in situ bioremediation of PCBs-contaminated sites. Moreover, the characterization of the microbial community composition is also significant in the environmental microbiology field. This characterization could be used for optimizing conditions to improve biostimulation and bioaugmentation, which, under good management, would enhance the bioremediation process.

\subsection{Future and prospective research}

In order to validate the preliminary results obtained about the toxicity of PCBs and metabolites for bacteria, further work should be directed to the evaluation of the response at the transcriptional and expression level of pure cultures exposed to different PCB congeners and metabolites. The following aspects are proposed for further work:

- To investigate the bacterial gene expression by extracting and analyze RNA from pure cell cultures exposed to individual PCBs and their hydroxyl metabolites. This would allow understanding further the impact of exposure on bacteria.

- To conduct proteomic analyses in order to characterize the array of the proteins expressed in response to PCB exposure.

Finally, since preliminary results obtained about the soil microbial community in a PCBcontaminated site (Confined Disposal Facility) showed a possible correlation between the 
microbial community structure and PCB profiles, it is also suggested to characterize the changes of soil microbial community in a PCB-contaminated site using a proteomic approach. this would provide further understanding of the effects of PCB contamination on native microbial activity. 


\section{References}

Abdo, Z., Schuette, U.M.E., Bent, S.J., Williams, C.J., Forney, L.J., and Joyce, P. (2006) Statistical methods for characterizing diversity of microbial communities by analysis of terminal restriction fragment length polymorphisms of $16 \mathrm{~S}$ rRNA genes. Environmental Microbiology 8: 929-938.

Abraham, W.R., Nogales, B., Golyshin, P.N., Pieper, D.H., and Timmis, K.N. (2002) Polychlorinated biphenyl-degrading microbial communities in soils and sediments. Current Opinion in Microbiology 5: 246-253.

Abramowicz, D.A., Brennan, M.J., Vandort, H.M., and Gallagher, E.L. (1993) Factors influencing the rate of polychlorinated biphenyl dechlorination in Hudson river sediments. Environmental Science \& Technology 27: 1125-1131.

Adebusoye, S.A., Ilori, M.O., Picardal, F.W., and Amund, O.O. (2008) Metabolism of chlorinated biphenyls: Use of 3,3'- and 3,5-dichlorobiphenyl as sole sources of carbon by natural species of Ralstonia and Pseudomonas. Chemosphere 70: 656-663.

Aguirre de Carcer, D., Martin, M., Karlson, U., and Rivilla, R. (2007) Changes in bacterial populations and in biphenyl dioxygenase gene diversity in a polychlorinated biphenyl-polluted soil after introduction of willow trees for rhizoremediation. Applied and Environmental Microbiology 73: 6224-6232.

Anderson, L., and Hunter, C.L. (2006) Quantitative mass spectrometric multiple reaction monitoring assays for major plasma proteins. Molecular \& Cellular Proteomics 5: 573588.

Applied-Biosystems (2005) Relative quantification: Getting started guide. Applied Biosystems 7300/7500/7500 Fast. Real-time PCR system. 
Ausubel, F.M., Brent, R., Kingston, R.E., Moore, D.D., Seidman, J.G., Smith, J.A., and Struhl, K. (1999) Short Protocols in Molecular Biology. New York: John Wiley and Sons.

Baker, G.C., Smith, J.J., and Cowan, D.A. (2003) Review and re-analysis of domainspecific 16S primers. Journal of Microbiological Methods 55: 541-555.

Baldwin, B.R., Nakatsu, C.H., and Nies, L. (2003) Detection and enumeration of aromatic oxygenase genes by multiplex and real-time PCR. Applied and Environmental Microbiology 69: 3350-3358.

Bartels, F., Backhaus, S., Moore, E.R.B., Timmis, K.N., and Hofer, B. (1999) Occurrence and expression of glutathiane-S-transferase-encoding bphK genes in Burkholderia sp strain LB400 and other biphenyl-utilizing bacteria. Microbiology-Sgm 145: 2821-2834.

Bedard, D.L., Pohl, E.A., Bailey, J.J., and Murphy, A. (2005) Characterization of the PCB substrate range of microbial dechlorination process LP. Environmental Science \& Technology 39: 6831-6838.

Blackwood, C.B., Oaks, A., and Buyers, J.S. (2005) Phylum- and class-specific PCR primers for general microbial community analysis. Applied and Environmental Microbiology 71: 6193-6198.

Borja, J., Taleon, D.M., Auresenia, J., and Gallardo, S. (2005) Polychlorinated biphenyls and their biodegradation. Process Biochemistry 40: 1999-2013.

Burken, J. (2003) Uptake and metabolism of organic compounds: Green-liver model. In Phytoremediation. Transformation and Control of Contaminants. McCutcheon, S., and Schnoor, J. (eds). Hoboken: John Wiley, pp. 59-84.

Callahan, M.A., and Slimak, M.W. (1979) Water-related environmental fate of 129 priority pollutants. Washington D.C.: U.S. Environmental Protection Agency. 
Camara, B., Herrera, C., Gonzalez, M., Couve, E., Hofer, B., and Seeger, M. (2004)

From PCBs to highly toxic metabolites by the biphenyl pathway. Environmental Microbiology 6: 842-850.

Campanella, B.F., Bock, C., and Schroder, P. (2002) Phytoremediation to increase the degradation of PCBs and PCDD/Fs - potential and limitations. Environmental Science and Pollution Research 9: 73-85.

Campos, V.M., Merino, I., Casado, R., Pacios, L.F., and Gomez, L. (2008)

Phytoremediation of organic pollutants. Spanish Journal of Agricultural Research 6: 3847.

Chavez, F.P., Gordillo, F., and Jerez, C.A. (2006) Adaptive responses and cellular behavior of biphenyl-degrading bacteria toward polychlorinated biphenyls.

Biotechnology Advances 24: 309-320.

Chekol, T., Vough, L.R., and Chaney, R.L. (2004) Phytoremediation of polychlorinated biphenyl-contaminated soils: the rhizosphere effect. Environment International 30: 799804.

Cho, Y.C., Sokol, R.C., Frohnhoefer, R.C., and Rhee, G.Y. (2003) Reductive dechlorination of polychlorinated biphenyls: Threshold concentration and dechlorination kinetics of individual congeners in aroclor 1248. Environmental Science \& Technology 37: $5651-5656$.

Chroma, L., Moeder, M., Kucerova, P., Macek, T., and Mackova, M. (2003) Plant enzymes in metabolism of polychlorinated biphenyls. Fresenius Environmental Bulletin 12: 291-295.

Chu, S., He, Y., and Xu, X. (1997) Determination of acute toxicity of polychlorinated biphenyls to Photobacterium phosphoreum. Bulletin of Environmental Contamination and Toxicology 58: 263-267. 
Correa, P.A., Lin, L., Just, C.L., Hu, D., Hornbuckle, K.C., Schnoor, J.L., and Van Aken, B. (2009) The effects of individual PCB congeners on the soil bacterial community structure and the abundance of biphenyl dioxygenase genes. Environment International: Accepted for publication.

Dale, J.W., Von Schantz, M. (2007) From Genes to Genomes: Concepts and Applications of DNA Technology Wiley-Interscience.

Di Toro, S., Zanaroli, G., and Fava, F. (2006) Intensification of the aerobic bioremediation of an actual site soil historically contaminated by polychlorinated biphenyls (PCBs) through bioaugmentation with a non acclimated, complex source of microorganisms. Microbial Cell Factories 5: Article number 11.

Dunbar, J., Ticknor, L.O., and Kuske, C.R. (2001) Phylogenetic specificity and reproducibility and new method for analysis of terminal restriction fragment profiles of 16S rRNA genes from bacterial communities. Applied and Environmental Microbiology 67: 190-197.

Fedi, S., Tremaroli, V., Scala, D., Perez-Jimenez, J.R., Fava, F., Young, L., and Zannoni, D. (2005) T-RFLP analysis of bacterial communities in cyclodextrin-amended bioreactors developed for biodegradation of polychlorinated biphenyls. Research in Microbiology 156: 201-210.

Field, J.A., and Sierra-Alvarez, R. (2008) Microbial transformation and degradation of polychlorinated biphenyls. Environmental Pollution 155: 1-12.

Fierer, N., Jackson, J.A., Vilgalys, R., and Jackson, R.B. (2005) Assessment of soil microbial community structure by use of taxon-specific quantitative PCR assays. Applied and Environmental Microbiology 71: 4117-4120.

Frame, G. (2001) The current state-of-the-art of comprehensive, quantitative, congenerspecific PCB analysis, and what we know about the distributions of individual congeners 
in commercial aroclor mixtures. In PCBs: Recent Advances in Environmental Toxicology and Health Effects. Robertson, L.W., Hansen, L.G. (ed): University Press of Kentucky, pp 3-9.

Francova, K., Sura, M., Macek, T., Szekeres, M., Bancos, S., Demnerova, K. et al. (2003) Preparation of plants containing bacterial enzyme for degradation of polychlorinated biphenyls. Fresenius Environmental Bulletin 12: 309-313.

Furukawa, K., and Fujihara, H. (2008) Microbial degradation of polychlorinated biphenyls: Biochemical and molecular features. Journal of Bioscience and Bioengineering 105: 433-449.

Furukawa, K., Suenaga, H., and Goto, M. (2004) Biphenyl dioxygenases: Functional versatilities and directed evolution. Journal of Bacteriology 186: 5189-5196.

Gerber, S.A., Rush, J., Stemman, O., Kirschner, M.W., and Gygi, S.P. (2003) Absolute quantification of proteins and phosphoproteins from cell lysates by tandem MS. Proceedings of the National Academy of Sciences of the United States of America 100: 6940-6945.

Gerhardt, P.M., G.; Wood, W.; Krieg, N (1993) Methods for general and molecular bacteriology. American Society for Microbiology.

Gibson, D.T., and Parales, R.E. (2000) Aromatic hydrocarbon dioxygenases in environmental biotechnology. Current Opinion in Biotechnology 11: 236-243.

Giesy, J.P., and Kannan, K. (1998) Dioxin-like and non-dioxin-like toxic effects of polychlorinated biphenyls (PCBs): Implications for risk assessment. Critical Reviews in Toxicology 28: 511-569.

Harms, H., Bokern, M., Kolbe, M., and Bock, C. (2003) Transformation of organic contaminants by different plant systems. In Phytoremediation. Transformation and 
Control of Contaminants. McCutcheon, S., and Schnoor, J. (eds). Hoboken: John Wiley, pp. 285-316.

Heid, C.A., Stevens, J., Livak, K.J., and Williams, P.M. (1996) Real time quantitative PCR. Genome Research 6: 986-994.

Hill, G.T., Mitkowski, N.A., Aldrich-Wolfe, L., Emele, L.R., Jurkonie, D.D., Ficke, A. et al. (2000) Methods for assessing the composition and diversity of soil microbial communities. Applied Soil Ecology 15: 25-36.

Hites, R.A. (1997) Gas chromatography mass spectrometry. In Handbook of instrumental techniques for analytical chemistry. Settle, F.A. (ed): Prentice Hall PTR, pp. 609-626.

Holoubek, I. (2001) Polychlorinated biphenyl (PCB) contaminated site worldwide. In PCBs: Recent Advances in Environmental Toxicology and Health Effects. Robertson, L.W., Hansen, L.G. (ed): University Press of Kentucky.

Hornbuckle, K.C., Smith, G.L., Miller, S.M., Eadie, B.J., and Lansing, M. (2004) Magnitude and origin of PCBs resuspended in open waters of Lake Michigan. Abstracts of Papers of the American Chemical Society 228: 017-ENVR.

Hu, D., Martinez, A., Hornbuckle, K.C. (2008). Discovery of non-aroclor PCB (3, 3'dichlorobiphenyl) in Chicago air. Environmental Science \& Technology 42: 7873-7877 Hübschmann, H.J. (2001) Handbook of GC/MS. Fundamental and Applications: Wiley$\mathrm{VCH}$.

Kohler, H.P.E., Kohlerstaub, D., and Focht, D.D. (1988) Co-metabolism of polychlorinated-biphenyls - enhanced transformation of aroclor 1254 by growing bacterial-cells. Applied and Environmental Microbiology 54: 1940-1945. 
Kucerova, P., Wiesche, C.I.N., Wolter, M., Macek, T., Zadrazil, F., and Mackova, M. (2001) The ability of different plant species to remove polycyclic aromatic hydrocarbons and polychlorinated biphenyls from incubation media. Biotechnology Letters 23: 13551359.

Leigh, M.B., Prouzova, P., Mackova, M., Macek, T., Nagle, D.P., and Fletcher, J.S. (2006) Polychlorinated biphenyl (PCB)-degrading bacteria associated with trees in a PCB-contaminated site. Applied and Environmental Microbiology 72: 2331-2342.

Liu, W.T., Marsh, T.L., Cheng, H., and Forney, L.J. (1997) Characterization of microbial diversity by determining terminal restriction fragment length polymorphisms of genes encoding 16S rRNA. Applied and Environmental Microbiology 63: 4516-4522.

Livak, K.J., and Schmittgen T.D. (2001) Analysis of relative gene expression data using real-time quantitative PCR and the 2(T)(-Delta Delta C) method. Methods 25: 402-408

Macek, T., Kotrba, P., Svatos, A., Novakova, M., Demnerova, K., and Mackova, M. (2008) Novel roles for genetically modified plants in environmental protection. Trends in Biotechnology 26: 146-152.

Mackova, M., Macek, T., Ocenaskova, J., Burkhard, J., Demnerova, K., and Pazlarova, J. (1997a) Biodegradation of polychlorinated biphenyls by plant cells. International Biodeterioration and Biodegradation 39: 317-325.

Mackova, M., Macek, T., Kucerova, P., Burkhard, J., Pazlarova, J., and Demnerova, K. (1997b) Degradation of polychlorinated biphenyls by hairy root culture of Solanum nigrum. Biotechnology Letters 19: 787-790. 
Mackova, M., Chroma, L., Kucerova, P., Burkhard, J., Demnerova, K., and Macek, T. (2001) Some aspects of PCB metabolism by Horseradish cells. International Journal of Phytoremediation 3: 401-414.

Mackova, M., Dowling, D.N., Macek, T. (2006) Phytoremediation and Rhizoremediation: Theoretical Background (Focus on Biotechnology): Springer.

Marsh, T.L. (1999) Terminal restriction fragment length polymorphism (T-RFLP): an emerging method for characterizing diversity among homologous populations of amplification products. Current Opinion in Microbiology 2: 323-327.

Meagher, R.B. (2000) Phytoremediation of toxic elemental and organic pollutants. Current Opinion in Plant Biology 3: 153-162.

Nogales, B., Moore, E.R.B., Abraham, W.R., and Timmis, K.N. (1999) Identification of the metabolically active members of a bacterial community in a polychlorinated biphenyl polluted moorland soil. Environmental Microbiology 1: 199-212.

Nogales, B., Moore, E.R.B., Llobet-Brossa, E., Rossello-Mora, R., Amann, R., and Timmis, K.N. (2001) Combined use of 16S ribosomal DNA and 16S rRNA to study the bacterial community of polychlorinated biphenyl-polluted soil. Applied and Environmental Microbiology 67: 1874-1884.

Novakova, M., Mackova, M., Chrastilova, Z., Viktorova, J., Szekeres, M., Demnerova, K., and Macek, T. (2009) Cloning the Bacterial bphC Gene Into Nicotiana tabacum to Improve the Efficiency of PCB-Phytoremediation. Biotechnology and Bioengineering 102: 29-37. 
Ogram, A. (1998) Isolation of nucleic acid from environmental samples. In Techniques in Microbial Ecology. Burlage, R.S.A., R.; Stahl, D.; Geesey, G.; Sayler, (ed). New York, NY: Oxford University Press, pp. 273-288.

Ohtsubo, Y., Kudo, T., Tsuda, M., and Nagata, Y. (2004) Strategies for bioremediation of polychlorinated biphenyls. Applied Microbiology and Biotechnology 65: 250-258.

Olson, P., Reardon, K., and Pilon-Smits, E. (2003) Ecology of rhizosphere bioremediation. In Phytoremediation. Transformation and Control of Contaminants. McCutcheon, S., and Schnoor, J. (eds). Hoboken: John Wiley, pp. 317-353.

Parnell, J.J., Park, J., Denef, V., Tsoi, T., Hashsham, S., Quensen, J., and Tiedje, J.A. (2006) Coping with polychlorinated biphenyl (PCB) toxicity: Physiological and genomewide responses of Burkholderia xenovorans LB400 to PCB-mediated stress. Applied and Environmental Microbiology 72: 6607-6614.

Pfaffl, M.W., Vandesompele, J., Kubista, M. (2009) Data Analysis software. In RealTime PCR: Current Technology and Applications. Logan, J., Edwards, K., Saunders, N. (ed): Caister Academic Press.

Pieper, D.H., and Seeger, M. (2008) Bacterial metabolism of polychlorinated biphenyls. Journal of Molecular Microbiology and Biotechnology 15: 121-138.

Rezek, J., Macek, T., Mackova, M., and Triska, J. (2007) Plant metabolites of polychlorinated biphenyls in hairy root culture of black nightshade Solanum nigrum SNC-90. Chemosphere 69: 1221-1227.

Rodrigues, J.L.M., Kachel, C.A., Aiello, M.R., Quensen, J.F., Maltseva, O.V., Tsoi, T.V., and Tiedje, J.M. (2006) Degradation of Aroclor 1242 dechlorination products in sediments by Burkholderia xenovorans LB400(ohb) and Rhodococcus sp strain RHA1(fcb). Applied and Environmental Microbiology 72: 2476-2482. 
Safe, S. (1993) Toxicology, structure-function relationship, and human and environmental-health impacts of polychlorinated-biphenyls - progress and problems. Environmental Health Perspectives 100: 259-268.

Sandermann, H. (1994) Higher plant metabolism of xenobiotics: The 'green liver' concept. Pharmacogenetics 4: 225-241.

Seah, S.Y.K., Labbe, G., Nerdinger, S., Johnson, M.R., Snieckus, V., and Eltis, L.D. (2000) Identification of a serine hydrolase as a key determinant in the microbial degradation of polychlorinated biphenyls. Journal of Biological Chemistry 275: 1570115708.

Seah, S.Y.K., Labbe, G., Kaschabek, S.R., Reifenrath, F., Reineke, W., and Eltis, L.D. (2001) Comparative specificities of two evolutionarily divergent hydrolases involved in microbial degradation of polychlorinated biphenyls. Journal of Bacteriology 183: 15111516.

Sondossi, M., Barriault, D., and Sylvestre, M. (2004) Metabolism of 2,2 '- and 3,3 'dihydroxybiphenyl by the biphenyl catabolic pathway of Comamonas testosteroni B-356. Applied and Environmental Microbiology 70: 174-181.

Supriyo, D., Saroj, K. , Arthur, L. W., Sisir K.D (2004) Toxicity of polychlorobiphenyls and its bioremediation. International Journal of Human Genetics 4: 281-290.

Thies, J.E. (2007) Soil microbial community analysis using terminal restriction fragment length polymorphisms. Soil Science Society of America Journal 71: 579-591.

Tiedje, J.M., and Boyd, S.A. (1987) Anaerobic degradation of chlorinated aromatic hydrocarbons. Developments in Industrial Microbiology Series 27: 117-127.

Van Aken, B. (2008) Transgenic plants for phytoremediation: helping nature to clean up environmental pollution. Trends in Biotechnology 26: 225-227. 
Van Aken, B., Correa, P. A., Schnoor J. L. (2009b) Phytoremediation of polychlorinated biphenyls: new trends and promises. Environmental Science \& Technology: Accepted for publication.

Vasilyeva, G.K., and Strijakova, E.R. (2007) Bioremediation of soils and sediments contaminated by polychlorinated biphenyls. Microbiology 76: 639-653.

Widada, J., Nojiri, H., and Omori, T. (2002) Recent developments in molecular techniques for identification and monitoring of xenobiotic-degrading bacteria and their catabolic genes in bioremediation. Applied Microbiology and Biotechnology 60: 45-59. Williams, W.A. (1994) Microbial Reductive Dechlorination of trichlorobiphenyls in anaerobic sediment slurries. Environmental Science \& Technology 28: 630-635.

Zeeb, B.A., Amphlett, J.S., Rutter, A., and Reimer, K.J. (2006) Potential for phytoremediation of polychlorinated biphenyl-(PCB-) contaminated soil. International Journal of Phytoremediation 8: 199-221. 